\title{
Energy
}

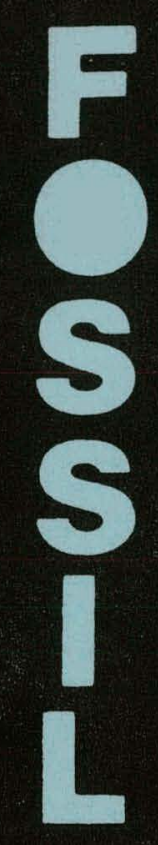

\section{ADVANCED DIRECT COAL LIQUEFACTION}

Quarterly Technical Progress Report No. 1 for the Period September-November 1983

By

A. S. Paranjape

February 7, 1984

Date Published

Work Performed Under Contract No. AC22-83PC60048

Kerr-McGee Corporation

Oklahoma City, Oklahoma

Technical Information Center

Office of Scientific and Technical Information United States Department of Energy 


\section{DISCLAIMER}

This report was prepared as an account of work sponsored by an agency of the United States Government. Neither the United States Government nor any agency Thereof, nor any of their employees, makes any warranty, express or implied, or assumes any legal liability or responsibility for the accuracy, completeness, or usefulness of any information, apparatus, product, or process disclosed, or represents that its use would not infringe privately owned rights. Reference herein to any specific commercial product, process, or service by trade name, trademark, manufacturer, or otherwise does not necessarily constitute or imply its endorsement, recommendation, or favoring by the United States Government or any agency thereof. The views and opinions of authors expressed herein do not necessarily state or reflect those of the United States Government or any agency thereof. 


\section{DISCLAIMER}

Portions of this document may be illegible in electronic image products. Images are produced from the best available original document. 


\title{
DISCLAIMER
}

\begin{abstract}
This report was prepared as an account of work sponsored by an agency of the United States Government. Neither the United States Government nor any agency thereof, nor any of their employees, makes any warranty, express or implied, or assumes any legal liability or responsibility for the accuracy, completeness, or usefulness of any information, apparatus, product, or process disclosed, or represents that its use would not intringe privately owned rights. Keference herein to any specific commercial product, process, or service by trade name, trademark, manufacturer, or otherwise does not necessarily constitute or imply its endorsement, recommendation, or favoring by the United States Government or any agency thereof. The views and opinions of authors expressed herein do not necessarily state or reflect those of the United States Government or any agency thereof.
\end{abstract}

This report has been reproduced directly from the best available copy.

Available from the National Technical Information Service, U. S. Department of Commerce, Springfield, Virginia 22161.

Price: Printed Copy A07

Microfiche A01

Codes are used for pricing all publications. The code is determined by the number of pages in the publication. Information pertaining to the pricing codes can be found in the current issues of the following publications, which are generally available in most libraries: Energy Research Abstracts (ERA); Government Reports Announcements and Index (GRA and I); Scientific and Technical Abstract Reports (STAR); and publication NTIS-PR-360 available from NTIS at the above address. 


\author{
ADVANCED DIRECT COAL LIQUEFACTION \\ QUARTERLY TECHNICAL PROGRESS REPORT NO. 1 \\ PERIOD SEPTEMBER - NOVEMBER 1983
}

Prepared by

A. S. Paranjape

KERR-MCGEE CORPORATION

Technology Division

Project Engineering Department

Oklahoma City, Oklahoma 73125

DATE PUBLISHED: February 7, 1984

Prepared for the United States

Department of Energy

Contract No. DE-AC22-83PC60048 
TABLE OF CONTENTS

Section

Page

1

ABSTRACT:

1-1

2

INTRODUCTION

2-1

3

SUMMARY

3-1

4

PROGRAM OUTLINE

4-1

GENERAL

DESCRIPTION \& SCHEDULE

4-1

4-2

Task 2

Task 3

Task 4

5

SUMMARY OF BENCH-SCALE RUNS - TASK 2

5-1

BENCH-SCALE RUN 32

BENCH-SCALE RUN 33

BENCH-SCALE RUN 34

5-1

$5-5$

$5-6$

6

DISCUSSION OF BENCH-SCALE RESULTS

$6-1$

BATCH REACTOR TEST PROGRAM - TASK 2

$7-1$

SCOPE OF WORK

EXPERIMENTAL

$7-1$

$7-2$

Reactor Heat-Up

Catalyst Particle Size

Catalyst Form (Oxide vs Sulfide)

Catalyst Age

Feed Resid Type

Parametric. Study

SUMMARY AND CONCLUSIONS

$7-12$

8

FUTURE PROGRAMS

8-1

APPENDIX A BENCH-SCALE UNIT - PROCESS DESCRIPTION

A-1

APPENDIX B OPERATING LOG

B-1

APPENDIX C OPERATING DATA

C-1 .

APPENDIX D

ANALYTICAL DATA - BENCH SCALE

D-1

APPENDIX E

ANALYTICAL DATA - FEED MATERIALS

E-1 


\section{ILLUSTRATIONS}

Figure

Page

5-1 Kerr-McGee Process Configuration No. 6

5-2 Kerr-McGee Process Configuration No. 4

6-1 Volume Pore Size Distribution in Shell 324M Catalyst in

7-1 Material Handling Scheme for Batch Reactor Test

Catalyst Volume Pore Size Distribution - Extrudates vs Crushed Catalyst

Catalyst Volume Pore Size Distribution - Oxide vs Presulfided Catalyst

7-5 . Catalyst Volume Pore Size Distribution - As a Function of Catalyst Age for LDAR

7-6 Catalyst Volume Pore Size Distribution - As a Function of Catalyst Age for FR-DAR

7-7 Catalyst Volume Pore Size Distribution - As a Function of Resid Type - SingleCycle Test

7-8 . Catalyst Volume Pore Size Distribution - As a Function of Resid Type - Three Cycle Test

7-9 Catalyst Volume Pore Size Distribution - Batch vs Continuous using FR-DAR

7-10 Catalyst Volume Pore Size Distribution - Batch vs Continuous using LDAR

A-1 Liquefaction Process Schematic

A-2 Three-Stage CSD Process with Secondary Extraction

$A-1$

A-3

Hydrotreater Process Schematic

A-8 


\section{TABLES}

Table

5-1

5-2

5-3

5-4

6-1 Overall Two-Stage Yields

6-2 Thermal and Catalytic Stage Yields

6-3 Effect of Resid Type on Shell 324M Catalyst Properties

7-1 Batch Reactor Catalyst Deactivation Test Conditions

7-2. Reactor Heatup Effect on Catalyst

7-3 Catalyst Particle Size Effect

7-4. Effect of Catalyst Presulfiding

$7-5$

7-6

7-7

7-8

7-9

7-10

7-11

$7-12$

A-1 Integrated Bench-Scale Unit Range of Operability

A-2 Integrated Bench-Scale Unit Process Capabilities

B-1 Daily Operating Log

B-2 On-Stream Factor

B-3 Hydrotreater Catalyst Age Log

C-1 Operating Data - Thermal Stage

C-2 Operating Data - Catalytic Stage

D-1 Analytical Data - Sheet 1 .

D-2 Analytical Data - Sheet 2
Page

5-12

5-12

5-13

5-13

6-14

6-15

6-16

7-24

7-24

7-25

7-26

7-26

$7-27$

$7-27$

$7-28$

$7-28$

7-29

$7-30$

$7-31$

A-9

A- 10

B-1

B-5

B-6

C- 1

C- 4

D- 1

D-4 


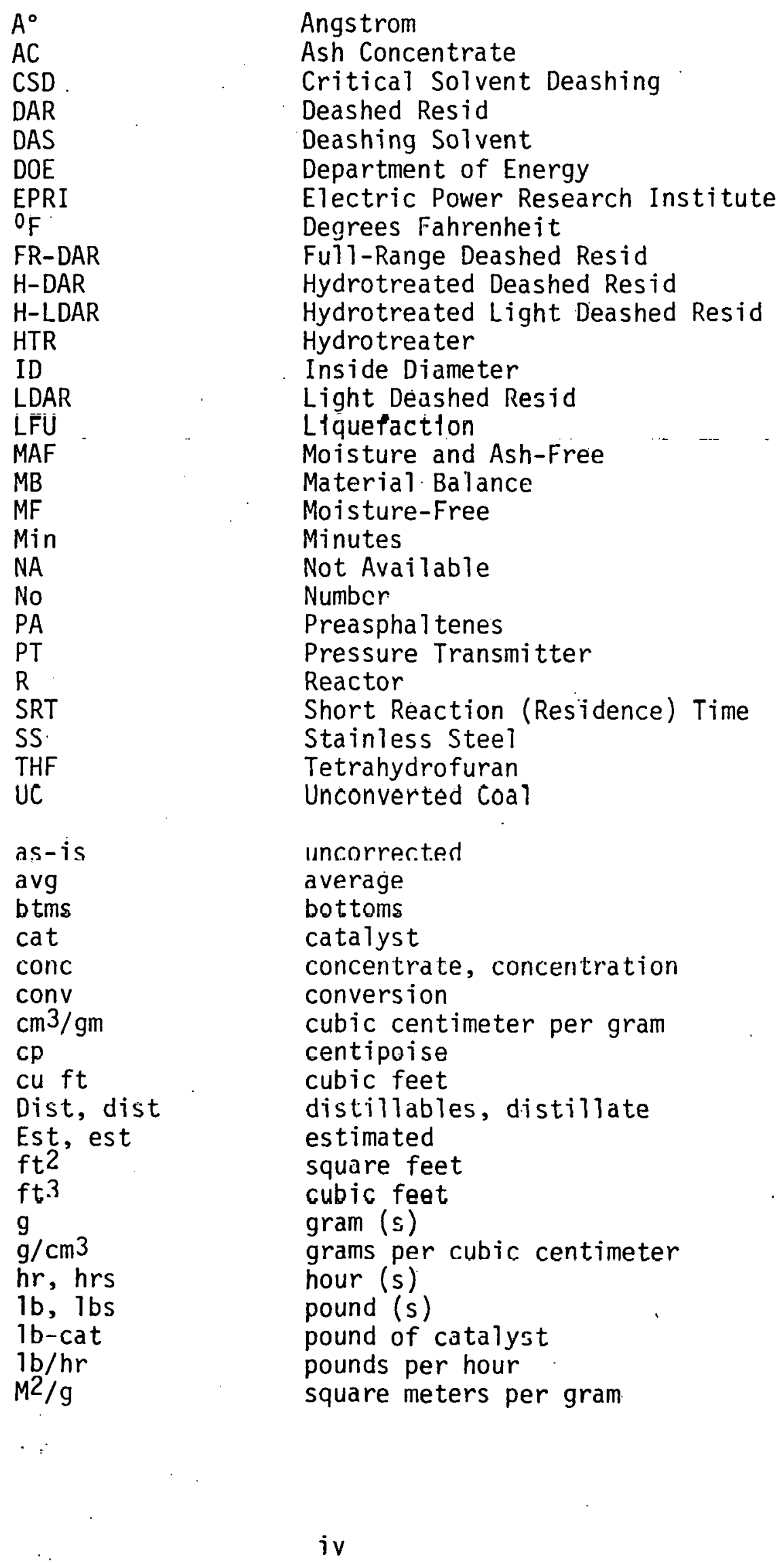

$A^{\circ}$

$A C$

CSD

DAR

DAS

DOE

EPRI

${ }^{0} \mathrm{~F}$

FR-DAR

$H-D A R$

H-LDAR

HTR

ID

LDAR

LFU

MAF

MB

MF

Min

NA

No

PA

PT

$\mathrm{R}$

SRT

SS.

THF

UC

as-is

avg

btms

cat

conc

conv

$\mathrm{cm} 3 / \mathrm{gm}$

$\mathrm{cp}$

cu ft

Dist, dist

Est, est

$\mathrm{ft}^{2}$

$\mathrm{ft} .3$

$\mathrm{g}$

$\mathrm{g} / \mathrm{cm} 3$

$\mathrm{hr}$, hrs

$1 b, 1 b s$

1b-cat

$1 \mathrm{~b} / \mathrm{hr}$

$\mathrm{M}^{2} / \mathrm{g}$

Angstrom

Ash Concentrate

Critical Solvent Deashing

Deashed Resid

Deashing Solvent

Department of Energy

Electric Power Research Institute

Degrees Fahrenheit

Fu11-Range Deashed Resid

Hydrotreated Deashed Resid

Hydrotreated Light Deashed Resid

Hydrotreater

Inside Diameter

Light Deashed Resid

Liquefaction

Moisture and Ash-Free

Material-Balance

Moisture-Free

Minutes

Not Available

Number

Preasphal tenes

Pressure Transmitter

Reactor

Short Reaction (Residence) Time

Stainless Steel

Tetrahydrofuran

Unconverted Coal

uncorrected

average

bottoms

catalyst

concentrate, concentration

conversion

cubic centimeter per gram

centipoise

cubic feet

distillables, distillate

estimated

square feet

cubic feet

gram (s)

grams per cubic centimeter

hour (s)

pound (s)

pound of catalyst

pounds per hour

square meters per gram 


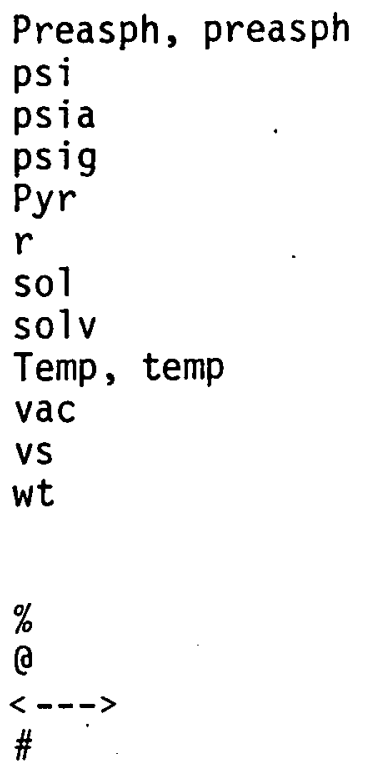

preasphaltenes

pounds per square inch

pounds per square inch absolute

pounds per square inch gauge

Pyridine

radius

soluble

solvent

temperature

vacuum

versus

weight

percent

at

negative value

pounds, number 
Section 1

ABSTRACT

During this reporting period, September-November 1983, three Bench-Scale coal liquefaction scoping runs were completed. In these three runs, Wyoming subbituminous coal was liquefied using three different two-stage process configurations. These process configurations differed in the type of fractionated deashed resid being recycled to the individual stages. The objective of these runs was to determine whether by recycle of specific resid streams to the thermal stage the second stage catalyst life could be improved without detrimentally affecting distillate yield or hydrogen consumption.

The results indicate that the two-stage process configuration consisting of hydrotreating the Light Deashed Resid and direct recycle of heavy Deashed Resid to the thermal stage produced the best results. This process configuration resulted in a distillate yield of 54 wt\% (MAF coal basis) and overall coal conversion in the 93-95\% range, as measured by pyridine-soluble analytical test while operating in a total distillate mode. These results are very encouraging for the lower rank Wyoming subbituminous coal. Among the three two-stage process configurations tested, the particular process configuration of hydrotreating Light Deashed Resid resulted in the least amount of catalyst deactivation.

As a part of this research effort, a test procedure for quick evaluation of various resids and catalysts in terms of coke precursors was also developed. This procedure utilizing as-produced oxide-form extrudates of catalyst is able to simulate closely in a batch reactor test the performance of a presulfided and extrudate form of catalyst in a continuous reactor.

This work is jointly sponsored by the Department of Energy, the Electric Power Research Institute, and the Kerr-McGee Corporation. 
Section 2

INTRODUCTION

Kerr-McGee Corporation has been actively involved in coal related research over the last two decades. Earlier research led to the development of a proprietary process, Critical Solvent Deashing (CSD), for the selective and continuous removal of ash, mineral matter and unconverted coal from coal liquids. In 1978, a transportable CSD unit was built by Kerr-McGee Corporation, with the fabrication of the fractionation portion of the unit being funded by EPRI. The CSD unit was provided on a no-fee basis by Kerr-McGee Corporation to the Advanced Coal Liquefaction Facility at Wilsonville, ALA, managed by Southern Company Services under DOE and EPRI contracts.

The CSD unit, being able to not only deash but also fractionate the resid, greatly increased the flexibility of options for coal liquefaction. New process concepts evolved incorporating resid fractionation and selective resid recycle in coal liquefaction. As a result of Kerr-McGee's and EPRI's interest in developing this technology, Kerr-McGee and EPRI jointly sponsored a multimillion dollar multi-year effort starting in August of 1979 for conducting research in Advanced Coal Liquefaction Technology. As a part of this effort, a new fifteen-pounds-per-hour coalfeed capacity Bench-Scale unit was built and has been operated at the Cimmaron Facility of the Kerr-McGee Corporation since 1980.

The current DOE contract was awarded to the Kerr-McGee Corporation on 2 September 1983 to perform exploratory research and development on process variations in two-stage liquefaction with emphas is on catalyst deactivation. This contract is jointly funded by DOE, EPRI and Kerr-McGee. Results derived from this program are expected to support and guide future Wilsonville coal. liquefaction research and deveropment.

This report covers work done on the Bench-Scale unit in testing three process options in two-stage liquefaction. Results from each of the three Bench-Scale runs as well as other related laboratory data are reported. 


\section{Section 3}

\section{SUMMARY}

During the first quarter of the contract period, three bench-scale runs were completed. These runs used different two-stage process configurations which involved recycle of different types of deashed resids. The overall objective of these runs was to determine which configuration resulted in the best catalyst life while maintaining maximum distillate products with minimum hydrogen consumption.

In these three runs, Wyoming subbituminous coal obtained from Kerr-McGee Clovis Point Mine (upper seam) was used. Two weight percent (MF coal basis) iron oxide was used in each run as a disposable catalyst. Fresh Shell 324M catalyst was charged to the hydrotreater at the start of each run. This catalyst was presulfided using dimethyl-disulfide in No. 2 fuel oil.

The first of the Bench-Scale Runs, No. 32, was started on 8 September and involved Light Deashed Resid (LDAR) recycle to the catalytic stage and DAR recycle directly to the thermal stage. Instead of terminating the run after twenty days as originally planned, the run was extended to forty-four days to obtain more definitive material balance data.

Following Run 32, the process configuration was changed in Run 33 to feed Full-Range Deashed Resid (FR-DAR) to the catalytic stage prior to recycle to the thermal stage. Run 33 lasted for fifteen days.

In Run 34, the process configuration was again changed and only Deashed Resid (DAR) was recycled to the catalytic stage and the LDAR was recycled directly to the thermal stage.

Other process conditions in each section were maintained as similar as possible for these runs. The primary difference between the configurations were the type of deashed resid streams being recycled from the CSD section to the catalytic and thermal stages.

During Run 32, the 1iquefaction unit produced vacuum bottoms having the lowest preasphaltenes content of any vacuum bottoms produced to-date at Kerr-McGee. 
During most of the operating period, the MAF coal conversions were maintained primarily in the 92-95\% range, and the coal values rejected to the ash concentrate stream were in the 20-22 wt\% (MAF Coal Basis) range. For a short period during Run 33, an exceptionally low coal value rejection to the ash concentrate of 16.8 wt\% was obtained.

Several of the material balances completed during these bench-scale runs were evaluated for process performance in terms of distillate yield $\left(\mathrm{C}_{4}\right.$ to $\left.-850^{\circ} \mathrm{F}\right)$. Catalyst deactivation during each run was evaluated based on the changes in the properties and chemical analyses of the aged catalysts. As the resid feed to the hydrotreater became heavier (higher preasphaltenes), the overall distillate yield decreased and the catalyst deactivation rate increased. The highest distillate yields. in the range of 43-57 wt\% (MAF Coal), were obtained during Run 32. This run also had the lowest catalyst surface area reduction per unit of catalyst age. These results indicate that this process configuration involving hydrotreating of LDAR was the best of these process configurations tested in terms of distillate yield and potentially improved catalyst life.

Laboratory test programs completed during this period include the development of a batch reactor test for expeditious testing of various resids and catalysts at low cost. Good agreement was achieved between batch and continuous reactor data in terms of catalyst deactivation and it appears that a batch reactor test shows promise in helping to identify the preferred resids and catalysts for use in the continuous unit. 


\section{Section 4}

PROJECT OUTLINE

\section{GENERAL}

Coal liquefaction research has evolved primarily to multistage processes that offer better utilization of hydrogen and better product quality. The multi-stage liquefaction of coal typically includes a thermal step, one or more hydrotreating steps, and a solids-separation step.

A variety of multistage configurations have been suggested and several alternate process arrangements are being tested. The more successful processes have the following features,

- Heterogeneous catalysts are used in one or more steps to condition and hydrotreat both distillate and resid.

- Resids produced from the coal, along with heavy process-derived distillates, are recycled between the thermal and catalytic steps.

- Process conditions are chosen in the various steps to minimize the production of light hydrocarbon gases and be conducive to the production of distillates.

Primary problems still to be solved in order to achieve a viable multistage coal liquefaction commercial process include,

- Control of heterogeneous catalyst deactivation at a rate that is economically acceptable.

- Maintenance of proper hydrogen utilization in the different process steps.

o Maintenance of suitable levels of resid conversion to distillate in the different process steps.

- Control of the quantity and composition of the coal-derived material that is rejected to the solids-discharge stream.

- Maintenance of the process parameters within a framework that will permit scale-up to commercial-size plants. 
DESCRIPTION AND SCHEDULE

Within the context of the above problems, the research program is subdivided into various tasks. Task 1 of the program consists of the Project Work Plan outlining the various tasks with their respective objectives, the proposed testing under each of these tasks and the schedule for completing these tasks in the contract period. Several of the tasks overlap in order to obtain necessary feedback to maintain program continuity.

Task 2 - Scoping Runs in the Kerr-McGee Continuous Coal Liquefaction Bench-Scale Unit

The primary objectives of Task 2 are to,

a) Evaluate alternate process options involving selective recycle of fractionated resid and distillate to determine which options generate less coke precursors in the resid that is fed to the catalytic stage, and produce a high overall distillate yield,

b) Evaluate these alternate process options using Wyoming subbituminous coal from Clovis Point mine with iron oxide added,

c) Evaluate selective alternate process options using Illinois bituminous coal, with and without iron oxide added, for comparison with the Wyoming subbituminous coal, and

d) Compare the use of Shell 324M ( $\mathrm{Ni}-\mathrm{Mo}$ ) versus an alternate catalyst such as Amocat 1-A (Co-Mo) as the catalyst in the catalytic stage for several of the alternate process options.

The general process parameters and process configurations for runs designed to achieve these objectives of Task 2 are discussed later.

Initially, a series of three runs are to be completed under Task 2 work in which the resid in the feed to the catalytic stage progressively becomes heavier in nature.

The resid used in the feed to the catalytic stage is to be obtained by fractionation of the resid in the CSD unit into a heavy fraction called Deashed Resid - DAR (CSD second-stage) and a lighter fraction called Light Deashed Resid - LDAR (CSD third- 
stage). The DAR from the CSU second-stage, the LDAR from the CSD third-stage, or both fractions, are to be fed to the catalytic stage. In addition, the relative percent of DAR and LDAR produced is to be varied by adjustment of the CSD secondstage conditions of temperature, pressure and deashing solvent/resid ratio in order to obtain the desired split of DAR and LDAR.

A fresh batch of Shell 324M catalyst is to be used in each of the first three runs. The catalyst age at the end of each run is expected to be on the order of $1201 \mathrm{~b}$ of $+850^{\circ} \mathrm{F}$ resid/1b catalyst. This is about the same catalyst age as will be obtained in the "coke precursors" batch reactor test and will permit direct comparison of the spent catalyst obtained from the continuous unit with the spent catalyst obtained from the batch reactor tests.

Following the evaluation of results of these three runs, an alternate catalyst, such as Amocat 1-A, is to be tested. The conditions for these runs will be selected based on an evaluation of the runs made using Shell $324 \mathrm{M}$ catalyst.

Several of the selected runs completed in Task 2 are to be made using Illinois No. 6 bituminous coal. The process configurations used, the addition of iron oxide to the thermal step, and the catalyst to be used in the catalytic stage will be based on the evaluation of the bench-scale runs made and batch reactor results.

Six batch reactor tests are scheduled in support of the bench-scale runs in Task 2 . The planned process conditions for these tests are discussed later. These tests are to be made as soon as possible after the starting materials become available.

A comparison of the hydrogen consumption, coal conversion, and yield structure for the four tests on Clovis Point coal will permit a direct comparison of the quality of these four different liquefaction solvents. The potential liquefaction solvent components from earlier bench-scale runs will be tested both with and without the addition of deashed resid from the CSD unit to study the effect of this resid on distillate yield.

The additional two tests using Illinois No. 6 coal are designed to determine if the addition of iron oxide is beneficial in improving distillate yield from an eastern bituminous coal. 
The hydrotreater feed from each bench-scale run will be tested for "coke precursors" as well. In addition, the liquefaction underflow from the pressure letdown step from one of the selected runs (Run 32 or equivalent) will be tested for "coke precursors".

\section{Task 3 - Disposable Catalysts}

The primary objective of Task 3 is to evaluate the use of disposable catalysts in the thermal step to,
a) decrease the coke precursor concentration in the resid produced,
b) increase distillate yield, and
c) improve product quality.

This task will be carried out using Wyoming subbituminous coal. It has already been established in preliminary development work leading up to the work planned in Task 2 that about 2 wt\% iron oxide (MF coal basis) will increase the coal conversion of the subbituminous coal from the 84-86 wt \% range to the 91-95 wt\% range (pyridine-soluble coal, MAF basis). Therefore, the plan in this task is to test the use of iron oxide at several concentrations, and to investigate alternate disposable catalysts.

Prior to making the bench-scale runs, a batch reactor study will be carried out to better define the relationship of the iron oxide concentration to coal conversion, distillate yield, and quality of product. Following these tests, several different disposable catalysts will be compared to iron oxide. The plan is to make a total of eight batch reactor tests.

Based on the results of the above eight. bat.ch reartar tests and the evaluation of the Task 2 results, process parameters will be selected for three additional benchscale runs. It is anticipated that only one process configuration and one type of coal will be used. The primary variables are expected to be the type of disposable catalyst to be tested and the quantity of disposable catalyst to be added.

\section{Task 4 - Secondary Extraction in the CSD Section}

The primary objectives of Task 4 are to establish the preferred process parameters for the secondary extraction step in the CSD section and to evaluate secondary extraction as a process option for improving soluble-coal recovery in this step. 
The preferred process parameters for carrying out secondary extraction will be 9 achieved by making three bench-scale runs on a uniform vacuum bottom feed from the Wilsonville facility. At the present time, vacuum bottoms from Wilsonville Run 243 appear to be the most suitable for this test. A soluble-coal recovery of $95 \%$ or greater should be achieveable using this vacuum bottom feed.

In these runs, process parameters in both the first stage and the secondary extractor will be varied to study the effects of different process parameter values on the soluble-coal recovery and the operability of the secondary extractor. Because of the short-residence time in the first stage and the secondary extractor, response is very rapid to changes in process parameters. Any process parameter change should provide very good response within eight to twelve hours. Consequently, it is expected that up to fifteen changes in process parameters will be made in each run. Since these process conditions are Kerr-McGee "Proprietary", the proposed actual conditions will be handled under separate documentation. 


\section{Section 5}

\section{SUMMARY OF BENCH SCALE RUNS}

BENCH-SCALE RUN NO. 32

Bench-Scale Run No. 32 was the first run under Task 2 of this contract. This run was made using Kerr-McGee Process Configuration No. 6 (see Figure 5-1). In this run, Wyoming subbituminous coal (Clovis Point mine) after mixing with 2 wt\% iron oxide (MF coal basis) was liquefied using a mixture of hydrotreater underflow and Deashed Resid (DAR) as the liquefaction solvent. The overhead from the CSD first stage was fractionated in the CSD second stage to feed about $50 \%$ of the resid as DAR to the liquefaction section as a component of the liquefaction solvent. The balance of the resid was removed as Light Deashed Resid (LDAR) and fed to the hydrotreater for obtaining the hydrotreater underflow.

Run 32 was started on 8 September. Shell 324M catalyst was presulfided using No. 2 fuel oil and dimethyl-disulfide. Presulfiding was completed on 12 September. After purging the fuel oil from the system, Light Deashed Resid (LDAR) and process solvent flows were established. Coal feed was started on 16 September. Earlier operation during September was plagued by mechanical problems and problems of line plugging in all three sections which prevented attaining any substantial integrated on-stream time. The cause of plugging appeared to be solids buildup in process lines from earlier runs which flaked-off during the early part of Run 32. After cleaning of these lines and overcoming additional startup problems, continuous operation in the hydrotreater and 7 iquefaction sections was established by 22 September by the addition of external LDAR (Wilsonville Run 241).

Process-derived vacuum bottoms started to be processed in the CSD section in early october. However, severe ash carryover occurred several times. As a consequence, during the first week of October, the CSD on-feed percentage was low. In addition, the soluble-coal recovery was very low. This latter problem was traced to deashing solvent by-passing the feed mixing system. This latter problem was corrected on 2 october. 
Laboratory analyses of vacuum bottoms from this period indicated that a vacuum bottoms with low preasphaltenes and low viscosity was being produced. With the composition of DAS being used at the time, this resulted in ash carryover problems as well as poor soluble-coal recoveries. At this point, the Solvency Index test was applied on a daily basis to determine the composition of deashing solvent that should be used to satisfactorily process vacuum bottoms currently being produced. In the Solvency Index test, the solubility of the vacuum bottoms in both the DAS and pyridine are determined at the reflux temperature of the solvents. The Solvency Index equals the solubility in the DAS divided by the solubility in pyridine times one-hundred. After the composition of the DAS was changed based on the Solvency Index test results, the CSD section began to function normally and resulted in improved operation. The deashing solvent composition was changed as necessary during the balance of the run to accomodate the changes in the solubility of the vacuum bottoms. Improved and stable CSD operation enabled smooth integrated operation. Excellent operation continued for five consecutive days starting 5 0ctober until a plug developed in the liquefaction preheater. This plug was caused by undetected loss of coal slurry flow and resulted in an interruption of coal feed for 27 hours. The unit was again fully integrated starting 9 october.

Use of the Solvency Index test basically eliminated the upset conditions which resulted in ash carryover and line plugging. This dramatic improvement both in the CSD operation as well as overall integrated operation, can readily be seen by comparing the on-stream percentages before and after 5 october as shown below.

\section{\% On-Stream Time - Run 32}

\begin{tabular}{|c|c|c|c|c|c|c|c|c|}
\hline \multirow[b]{2}{*}{ Period } & \multirow[b]{2}{*}{ Days } & \multicolumn{2}{|c|}{$\begin{array}{c}\text { Liquefaction } \\
\text { Section }\end{array}$} & \multicolumn{2}{|c|}{$\begin{array}{c}\text { CSD } \\
\text { Section }\end{array}$} & \multicolumn{2}{|c|}{$\begin{array}{l}\text { Hydrotreater } \\
\text { Section }\end{array}$} & \multirow{2}{*}{$\begin{array}{c}\text { Integrated } \\
\text { Unit } \\
\text { Resid+Coal }\end{array}$} \\
\hline & & Solv & Coal & Solv & Vac Bot & Solv & Resid & \\
\hline $\begin{array}{rll}10 & \text { Sep-16 Sep } \\
17 & \text { Sep-22 } & \text { Sep } \\
23 & \text { Sep- } 4 & \text { Oct } \\
5 & 0 c t-12 & 0 c t \\
13 & \text { Oct-20 } & \text { Oct }\end{array}$ & $\begin{array}{r}7 \\
6 \\
12 \\
8 \\
8\end{array}$ & $\begin{array}{r}86 \\
100 \\
99 \\
89 \\
100\end{array}$ & $\begin{array}{l}1^{1} \\
55 \\
97 \\
87^{4} \\
86\end{array}$ & $\begin{array}{r}95 \\
31 \\
95 \\
99 \\
100\end{array}$ & $\begin{array}{c}77 \\
0^{2} \\
71 \\
100 \\
98\end{array}$ & $\begin{array}{l}100 \\
100 \\
100 \\
100 \\
100\end{array}$ & $\begin{array}{c}43 \\
9^{3} \\
100 \\
100 \\
100\end{array}$ & $\begin{array}{r}1 \\
0 \\
52 \\
87 \\
84\end{array}$ \\
\hline
\end{tabular}

NOTES:

1 Plugged underflow 1 ine on vacuum flash drum.

2 Plugged overhead lines.

3 No resid available for feed.

4 Preheater plugged due to flow interruption. 
During this latter period, the on-stream time for CSD section was above $98 \%$. The CSD was off feed for only 1.5 hours in the 16-day period. Stable operation was achieved throughout the bench-scale unit for these sixteen days from 5 0ctober to 20 0ctober, with an average of $86 \%$ integrated on-stream time. In addition, during the last three days, the MAF coal rejection to ash concentrate was reduced to an average of $20.7 \mathrm{wt} \%$. These were the best results achieved till that date in these two areas.

Coal conversions for Run 32 were primarily in the range from 90 to $93 \%$ (MAF coal basis). However, on September 19 and 20, the coal conversions were 95.9 and 95.6, respectively. These were the highest coal conversions attained to date at KerrMcGee on Wyoming coal. During this two-day period, the CSD section was not operating, consequently there was no resid recycle and the liquefaction solvent was primarily distillable hydrotreated process soivent. In addition, the catalyst was very active and had aged to only 19 lb-resid/lb-catalyst.

A total of seven material balances were completed during this run. However, due to intermittent external resid input and due to the transient nature of processing during two of these MB periods, the results of these material balances were not calculated. The remaining $M B$ results are included in the next section.

The aged Shell 324M catalyst was removed from the hydrotreater on 21 October for evaluation. This is the first catalyst which has been used for continuous hydrotreating of only LDAR. The age of this spent Shell $324 \mathrm{M}$ catalyst is $1871 \mathrm{~b}+850^{\circ} \mathrm{F}$ resid/lb catalyst.

The following summary gives the Shell 324M catalyst age for the various Run 32 material balance periods.

\begin{tabular}{|c|c|c|}
\hline \multicolumn{2}{|c|}{ Run 32 Material Balance } & Catalyst Age \\
\hline Number & Start Date & lbs-resid/1b-catalyst \\
\hline 1 & 19 Sept & 19 \\
\hline 2 & 9 oct & 143 \\
\hline 4 & 11 oct & 156 \\
\hline 5 & 14 oct & 171 \\
\hline 6 & $180 \mathrm{ct}$ & 182 \\
\hline
\end{tabular}


During Run 32, the liquefaction unit produced different quality vacusis bottoms thin had ever been produced from Clovis Point coal. These vacuum bottoms had the lowest preasphaltenes content of any vacuum bottom produced to-date at Kerr.McGee. This was also reflected in the low viscosity of vacuum bottoms even at high ash concentrations. The following summary provides some of this data for the th-uay's with highest ash content vacuum bottoms as well as those from a segment of eight consecutive days of operation. It is remarkable that even these high-ash vicuum bottoms were still flowable in the 500 to $550^{\circ} \mathrm{F}$ temperature range.

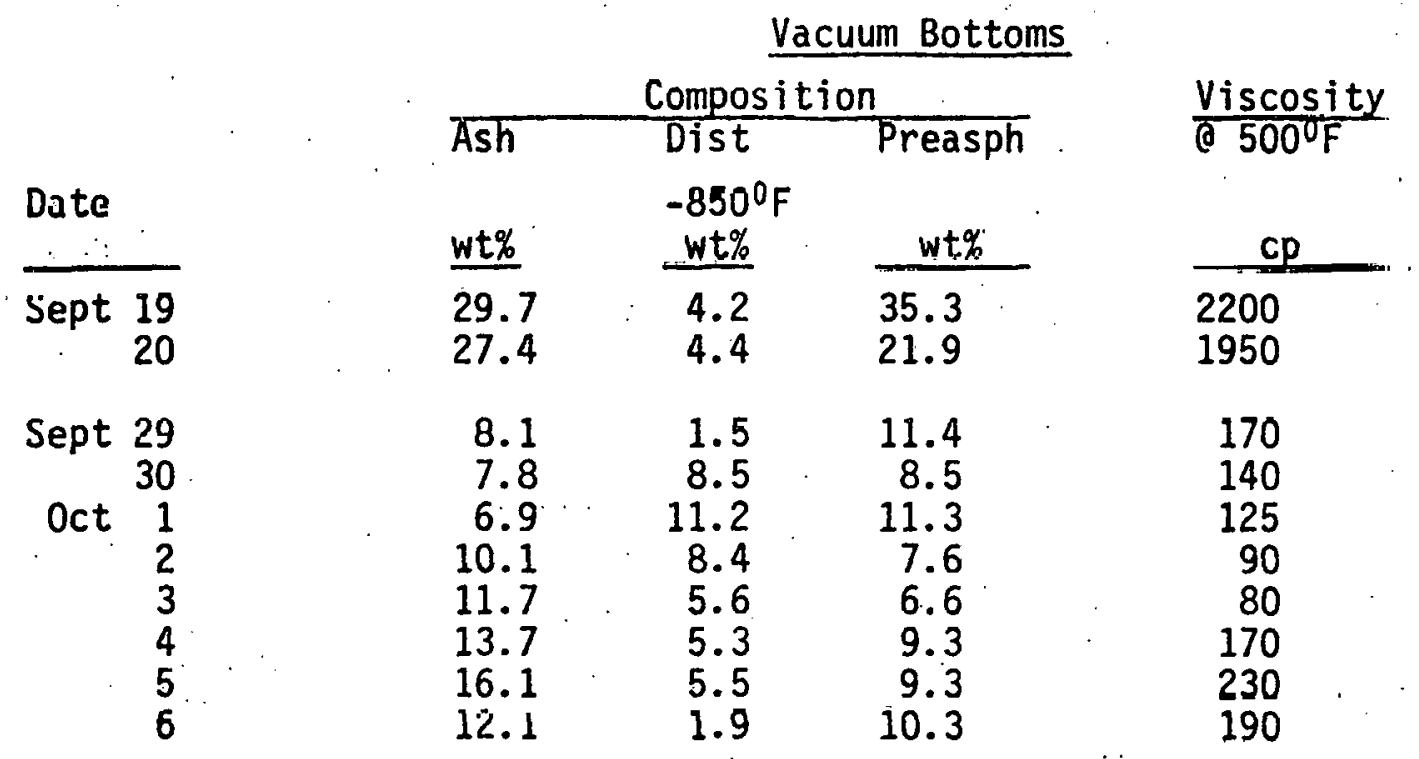

The first material balance was completed very early into the run when ine catalyst age was only 19 lbs-resid/lb-cat. During this MB, the CSD section was not operating because of ash carryover and plugging problems. Liquefaction and hydro:reater sections were operating but at a reduced level; moreover, resid recycle dilectly from CSD to the thermal stage was absent. The exceptionally high coal convelsions in excess of 95 wt\% during this two-day period are believed to be due to the composition of the process solvent which consisted of only the hydrotreater underflsiv. Analyses of the hydrotreater feed and underflow materials for this two-day perion are given in Table 5-1. Although there is a substantial difference between the 1iquefaction solvent (hydro-underflow) compositions for the two days, this solvent his a much higher hydrogen to carbon ratio. This is attributed to the fresh cataly:t charçe in the hydrotreater and may partially explain the high coal conversions on these two days. 
Following the first material balance, resid level in the system was increased to the desired range using LDAR from Wilsonville Run 241 until: the CSD unit could be brought on-line. The remaining material balances were completed in a staggered fashion to allow the resid levels to build-up prior to start of a MB period. The operating conditions during these Run 32 MB periods are summarized in Table 5-2.

BENCH-SCALE RUN NO. 33

Bench Scale Run 33 was the second run completed under Task 2 of this contract. This run was completed using Kerr-McGee Process Configuration No. 4 (see Figure 5-2). In this process configuration, Full-Range Deashed Resid (FR-DAR) was hydrotreated prior to its recycle to the thermal stage as the liquefaction solvent. The FR-DAR was obtained from the CSD second stage without undergoing any resid fractionation as was done in Process Configuration No. 6 (Run 32). In this flowscheme, the hydrotreater resid feed was a little heavier and contains more preasphaltenes-type materials. This change in hydrotreater feed type was made in order to permit a direct comparison of the two process configurations with regard to the product slate and deactivation of the catalyst by the type of resid hydrotreated. Wyoming subbituminous coal containing 2 wt\% (MF coal basis) iron oxide was liquefied using hydrotreated FR-DAR as the liquefaction solvent.

Run 33 was started on 23 0ctober. A fresh batch of Shell 324M catalyst was added to the hydrotreater reactor and presulfided using No. 2 Fuel $0 i 1$ and dimethyl-disulfide. Complete integration was achieved on 26 0ctober, just three days after presulfiding of the catalyst had started. The unit operated smoothly in the last week of october with very little downtime. The coal conversions were in the $92-95$ wt\% range, with MAF coal rejection to the ash concentrate in the $20 \mathrm{wt} \%$ range.. The first 24-hour material balance was completed on 31 October.

Three 24-hour duration material balances were completed before this run was terminated on 8 November. This run lasted for fifteen days (excluding the period of catalyst presulfiding). Good overall integrated operation was achieved for over $80 \%$ of the run time.

On the basis of daily control samples, coal conversions were maintained at 92-95: level. During two separate four-day periods, the MAF coal rejection to ash concentrate was low and averaged 19.3 and 18.2 wt\%, respectively. An exceptionally low value of 16.4 wt\% (MAr coal basis) was attained for a short period. 
A surnmary of the characteristics of the vacuum bottoms produced during this run is given below.

\begin{tabular}{|c|c|c|c|c|c|}
\hline & & \multicolumn{3}{|c|}{ Vacuum Bottoms } \\
\hline & & \multicolumn{3}{|c|}{ Composition } & \multirow{2}{*}{$\frac{\text { Viscosity }}{0500^{0} \mathrm{~F}}$} \\
\hline & & $\overline{\text { Ash }}$ & & & \\
\hline \multirow{6}{*}{ A } & Date & wt. $\%$ & $w t \%$ & $w t \%$ & $\mathrm{cp}$ \\
\hline & Oct 31 & 11.4 & 1.4 & 9.6 & 225 \\
\hline & Nov 2 & 11.4 & 1.7 & 11.3 & 180 \\
\hline & 4 & 16.7 & 3.6 & 16.9 & 425 \\
\hline & 6 & 16.3 & 2.6 & 13.7 & 480 \\
\hline & 8 & Ib. 4 & 1.5 & 11.3 & 570 \\
\hline
\end{tabular}

In cumparison to Run 32, these vacuum bottoms had higher preasphaltenes and ash contents and higher viscosity. It should be noted that a higher concentration of hydro-LDAR was used in the liquefaction solvent during Run 32 as compared to hydroDAR concentration used in Run 33 . The operating conditions during these Run $33 \mathrm{MB}$ periods are summarized in Table 5-3.

The catalyst age for the various material balance periods of Run 33 is summarized Lelü.

\begin{tabular}{|c|c|c|}
\hline $\begin{array}{c}\text { Run } \\
\text { Number }\end{array}$ & $\frac{\text { Material Balance }}{\text { Start Date }}$ & $\begin{array}{c}\text { Catalyst Age } \\
\text { lbs-resid/1b-catalyst }\end{array}$ \\
\hline 1 & 30 oct & 48 \\
\hline 3 & 3 Nov & 83 \\
\hline 4 & 4 Nov & 91 \\
\hline 5 & $5 \mathrm{Nov}$ & 101 \\
\hline
\end{tabular}

BENCH-SCALE RUN NO. 34

Bench-scale Run 34 was the third run completed under Task. 2 of this contract. Run 34 was completed using Kerr-McGee Process Configuration No. 8 (see Figure 5-3). In this process configuration, only DAR (approximately $83 w$ t\% of deashed resid) was hydrotreated with the LDAR (approximately $17 \mathrm{wt} \%$ of deashed resid) being fed directly back to the liquefaction section as a component of the liquefaction solvent. 
Run 34 started immediately following Run 33. Fresh Shell 324M catalyst was put in the hydrotreater on 9 November. Presulfiding using dimethyl-disulfide in No. 2 Fuel $0 i 1$ was started on 10 November. During the presulfiding period, the other two sections (LFU and CSD) were maintained in standby conditions using solvent flows. The required resid level was built up by processing of vacuum bottoms from Run 32 . After presulfiding of catalyst was completed on 11 November, the unit was integrated on coal and resid starting 12 November.

All three sections operated close to target parameter conditions most of the period. The integrated on-stream percentage for the entire run was somewhat lower $(70 \%)$. A11 of the downtime occurred in the CSD section because of pump problems and a leak at the second-stage overhead pressure control valve. The interruption of resid feed varied from 6 to 16 hours. During these interruptions, resid flows to the liquefaction and hydrotreater sections were maintained by utilizing resid from the system inventory.

Four 24-hour material balances were completed in this twelve-day run. During material balance No. 4, CSD operation was very erratic and resulted in poor soluble coal recovery and this MB was discarded. On the basis of daily control samples, coal conversions were being maintained at the 92 to $95 \%$ level. Only during the last two days, the coal conversion dropped to the $90 \%$ level. The MAF coal rejection to ash concentrate varied primarily from 18.0 to $23.0 \mathrm{wt} \%$. This run was terminated on 21 November after the last material balance was completed and the unit was shutdown on 22 November. The aged Shell 324M catalyst was removed for evaluation and replaced with a fresh batch of Shell 324M catalyst in preparation for the next run.

The catalyst age for the various material balance periods of Run 34 is summarized below.

\begin{tabular}{|c|c|c|}
\hline Number & Start Date & $\begin{array}{l}\text { Catalyst Age } \\
\text { lbs-resid/lb-catalyst }\end{array}$ \\
\hline 1 & $15 \mathrm{Nov}$ & 20 \\
\hline 2 & $17 \mathrm{Nov}$ & 31 \\
\hline 3 & $19 \mathrm{Nov}$ & 43 \\
\hline 4 & $20 \mathrm{Nov}$ & 46 \\
\hline
\end{tabular}


The vacuum bottoms obtained during Run 34 had about the same preasphaltenes and ash contents as in Run 33 but had somewhat lower viscosity and higher $\mathrm{H} / \mathrm{C}$ atomic ratio. In view of the relatively heavier resid processed in Run 34 versus Run 33, these results are somewhat surprising but may be explainable by the relatively low catalyst age of 46 lbs-resid/lb-cat for Run 34 versus 101 lbs-resid/lb-cat for Run 33 which possibly resulted in better quality liquefaction solvent and thus improved thermal stage performance. The operating conditions for Run 34 MB periods are summarized in Table 5-4.

The daily operations $\log$ and the daily operating and analytical data for all three runs (No. 32, 33 and 34) are given in Appendix B, C and D, respectively. The percent on-stream time for individual sections as well as the integrated unit are summarized in Appendix $B$. The daily catalyst age log for each of the runs is also included in Appendix B. 


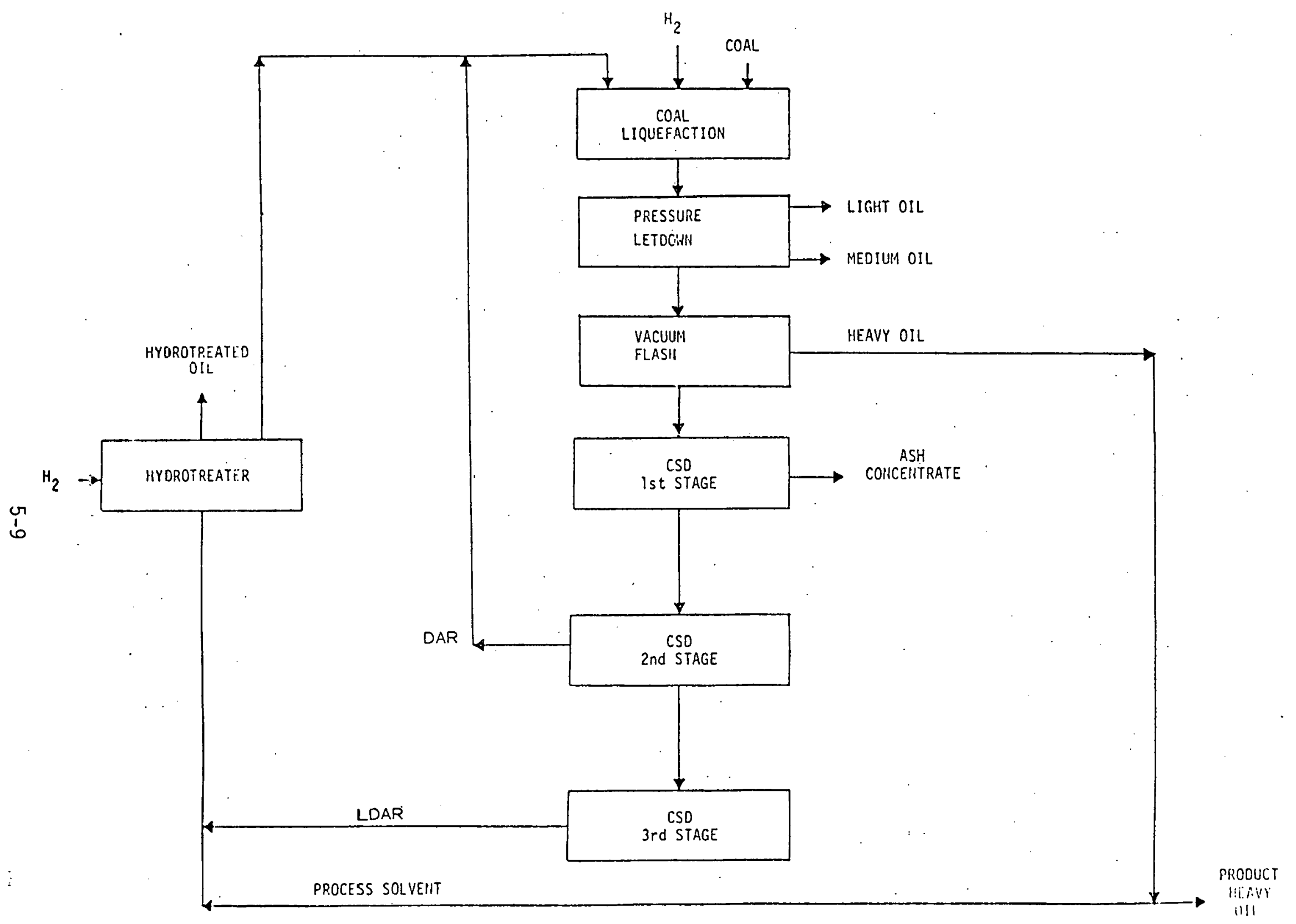

KERR-HCGEE PROCESS COHFICURATIOII NO. 6

FIGURE $5-1$ 


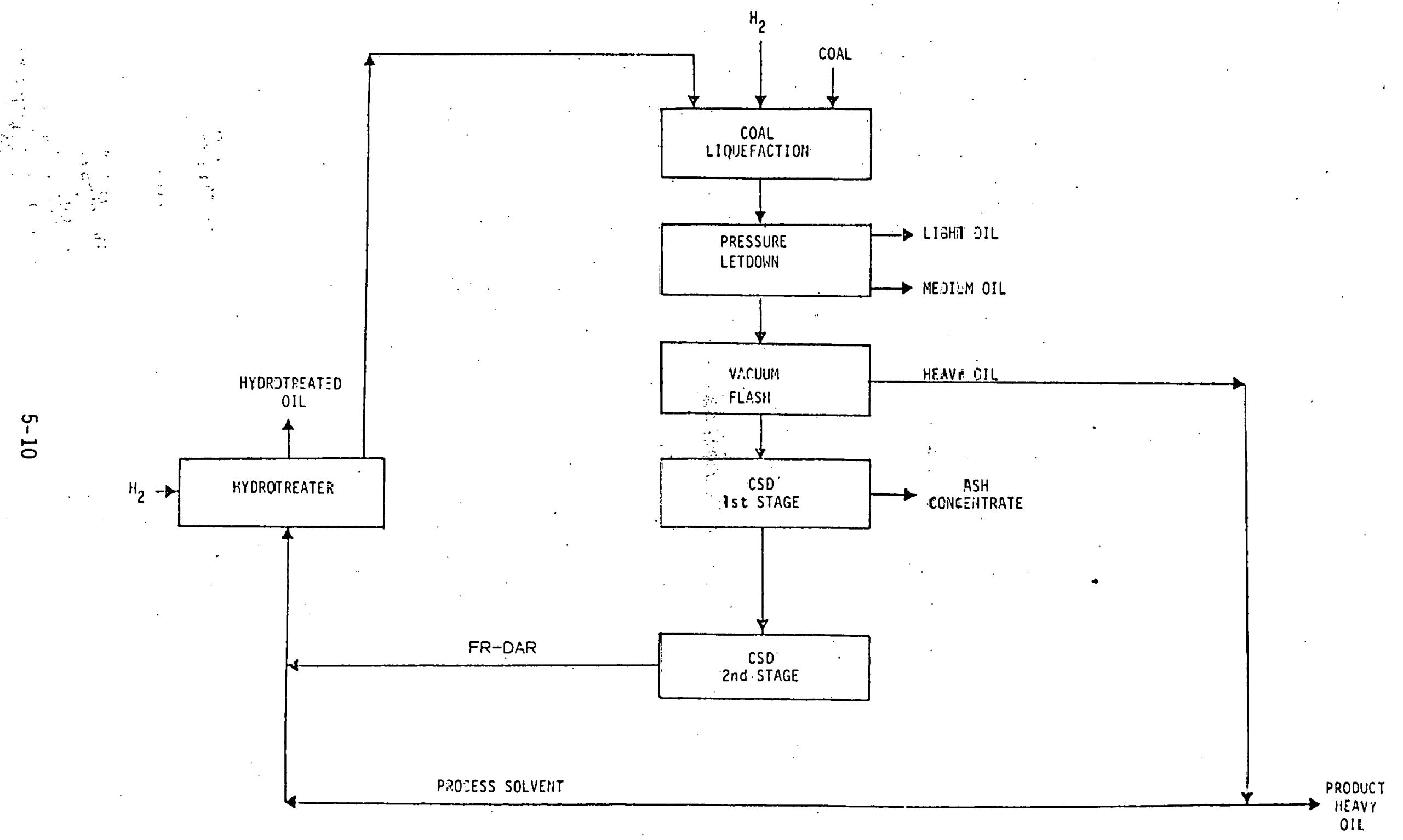

R.CRR-HCGEE PROCESS CONFIGURATIGN HO. 4

FIGLRE $5-2$ 


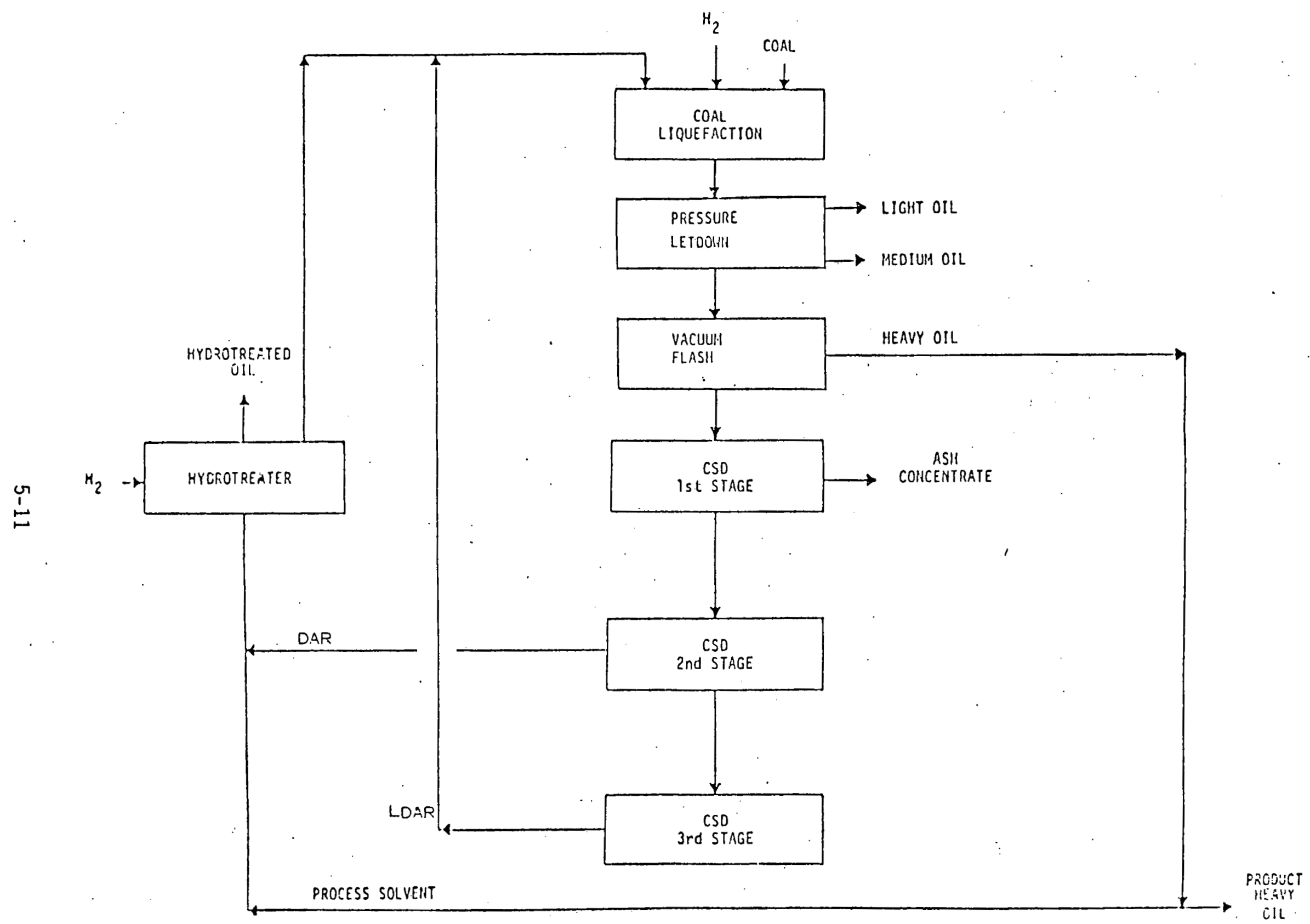

KEPR-IKCGEE PROCESS COHFIGURATIO:H HO. B

FIGURE 5-3 


\section{Table 5-1}

Analyses of Special Hydro-feed and Underflow Samples - Run 32

\begin{tabular}{|c|c|c|c|c|c|c|c|}
\hline \multirow{2}{*}{ Material Type } & \multirow{2}{*}{$\begin{array}{c}\text { Sample } \\
\text { Date }\end{array}$} & \multirow{2}{*}{$\begin{array}{l}\text { Ratio } \\
\underline{H / C}\end{array}$} & \multicolumn{5}{|c|}{ Sample Analysis, wt \% } \\
\hline & & & $\mathrm{H}$ & $\mathrm{C}$ & $\mathrm{N}$ & $S$ & 0 (diff) \\
\hline \multirow[t]{2}{*}{ Hydrotreater feed } & $9 / 19$ & 1.46 & 10.84 & 88.20 & 0.19 & $<0.01$ & 0.76 \\
\hline & $9 / 20$ & 1.22 & 9.14 & 89.00 & 0.69 & 0.16 & 1.01 \\
\hline \multirow{2}{*}{$\begin{array}{l}\text { Hydrotreater } \\
\text { underflow }\end{array}$} & $9 / 19$ & 1.49 & 11.02 & 88.30 & 0.05 & $<0.01$ & 0.62 \\
\hline & $9 / 20$ & 1.37 & 10.17 & 88.60 & 0.25 & $<0.01$ & 0.97 \\
\hline
\end{tabular}

Table 5-2

Summary of Operating Conditions - Run 32

Run Number

Material balance no.

Start Date, 1983

Flowsheet no.
32

\begin{tabular}{ccccc}
\hline 1 & 2 & 4 & 5 & 6 \\
Sept 18 & 0ct 9 & oct 12 & Oct 14 & Oct 18 \\
6 & 6 & 6 & 6 & 6
\end{tabular}

Coal Dissnlver Conditions

Coal type

MF coal rate, $1 \mathrm{~b} / \mathrm{hr}$

Temperat.ure, ${ }^{\circ} \mathrm{F}$

Pressure, psig

MF coal space rate ${ }^{1}$, $\mathrm{ib} / \mathrm{hr}^{-\mathrm{ft}^{3}}$

$+850^{\circ} \mathrm{F}$ resid in solv., $w \mathrm{t} \%$.

Ratio, liq.solv./MF coal

\begin{tabular}{|c|c|c|c|c|}
\hline $\begin{array}{r}\text { Wy } \\
4.96 \\
827 \\
2400\end{array}$ & $\begin{array}{c}\text { g subb } \\
6.86 \\
823 \\
2366\end{array}$ & $\begin{array}{c}\text { minous } \\
7.27 \\
821 \\
2364\end{array}$ & $\begin{array}{r}\text { vis } P \\
5.5 \\
826 \\
2372\end{array}$ & $\begin{array}{c}\text { Mine) } \\
5.26 \\
827 \\
2400\end{array}$ \\
\hline 14.6 & 20.2 & 21.4 & 16.3 & 15.5 \\
\hline $\begin{array}{r}5.6 \\
2.01\end{array}$ & $\begin{array}{l}46.7 \\
2.15\end{array}$ & $\begin{array}{l}48.5 \\
1.97\end{array}$ & $\begin{array}{l}42.4 \\
2.01\end{array}$ & $\begin{array}{l}31.6 \\
2.62\end{array}$ \\
\hline
\end{tabular}

Hydrotreater Conditions

\begin{tabular}{|c|c|c|c|c|c|}
\hline $\begin{array}{l}\text { Temperature, }{ }^{0} \mathrm{~F} \\
\text { Pressure, psig }\end{array}$ & $\begin{array}{r}695 \\
2250\end{array}$ & $\begin{array}{r}699 \\
2286\end{array}$ & $\begin{array}{r}688 \\
2302\end{array}$ & $\begin{array}{r}698 \\
2299\end{array}$ & $\begin{array}{r}700 \\
2250\end{array}$ \\
\hline $\begin{array}{c}\text { Feed space rate, } \\
\text { it } / \mathrm{hr}-\text { it cat }\end{array}$ & 0.98 & 1.01 & 1.01 & 1.11 & 0.97 \\
\hline $\begin{array}{l}+850^{\circ} \mathrm{F} \text { resid in feed, wt\% } \\
\text { Catalyst type }\end{array}$ & 3.73 & 40.3 & $\begin{array}{r}31.8 \\
324\end{array}$ & 24.9 & 21.3 \\
\hline
\end{tabular}

1 Based on net volume above $800^{\circ} \mathrm{F}$ 
Table 5-3

Summary of Operating Conditions - Run 33

Run Number

Material balance number

Start Date, 1983

Flowsheet number

\begin{tabular}{lccc}
\multicolumn{4}{c}{33} \\
\hline $\operatorname{Oct}_{4}^{3} 30$ & $\operatorname{Nov}_{4}^{3}$ & $\operatorname{Nov}_{4} 5$ & Nov 8
\end{tabular}

Coal Dissolver Conditions

Coal type

MF coal rate, $7 \mathrm{~b} / \mathrm{hr}$

Temperature, ${ }^{\circ} \mathrm{F}$

Pressure, psig

MF coal space rate ${ }^{1}, 1 \mathrm{~b} / \mathrm{hr}-\mathrm{ft}^{3}$

$+850^{\circ} \mathrm{F}$ resid in solvent, wt

Ratio, liq. solvent/MF coal
Wyoming
7.0

825

2400

20.6

38.1

1.73 subb it

bituminous (

tuminous
8.67

830

2352

25.5

21.5

1.87

(Clovis Point Mine)

$7.78 \quad 7.26$

830

2351

22.9

20.8

2.01

831

2354

21.4

19.6

1.97

Hydrotreater Conditions

Temperature, ${ }^{0} \mathrm{~F}$

Pressure, psig

Feed space rate, $1 \mathrm{~b} / \mathrm{hr}-1 \mathrm{~b}$ cat

$+850^{\circ} \mathrm{F}$ resid in feed, wt\%

Catalyst type
700

2250

1.11

32.1
699

2286

1.48

21.6

She 1

$\begin{array}{rr}695 & 699 \\ 2286 & 2281 \\ 1.48 & 1.37 \\ 21.1 & 17.7\end{array}$

1 Based on net volume above $800^{\circ} \mathrm{F}$

Table 5-4

Summary of Operating Conditions - Run 34

Run Number

Material balance number

Start Date, 1983

Flowsheet number

$\begin{array}{ccc}\frac{34}{1} \operatorname{Nov}_{8}^{2} & \operatorname{Nov}_{8} 17 & \text { Nov }_{8}^{19}\end{array}$

Coal Dissolver Conditions

Coal type

MF coal rate, $1 \mathrm{~b} / \mathrm{hr}$

Temperature, of

Pressure, psig

MF coal space rate ${ }^{1}, 1 \mathrm{~b} / \mathrm{hr}_{-} \mathrm{ft}^{3}$

$+850^{\circ} \mathrm{F}$ resid in solvent, wt\%

Ratio, liq. solvent/MF coal

Hydrotreater Conditions

Temperature, ${ }^{\circ} \mathrm{F}$

Pressure, psig

Feed space rate, $1 \mathrm{~b} / \mathrm{hr}-\mathrm{lb}$ cat

$+850^{\circ} \mathrm{F}$ resid in feed, $w t \%$

Catalyst type

1 Based on net volume above $800^{\circ} \mathrm{F}$
Wyoming subbituminous (clovis Point. Mine)

$\begin{array}{ccc}7.83 & 7.43 & 6.72 \\ 834 & 828 & 825 \\ 2359 & 2361 & 2349 \\ 23.0 & 21.9 & 19.8 \\ 29.5 & 23.9 & 20.0 \\ 1.96 & 1.91 & 1.74\end{array}$

$\begin{array}{lll}695 & 699 & 697\end{array}$

$2287 \quad 2283 \quad 2281$

$\begin{array}{lll}1.25 & 1.12 & 1.26\end{array}$

$18.7 \quad 16.1 \quad 19.4$

Shell $324 \mathrm{M}$ 
DISCUSSION OF BENCH SCALE RESULTS - TASK 2

During the first quarter of this contract period, three Bench-Scale Runs (Nos. 32, 33 and 34$)$ were completed. These runs utilized a two-stage process configuration (Figures 5-1,5-2 and 5-3) with the difference in the runs being in the type of resid being recycled. The objective of this study was to determine whether selective recycle of certain resid streams had a beneficial effect on the second stage catalyst life. Previous work completed under an EPRI contract, RP-1715-1, showed that it was not necessary to recycle FR-DAR to the hydrotreater but that similar process performance could be obtained by hydrotreating only the LDAR and recycling the remaining resid directly back to the thermal stage. The expected advantage is that the catalyst fouling rate will be lower with LDAR than with FR-DAR. These runs were made in a manner in which the resid being fed to the catalytic stage was made heavier (higher preasphaltenes) in each succeeding run and the remaining resid being recycled directly back to the thermal stage. The resid fed to the catalytic stage was analyzed for composition, stability, potential coke precursor concentration and the tendency of the resid to deposit coke on a heterogeneous catalyst.

MATERIAL BALANCES - RUN 32

During Run 32, seven material balances were made. Of these, the selected five material balance results are presented in Tables $6-1$ and 6-2. Table 6-1 gives the overall two-stage yields. The results of the thermal and catalytic stages are given in Table $6-2$.

The calculated distillate $\left(\mathrm{C}_{4}\right.$ to $\left.-850^{\circ} \mathrm{F}\right)$ yields for Run 32 ranged from 43.5 wti to $57.0 \mathrm{wt} \%$ (MAF coal basis). Similarly, the net deashed resid yield ranged from a negative $5.4 \mathrm{wt} \%$ to $10.3 \mathrm{wt} \%$. The hydrogen consumption appeared to vary from $5.2 w t \%$ to $6.6 w t \%$.

In a truly balanced system with a total distillate product slate, the quantity of deashed resid produced as a product is zero. The actual quantity of deashed resid processed per pound of MAF coal varied from one material balance to another with the imbalances madeup by addition of external resid. The MB results presented here are on a total equivalent MAF coal feed basis. To accomplish this, the actual MAF 
coal input was increased by a quantity which equalled the resid input to arrive at the total 'Equivalent' MAF Coal Feed. The ash concentrate stream was prorated upwards to reflect this higher equivalent MAF coal feed. By this procedure, a common basis is used in all of the balances and this is expected to permit a direct comparison of various runs involving external addition of resid. Such a methodology assumes that coal-derived resid behaves like coal and also converts in a fashion similar to MAF coal.

The resid conversion based on pyridine-soluble coal and resid in the liquefaction solvent was the highest in MB-1. (78 wt\%). However, the net distillate yield for MB-1 was lower (45.8 wt\% MAF coal). This is because deashed resid was not recycled in this run to provide additional distillate yield. During MB-1, the liquefaction solvent and hydrotreater feed streams contained only 5.6 and $3.7 \mathrm{wt} \%$ of $+850^{\circ} \mathrm{F}$ resid material, respectively. This resid came from the liquefaction section.

Overall hydrotreater resid conversion for MB-1 is extremely high (66 wt\%). This is believed to be due to the very active catalyst (catalyst age of only 19 1bs-resid/lbcatalyst) in the early part of the run.

The rejected coal values to ash concentrate averaged below $20 \mathrm{wt} \%$ of MAF coal feed in most of the material balances. The lowest value of 16.6 wt\% was obtained during MB- 6 and the highest coal value rejection of 25.3 wt\% was observed in MB-2. The overall gas yield (including water and $C_{1}-C_{3}$ hydrocarbon) was again high during MB-6. This is believed to be due to slightly higher dissolver temperature during this period.

In a truly balanced system with total distillate product slate, the resid product quantity is zero. Among the runs completed thus far, MB-4 and -6 appear to be nearly in resid balance as was intended in this process configuration. Since during MB-6, the gas make was unusually higher and energy rejection unusually lower, the results of MB-4 are closest to the typical two-stage product yields to be expected from this process configuration under the conditions tested. The yields for selected Run 32 balances were recalculated for the net "Zero Resid Product" case. This was done by estimating the resid contribution to the gas (plus water) and distillate fractions in the same proportions as were actually observed. Similarly, hydrogen consumption was adjusted upward to reflect increased resid conversion. The final results are summarized below. 
Adjusted Product Yields for "Zero Resid Product" Case

\begin{tabular}{|c|c|c|c|c|}
\hline \multirow[b]{2}{*}{ Yield, wt\% MAF Coal } & \multicolumn{4}{|c|}{ Run $32 \mathrm{MB}$ Number } \\
\hline & 2 & 4 & 5 & 6 \\
\hline Hydrogen & $\langle 5.4\rangle$ & $<5.2>$ & $<5.2>2$ & $\langle 5.6\rangle$ \\
\hline $\begin{array}{l}\text { Gases including water } \\
\text { plus } C_{1}-C_{3}\end{array}$ & 28.6 & 35.6 & 31.4 & 45.7 \\
\hline $\mathrm{C}_{4}$ to $-850^{\circ} \mathrm{F}$ liquids & 57.0 & 49.5 & 55.0 & 43.3 \\
\hline$+850^{\circ} \mathrm{F}$ resid & 0 & 0 & 0 & 0 \\
\hline Coal values in ash conc & $19.9^{1}$ & 20.1 & 18.9 & 16.6 \\
\hline Net & 100.0 & 100.0 & 100.0 & 100.0 \\
\hline
\end{tabular}

1 Adjusted based on the assumption that improved CSD operation would result in reducing coal value rejection to levels comparable to other MB periods.

2 Hydrogen consumption would decrease in the same proportion as the quantity of resid converted is decreased.

The adjusted distillate yields for "Zero Resid Product" case range from 43 to 57 wt \% of MAF coal. MB-4 showed an unusually high calculated water make (possibly due to forced oxygen balance technique used). If this is lowered by $3 \%$ to the $8 \%$ level observed in MB-2 or MB-5, the distillate yield for MB-4 could increase by about 5 wt\% to 53-54 wt\% which is about the same as MB-2 and MB-5 periods. Similarly, MB-6 had the highest gas make and hydrogen consumption during Run 32. A lower dissolver temperature could have resulted in slightly lower hydrogen consumption and increased distillate yield. Among factors causing a lower distillate yield in MB-6 are the lower resid concentration in the liquefaction solvent and hydrotreater feed for this $M B$ period and possibly a somewhat deactivated catalyst. For the other three MB periods, the resid concentration of liquefaction solvent was an average of 46 wt\% versus 32 wt\% for MB-6. And the hydrotreater feed resid concentration for MB-6 was only 21 wt\% compared to an average of $32 \mathrm{wt} \%$ for other MB periods. If one compares the averaged product yields with the set Run Target, the results are as shown below. The Target values were estimates based on preliminary material balances calculated using assumed coal and restd conversions. 
Yield, wt \% MAF Coal

Hydrogen

Gases, including water plus $\mathrm{C}_{1}-\mathrm{C}_{3}$

$\mathrm{C}_{4}$ to $-850^{\circ} \mathrm{F}$ liquids

$+850^{\circ} \mathrm{F}$ resid

Coal values in ash conc

Net

\begin{tabular}{lcc}
\multicolumn{3}{c}{ Run 32} \\
Target & \multicolumn{1}{c}{ Average of MB-2,4 \& 5} \\
\hline Values & Actual & Adjusted \\
$<4.0>$ & $<5.3>$ & $<5.3>$ \\
30.0 & 32.2 & 31.9 \\
54.6 & 54.3 & 53.8 \\
0 & $<2.6>$ & 0 \\
19.4 & 21.4 & 19.6 \\
\hline 100.0 & $\frac{100.0}{100.0}$ & 100.0
\end{tabular}

The above results show that the actual or adjusted yields are close to the target with the exception of hydrogen consumption. There appears to be some room for improvement in the distillate yield, if the gas yield could be reduced. Obviously, even if the gas yield was decreased by as much as $5-6$ rel \% ( 2 absolute \%), the hydrogen consumption would not be as low as the target value.

These results are very encouraging, particularly with regard to the overall coal conversions, the distillate yield and coal value rejection from a lower rank subbituminous western coal.

\section{MATERIAL BALANCES - RIIN 3.3}

During Run 33, a total of five material balances were made. Of these, four balances were considered satisfactory and were selected for calculation of final results. These results are summarized in rables 6-1 and 6-2 along with Run 32 and Run 34 results.

The calculated distillate $\left(C_{4}\right.$ to $\left.-850^{\circ} \mathrm{F}\right)$ yields for Run 33 ranged from a lnw nf 36.4 wt\% (MAF coal basis) for MB-1 to a high of $46.4 \mathrm{wt} \%$ for MB-4. Net resid yields ranged between 2.5 to $11.3 \mathrm{wt} \%$. MB-3 appeared to be closest to a resid balanced system and probably is the most representative of the type of results obtained. The soluble-coal recoveries in the CSD section were excellent and are reflected by the exceptionally low levels of rejected coal values in ash concentrate.

Since all four MB periods showed a net resid imbalance, the two-stage yields were recalculated for the "Zero Resid Product" case. This adjustment was similar to that made in Run 32 by redistribution of the resid product to the distillate and gas 
(including water) fractions in the same proportions as actually observed during the MB period. Hydrogen consumptions with the exception of MB-1 were increased to reflect this increase in resid conversion. Hydrogen consumption for MB-1 is possibly in error and was not adjusted in view of its high value in comparison with other MB periods. The results of the recalculations are summarized below.

Adjusted Product Yields for "Zero Resid Product" Case

\begin{tabular}{|c|c|c|c|c|}
\hline Yield, wt\% MAF Coal & 1 & $\frac{\text { Run } 33}{3}$ & $\frac{\text { Number }}{4}$ & 5 \\
\hline Hydrogen & $\langle 6.1\rangle$ & $\langle 5.3\rangle$ & $\langle 5.9\rangle$ & $\langle 6.1\rangle$ \\
\hline $\begin{array}{l}\text { Gases including water } \\
\text { plus } C_{1}-C_{3}\end{array}$ & 46.6 & 43.9 & 37.1 & 45.9 \\
\hline $\begin{array}{l}\mathrm{C}_{4} \text { to }-850^{\circ} \mathrm{F} \text { liquids } \\
+850^{\circ} \mathrm{F} \text { resid } \\
\text { Coal values in ash conc }\end{array}$ & $\begin{array}{c}41.7 \\
0 \\
17.8\end{array}$ & $\begin{array}{c}43.7 \\
0 \\
17.7\end{array}$ & $\begin{array}{l}49.3 \\
0 \\
19.5\end{array}$ & $\begin{array}{c}43.4 \\
0 \\
16.8\end{array}$ \\
\hline Net & 100.0 & 100.0 & 100.0 & 100.0 \\
\hline
\end{tabular}

The adjusted distillate yields for the "Zero Resid Product" case range from 41.7 to 49.3 wt\% MAF coal with an average of 45.5 wt \%. This is about 15 relative percent lower than obtained in Run 32. A comparison of the averaged product yields for MB-3, -4 and -5 with the Run Target is given below.

Run 33

\begin{tabular}{|c|c|c|c|}
\hline Yield, wt\% MAF Coal & $\overline{\text { Target }}$ & Ave & MB $3,4, \& 5$ \\
\hline & Values & Actual & Adjusted \\
\hline Hydrogen & $\langle 4.2\rangle$ & $\langle 5.5\rangle$ & $\langle 5.8\rangle$ \\
\hline Gases, including water & 30.8 & 40.2 & 42.3 \\
\hline $\begin{array}{l}\mathrm{C}_{4} \text { to }-850^{\circ} \mathrm{F} \text { liquids } \\
+850^{\circ} \mathrm{F} \text { resid } \\
\text { Coal values in ash conc }\end{array}$ & $\begin{array}{l}54.0 \\
0 \\
19.4\end{array}$ & $\begin{array}{c}43.3 \\
0 \\
18.0\end{array}$ & $\begin{array}{l}45.5 \\
0 \\
18.0\end{array}$ \\
\hline Net & 100.0 & 100.0 & 100.0 \\
\hline
\end{tabular}

The hydrogen consumption values are higher than estimated as was observed in Run 32 . It is obvious that the gas (plus water) make is higher than estimated and correspondingly the distillate yield is less than anticipated.

Reviewing the performance of thermal and catalytic stages (see Table 6-2) it becomes obvious that the process conditions of these stages need some adjustments. During 
Run 33 the catalytic stage produced a negligible or negative distillate yield and almost all of the distillate was produced in the thermal stage. Temperature of the thermal stage already is a little too high in view of the high gas make. Thus, it may be beneficial in this process flowscheme to decrease the severity of the thermal stage by slightly lowering the dissolver temperature. This will help decrease the gas yield. In order to help improve net distillate product, the hydrotreater needs to be operated at a slightly higher temperature, perhaps $730^{\circ} \mathrm{F}$. This is also reasonable in view of the heavier type of resid being hydrotreated in Run 33 in comparison to Run 32 .

\section{MATERIAL BALANCES - RUN 34}

During Run 34, a total of four 24-hour material balances were completed. However, during MB-4, CSD operation was very erratic and resulted in unusualiy high coal value rejection to the ash concentrate. As a result, MB-4 period was discarded.

The calculated distillate yields for Run 34 ranged from a low of $32.8 \mathrm{wt} \%$ to a high of $38.6 \mathrm{wt} \%$ (MAF coal basis). Net resid yields ranged between 8.9 and $15.7 \mathrm{wt} \%$. The coal values in ash concentrate averaged in the 20-21 wt\% range except for the first MB period. Erratic operation of CSD resulted in low soluble-coal recovery for this period.

A11 three MB periods indicated a net resid product meaning the system was in resid imbalance. The two-stage yields were thus recalculated for the "Zero Resid Product" case. This adjustment was made using the same techniques as before. However, the hydrogen consumption for MB-1 was not increased as it is already high and possibly in error in comparison to the other MB periods. The results of the recalculations resulted in the following adjusted product yields.

Adjusted Product Yields for "Zero Resid Product" Case

Yield, wt\% MAF Coal

Hydrogen

Gases including water plus $\mathrm{C}_{1}-\mathrm{C}_{3}$

$\mathrm{C}_{4}$ to $-85 \mathrm{n}^{\circ} \mathrm{F}$ liquids

$+850^{\circ} \mathrm{F}$ resid

Coal values in ash conc

Net

\begin{tabular}{|c|c|c|}
\hline \multicolumn{3}{|c|}{ Run 34 MB Number } \\
\hline $1-$ & 2 & 3 \\
\hline$<5.8>$ & $\langle 5.4\rangle$ & $\langle 5.8\rangle$ \\
\hline 45.7 & 45.5 & 40.5 \\
\hline $\begin{array}{c}39.1 \\
0 \\
21.0^{1}\end{array}$ & $\begin{array}{c}39.7 \\
0 \\
20.5\end{array}$ & $\begin{array}{c}43.5 \\
0 \\
21.8\end{array}$ \\
\hline 100.0 & 100.0 & 100.0 \\
\hline
\end{tabular}

1 Coal value rejection adjusted to levels comparable to other MB periods. 
The adjusted distillate yields for the "Zero Resid Product" case range from 39.1 to 43.5 wt \% MAF coal with an average of $41.5 \mathrm{wt} \%$ for $M B-2$ and -3 . This value is about 9 relative percent lower than obtained in Run 33 and 23 relative percent lower than obtained in Run 32. A comparison of these averaged product yields (MB's 2 and 3) for Run 34 with the Run Target is given below.

\section{Yield, wt\% MAF Coal \\ Hydrogen \\ Gases including water \\ plus $C_{1}-C_{3}$
$C_{4}$ to $-850^{\circ} \mathrm{F}$ liquids \\ $+850^{\circ} \mathrm{F}$ resid \\ Coal values in ash conc}

Net

\begin{tabular}{|c|c|c|}
\hline \multicolumn{3}{|c|}{34} \\
\hline $\begin{array}{l}\text { Target } \\
\text { Value }\end{array}$ & $\begin{array}{l}\text { Avera } \\
\text { Actual }\end{array}$ & $\begin{array}{l}\text { MB 2 \& } 3 \\
\text { Adjusted }\end{array}$ \\
\hline$\langle 5.1\rangle$ & $\langle 4.9\rangle$ & $\langle 5.6\rangle$ \\
\hline 36.2 & 36.3 & 43.0 \\
\hline $\begin{array}{c}49.0 \\
0 \\
19.9\end{array}$ & $\begin{array}{l}35.2 \\
12.3 \\
21.1\end{array}$ & $\begin{array}{c}41.5 \\
0 \\
21.1\end{array}$ \\
\hline 00.0 & 100.0 & 100.0 \\
\hline
\end{tabular}

Although the actual hydrogen consumption appears to be closer to the target, in view of the appreciable quantity of resid product, the actual hydrogen consumption in a resid balanced (zero resid product) system will be higher than the target under the process conditions tested. Again for Run 34, the total gas yield was higher and distillate yield lower than the target. Breakdown of results for the thermal and catalytic stages (Table 6-2) shows that process conditions in both of these stages need some adjustments. Similar to Run 33, the catalytic stage produced either a negative or negligible distillate yield and most of the distillate was produced in the thermal stage. By reducing the dissolver temperature, lower gas yield and correspondingly lower overall hydrogen consumption should be achieved. In view of the heavier fraction of DAR being hydrotreated, the hydrotreating temperature needs to be raised to as high as $750^{\circ} \mathrm{F}$.

How these changes in the reaction conditions of the thermal and catalytic stages affect the product yields under these process configurations remains to be evaluated. However, one thing is certain, that as the resid being hydrotreated becomes heavier, higher hydrotreating temperatures are required even to achieve a net resid balance. Based on the results of these three exploratory runs, hydrotreating of LDAR appears to produce a better quality solvent for coal liquefaction. 
OVERALL RESULTS

Comparison of the Runs 32,33 and 34

On the basis of daily control as well as material balance samples, the overall MAF coal conversions for all three runs ranged primarily in the 92-95 \% range. There appeared to be a small decrease in MAF coal conversion values as the run progressed with heavier resid feedstock to the hydrotreater. Results in Table 6-2 show that for several material balances the catalytic stage had a net negative distillate product yield. This indicates that the hydrotreater reactor temperature was lower than required for the type of resid being processed. A greater percentage of the overall hydrogen transfer was being made in the catalytic stage and a derreasing amount was being transferred in the thermal stage as the resid feed herame progressively heavier. The following summary compares the relative hydrogen transfers between the thermal and catalytic stages.

\section{Comparison of Hydrogen Consumption}

\begin{tabular}{|c|c|c|c|c|c|}
\hline \multirow[b]{2}{*}{ Run No. } & \multirow{2}{*}{$\begin{array}{c}\text { Total } \\
\text { wt } \% \\
\text { MAF Coal } \\
\end{array}$} & \multicolumn{2}{|c|}{ Thermal Stàge } & \multicolumn{2}{|c|}{ Catalytic Stage } \\
\hline & & $\begin{array}{c}\text { wt } \% \\
\text { MAF Coal }\end{array}$ & $\begin{array}{l}\% \text { of } \\
\text { Total }\end{array}$ & $\begin{array}{l}\text { Wt } \% \\
\text { MAF Coal }\end{array}$ & $\begin{array}{l}\% \text { of } \\
\text { Total }\end{array}$ \\
\hline 32 (4 MB Avg) & 5.4 & 3.1 & 57 & 2.3 & 43 \\
\hline 33 (4 MB Avg) & 5.7 & 3.1 & 43 & 2.6 & 46 \\
\hline 34 ( $3 \mathrm{MB}$ Avg) & 5.2 & 2.5 & 48 & 2.7 & 52 \\
\hline
\end{tabular}

As the resid feed to the hydrotreater became heavier, the overall distillate product yield decreased. Moreover, the catalyst deactivation rate increased and will be discussed later.

A comparison of the overall adjusted product yields from the three runs. is given in the following table.

Run Number

Average of MB No.

Process Configuration No.

Adjusted Yields, wt \% MAF Coal

Hydrogen

Gases including water, plus $C_{1}-C_{3}$

$\mathrm{C}_{4}$ to $-850^{\circ} \mathrm{F}$ 1 iquids

$+850^{\circ} \mathrm{F}$ resid

Coal values in ash conc

Net

$\begin{array}{ccr}32 & 33 & 34 \\ 2,4,5 & 3,4,5 & 2,3 \\ 6 & 4 & 8\end{array}$

$\langle 5.3\rangle \quad\langle 5.8>\quad<5.6\rangle$

$\begin{array}{lll}31.9 & 42.3 & 43.0\end{array}$

$\begin{array}{lll}53.8 & 45.5 & 41.5\end{array}$

0000

$\begin{array}{lll}19.6 & 18.0 \quad 21.1\end{array}$

$\overline{100.0} \overline{100.0} \quad \overline{100.0}$ 
These results show the decreasing quantity of distillate and increasing quantity of gases plus water being produced as the process configuration was changed to handle heavier resid feed in the catalytic stage.

Changing process configurations also affected the product characteristics and compositions. The following table provides a comparison of the average compositions and characteristics of key process streams from Run 32,33 and 34 .

Process Configuration No.

$\frac{\begin{array}{c}\text { Avg } \\ \text { Run 32 }\end{array}}{6} \quad \frac{\begin{array}{c}\text { Avg } \\ \text { Run } 33\end{array}}{4} \quad \frac{\begin{array}{c}\text { Avg } \\ \text { Run 34 }\end{array}}{8}$.

Hydrotreater Feed

$\mathrm{H} / \mathrm{C}$ atomic ratio

Resid fraction PA wt\%

$\begin{array}{lll}1.13 & 1.16 & 1.26 \\ - & 10.8 & 13.1\end{array}$

Hydro-Underflow

$\mathrm{H} / \mathrm{C}$ atomic ratio

Resid fraction PA wt\%

$\begin{array}{lll}1.28 & 1.25 & 1.32 \\ 1.9 & 2.8 & 6.1\end{array}$

Solvent used for Hydrotreating

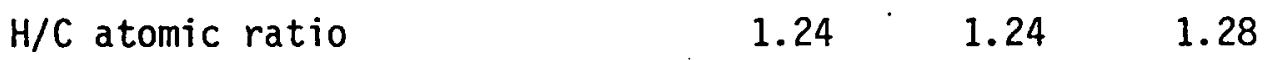

Vacuum Bottoms

$\begin{array}{lccc}\text { H/C atomic ratio } & 0.78 & 0.77 & 0.81 \\ \text { Ash, wt \% } & 8.0 & 16.45 & 15.33 \\ \text {-850\% Distillables, wt\% } & 6.4 & 2.6 & 5.9 \\ \text { Composition of soluble-coal } & & & \\ \text { fraction, wt \% } & & & \\ \text { Oils } & 15.6 & 6.8 & 9.5 \\ \text { Asphaltenes } & 67.5 & 74.8 & 73.1 \\ \text { Preasphaltenes } & 16.9 & 18.4 & 17.4 \\ \text { Average Viscosity, cp } & 189 & 425 & 245 \\ \text { Range, cp } & 115-250 & 225-570 & 215-300\end{array}$

Ash Concentrate
$\mathrm{H} / \mathrm{C}$ atomic ratio
0.73
0.72
0.74
Preasphait tenes (PA), wt\%
23.8
20.1
19.5

The differences in the $\mathrm{H} / \mathrm{C}$ ratios of hydrotreater feed and underflow are probably directly related to the catalytic stage performance. The small increases of $\mathrm{H} / \mathrm{C}$ ratios in the hydro feed and underflow for Run 33 and 34 indicate that the degree of hydrogenation during these runs was not as good as in Run 32. Since in all process configurations, the hydro-underflow was used as a liquefaction solvent either by itself or in combination with other material, this difference of hydro-underflow composition is expected to have a direct effect on the quality of vacuum bottoms produced provided all other process parameters in 
the thermal stage remain the same. In case of Run 32, 33 and 34 , the therma 1 stage conditions were essentially similar and as a result the hydro-underflow composition effect on vacuum bottoms can be readily observed. For Run 32 , DAR was directly recycled (without hydrotreating) to the thermal stage. Under normal circumstances, this would produce vacuum bottoms of higher preasphaltene content, having higher viscosity. However, on a soluble-coal basis, the preasphaltene content of Run 32 vacuum bottoms are the lowest. The viscosity of Run 32 vacuum bottoms is also the lowest. However, the lower ash content of these vac-bottoms may be partially responsible for the lower viscosity.

The coal values rejected to ash concentrate had about the same $H / C$ atomic ratio for all three runs. However, more of the preasphaltenes were being rejected to this stream during Run 32 showing preferential concentration and elimination (by rejection) of these coke precursors under process configuration No. 6 . Once proper operating conditions were established, the operation of the CSD section was much smoother during Run 32. Although the analytical data does not reflect this improved operability, Run 32 process configuration appears to provide the best process configuration tested to-date. The above observations coupled with catalyst analyses reinforce the belief that only light deashed resid should be hydrotreated with this particular catalyst for better hydrotreater catalyst 1 ife as well as improved thermal stage products.

\section{CATALYST DEACTIVATION}

The effect of various hydrotreater feeds on catalyst deactivation was evaluated by 1) studying the change in pore size distribution of the spent catalyst, 2) the reduction of the average pore radius, 3) the reduction of the available surface area and 4) the chemical analyses. In order to measure the effect of each feed type, a fresh batch of catalyst was used for each run. The catalyst was presulfided before use.

Run 32 was the first of the series of three runs completed to determine the effect of various types of hydrotreater feeds on catalyst deactivation (coke precursors). The hydrotreater feed for Run 32 was Light Deashed Resid (LDAR). The feed for the next run (Run 33) was Full-Range Deashed Resid (FR-DAR) and Run 34 feed contained only the heavy fraction of DAR. One can thus see that as the program progressed i. from Run $32 \rightarrow 33 \rightarrow 34$, the resid got heavier and contained more preasphaltene-type materials which are believed to be primary coke precursors. 
The volume pore size distributions of the aged catalyst from the above three runs are given in Figure 6-1. This figure also compares some prior Bench-Scale aged catalyst data with higher overall catalyst age for similar types of resid processed. Comparison of these distributions show that the pore pluggage and carbon deposition accelerate as the resid feed became heavier. For all three runs, pores ranging in radii of $56-70 A^{\circ}$ were plugged off even though the catalyst age differs by almost an order of magnitude.

Comparison of the pore size distribution data for Run 32 and 33 (curves 2 and 3 , Figure 6-1) shows the higher buildup of carbon on the catalyst while hydrotreating the FR-DAR than when hydrotreating the LDAR. The mean pore radii for the two aged catalyst samples are about the same. However, the pore size distribution is slightly less for the FR-DAR treated catalyst. This would indicate that if the two catalysts had about the same age, the mean pore radius would be much smaller after hydrotreating the FR-DAR in comparison to hydrotreating LDAR.

Comparison of the pore size distribution for Run 32 and 34 (curves 2 and 4 , Figure $6-1)$ shows the accelerated catalyst pore plugging when hydrotreating the heavier fraction of DAR. The mean pore radii of the two aged: catalysts are identical (about $45 \mathrm{~A}^{\circ}$ ), however, the catalyst age for Run 34 (curve 3 ) was roughly a fourth of the catalyst age for Run 32. Obviously from a desired extended catalyst age viewpoint, one could conclude that LDAR hydrotreating is preferred over hydrotreating of DAR.

The pore size distribution curves shown in Figure 6-1 also indicate that the catalyst after the LDAR hydrotreating (Run 32) was deactivated to a lesser extent than the catalyst after Run 20 which hydrotreated about equal amounts of Ful1-Range DAR. The average pore radius for Run 32 aged catalyst was only slightly smaller than for the original catalyst at a catalyst age of 187 lbs-resid/lb-catalyst.

Properties of the aged catalysts from Run 32,33 and 34 along with their analyses are given in Table 6-3. There is little change in the available surface areas of the catalyst. Run 32 had the highest net available surface area reduction of $27 \%$. The least surface area reduction of $18.9 \%$ was for Run 34 . However, if these surface area reductions are expressed by taking into consideration the catalyst age, the results are dramatically different. For instance, percent surface area reduction expressed as a fraction of catalyst age `(percent surface reduction per unit increase 
of catalyst age) is only 0.14 for Run 32. This value increased to 0.25 and 0.37 for Run 33 and 34, respectively. This again indicates that loss of available surface area is more rapid with heavier resid feed.

Table 6-3 also provides a comparison of aged catalyst from Run 32 and prior benchscale runs 20 and 29 . These analyses indicate that the Run 32 catalyst was not deactivated to the same extent as the catalyst removed after Runs 20 and 29 . The age of the catalyst for Run 20 was only slightly higher than Run 32. Full-Range DAR was hydrotreated in Run 20 while LDAR was hydrotreated in Run 32 . A11 of the physical and chemical measurements listed indicate that the LDAR had a lesser deactivation effect on the catalyst than the other feed types.

The chemical analyses of the aged catalyst qiven in Table 6-3 also show some interesting patterns. The amount of carbon depositions in aged catalyst increased from Run 32 to Run 33, even at roughly half the catalyst age. A similar comparison between Run 32 and 34 shows that the carbon deposition was much more rapid while processing the heavier fraction of the DAR. For minimizing the coke precursors responsible for carbon deposition, it becomes obvious that LDAR is a preferred hydrotreater feed.

The sulfur levels in the aged catalyst appear to decrease in all cases but at somewhat different rates. Whether this is of any significance and how it relates to the catalyst deactivation has not been explored.

Other significant differences are observed in the trace metal contaminations. In each case, the higher catalyst age correlates with increased trace metal deposition on the catalyst. The reported value of $0.21 \%$ titanium deposition in Run 32 was rechecked and cannot be explained in view of the prior historical data while processing similar resid feed. 


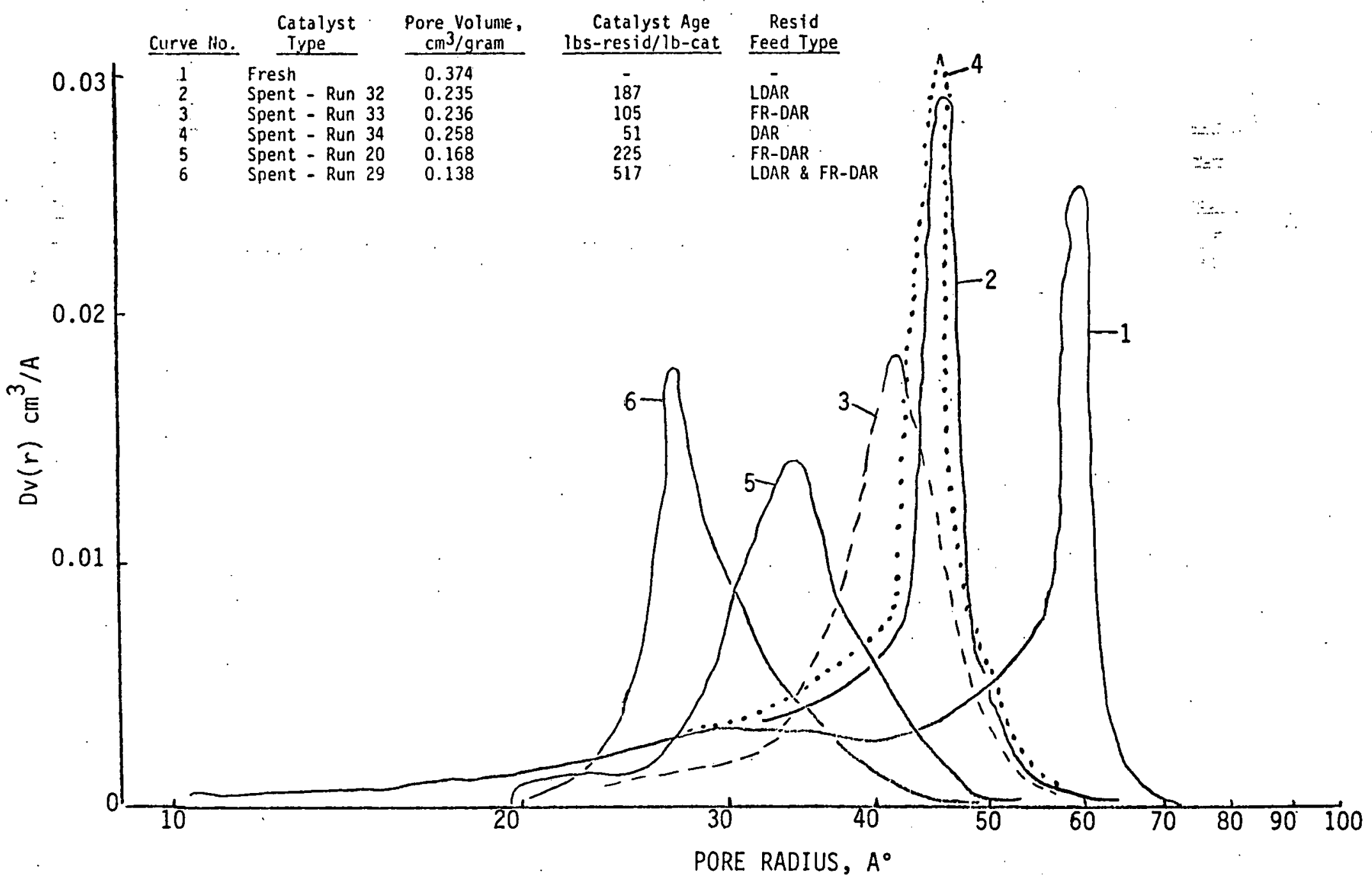

Figure 6-1. Volume Pore Size Distribution in Shell 324M Catalyst (1/32" extrudate) when used in Continuous Hydrotreatment of Full-Range Deashed Resid and Light Deashed,Resid 
Table 6-1

OVE ZALL TWO-STAÄE YIELDS

$\therefore$ Run Number

Material balance No.

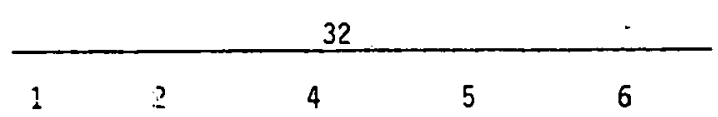

Wt $\%$, MAF Coal Equivalent

\begin{tabular}{|c|c|}
\hline \multirow{3}{*}{$\begin{array}{l}0 \\
1 \\
1\end{array}$} & Hydrogen \\
\hline & $\operatorname{Gases}\left(\mathrm{H}_{2} \mathrm{~S}, \mathrm{CO}, \mathrm{CO}_{2}, \mathrm{NH}_{3}\right)$ \\
\hline & Water \\
\hline 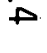 & $C_{1}-C_{3}$ hydrocarbons \\
\hline & $C_{4}$ to $-850^{\circ} \mathrm{F}$ resid \\
\hline & $+850^{\circ} \mathrm{F}$ resid \\
\hline
\end{tabular}

ccal v $\equiv l$ ues in ash conc

Net

\begin{tabular}{|c|c|c|c|c|}
\hline$\langle 6.6\rangle$ & $\langle E .4\rangle$. & $\langle 5.2\rangle$. & $\langle 5.4\rangle$ & $\langle 5.6\rangle$ \\
\hline$\therefore 16.2$ & $i .4$ & 9.5 & 8.8 & $1 E .3$ \\
\hline 10.5 & $\varepsilon .3$ & 13.9 & 9.1 & -11.8 \\
\hline 20.0 & $1 c .9$ & 12.5 & 14.2 & 17.9 \\
\hline 45.8 & $5 \pi .0$ & 53.0 & 56.1 & $4 \Xi .5$ \\
\hline 10.3 & $\langle E .4\rangle$ & $\langle 3.8\rangle$ & $\langle 1.7\rangle$ & $\quad c .5$ \\
\hline $3.8^{1}$ & 25.3 & 2.J. 1 & $18.9^{\circ}$ & $1 E .6$ \\
\hline 100.0 & 100.0 & 100.0 & 100.0 & $: O C .0$ \\
\hline
\end{tabular}

Unconierted coal, CSO not operatec

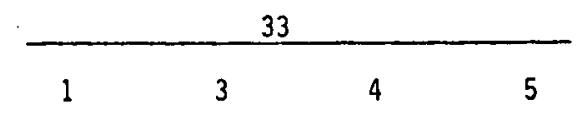

\begin{tabular}{lrrr}
$\langle 5.1\rangle$ & $\langle 5.2:$ & $\langle 5.6\rangle$ & $\langle\equiv .8\rangle$ \\
11.0 & 15.3 & 9.2 & $1 \Xi .8$ \\
14.9 & 14.7 & 14.3 & 17.2 \\
14.7 & 12.6 & 11.5 & $1 \Xi .1$ \\
35.4 & 42.4 & 46.4 & 41.2 \\
11.3 & 2.5 & 4.7 & 4.7 \\
17.8 & 17.7 & 19.5 & 15.8 \\
\hline 100.0 & $\overline{100.0}$ & $\overline{100.0}$ & $\overline{001.0}$
\end{tabular}

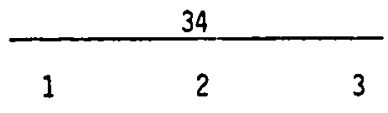

\begin{tabular}{llr}
$\langle 5.8\rangle$ & $\langle 4.5\rangle$ & $\langle 5.3\rangle$ \\
11.0 & 13.3 & 11.4 \\
13.0 & 11.2 & 12.7 \\
14.4 & 12.1 & 11.9 \\
32.8 & 31.7 & 33.6 \\
10.2 & 15.7 & 8.9 \\
24.4 & 20.5 & 21.8 \\
\hline 100.0 & 100.0 & 100.0
\end{tabular}




\section{Run Nun:ber}

Meterial Balance No.$$
\text { (1) }
$$

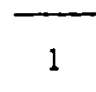

Thermal stage Yields. Wt: MAF Coal

Liquefaction plus CSD Units

\begin{tabular}{|c|c|c|c|c|c|}
\hline $\begin{array}{l}\text { Geses }\left(\mathrm{CO}, \mathrm{CO}_{2}, \mathrm{H}_{2} \mathrm{~S}, \mathrm{IH}_{3}\right. \\
\text { Water } \\
\mathrm{C}_{\mathrm{J}}-\mathrm{C}_{3} \text { hydrocarbons } \\
\mathrm{C}_{1}-850^{\circ} \mathrm{F} \text { liquids } \\
+850^{\circ} \mathrm{F} \text { resid } \\
\mathrm{Coal} \text { values in } \mathrm{AC}\end{array}$ & $\begin{array}{r}14.5 \\
8.9 \\
18.6 \\
44.3 \\
14.6 \\
3.8\end{array}$ & $\begin{array}{r}7.3 \\
5.8 \\
12.4 \\
48.7 \\
3.8 \\
25.3\end{array}$ & $\begin{array}{r}8.9 \\
12.0 \\
12.0 \\
47.0 \\
3.1 \\
20.1\end{array}$ & $\begin{array}{r}8.5 \\
7.6 \\
13.8 \\
52.2 \\
2.8 \\
18.9\end{array}$ & $\begin{array}{r}15.1 \\
8.7 \\
17.0 \\
27.2 \\
17.7 \\
16.6\end{array}$ \\
\hline tb-Total & 104.7 & 103.3 & .103 .1 & 103.8 & 102.3 \\
\hline
\end{tabular}

\section{Catalytic Stage Ylelds, wtz MA: Coal}

\section{Hydrotreater Unit}

Gases $\left(\mathrm{CO}, \mathrm{CO}_{2} ; \mathrm{H}_{2} \mathrm{~S}, \mathrm{HH}_{3}\right)$

$\mathrm{C}:-\mathrm{C}_{3}$ hydrocarbons

$\mathrm{C}_{4}-850^{\circ} \mathrm{F}$ liquids

$+850^{\circ} \mathrm{F}$ resid

Sub-Total

Total Yield,

$w: \%$ MAF COAl

Less Het Total

Input

NET

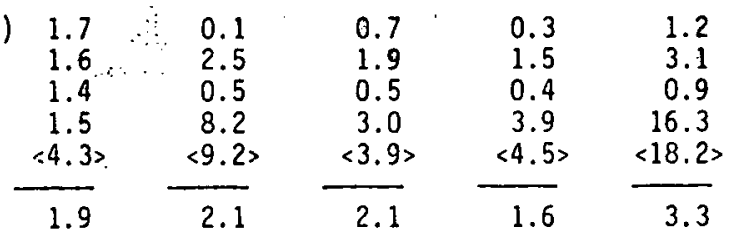

$\begin{array}{lllll}106.6 & 105.4 \quad 05.2 & 105.4 & 105.6\end{array}$

$$
\frac{6.6}{100.0} \quad \frac{5.4}{100.0} \quad \frac{5.2}{100.0} \quad \frac{5.4}{100.0} \quad \frac{5.6}{100.0}
$$

Table 6-2

$\therefore=\cdots$

$\therefore: 3$.

THERM,AL AND CATALYTIC STAGE YIELDS $\quad \cdot . \cdot \ldots$

33

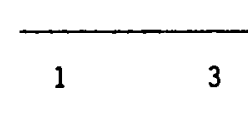

\begin{tabular}{rr}
10.1 & 14.6 \\
12.5 & 10.7 \\
13.6 & 11.9 \\
44.8 & 42.7 \\
5.2 & 4.9 \\
17.8 & 17.7 \\
\hline 104.0 & 102.5
\end{tabular}

$\begin{array}{r}8.5 \\ 9.7 \\ 10.8 \\ 46.5 \\ 7.8 \\ 19.5 \\ \hline 102.8\end{array}$

$\begin{array}{r}11.9 \\ 14.8 \\ 12.3 \\ 46.1 \\ 1.2 \\ 16.8 \\ \hline 103.1\end{array}$
$0.9 \quad 017 \quad 0.79$
$2.4 \quad \because 40 \quad \cdots 4.6 \quad 2.4$
$\begin{array}{rrrr}1.1 & 0.7 & 0.8> & 0.8 \\ <8.4\rangle & <0.3\rangle & \langle 0.1\rangle & \langle 4.9\rangle\end{array}$
$\frac{6.1}{2.1} \frac{<2.4>}{2.7}$
$\frac{<3.2>}{2.8}$
$\frac{3.5}{2.7}$

$\begin{array}{llll}106.1 & 105.2 & 105.6 & 105.8\end{array}$

$\frac{6.1}{100.0} \quad \frac{5.2}{100.0} \quad \frac{5.6}{100.0} \quad \frac{5.8}{100.0}$

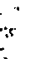

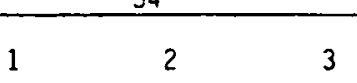

1 :SO not operated, value reported is unconverted coal. 
Table 6-3

$E=$ fect of Resid Type on Sheil 324N Catalyst Priferties

\begin{tabular}{|c|c|c|c|c|c|c|}
\hline Catalyst & Fre:sh' & $\begin{array}{l}\text { Spent } \\
\text { Run } 32 \\
\end{array}$ & $\begin{array}{l}\text { Spent } \\
\text { Run } 33 \\
\end{array}$ & $\begin{array}{l}\text { Spent } \\
\text { Run }=4\end{array}$ & $\begin{array}{l}\text { Spent } \\
\text { Run } 20 \\
\end{array}$ & $\begin{array}{l}\text { Spent } \\
\text { Run } 29 \\
\end{array}$ \\
\hline Resid type processed & & LDAR & FR-DAR & DAR: & FR-DAR & $\begin{array}{l}\text { FR-DAR } \\
\& \text { LDAR }\end{array}$ \\
\hline Age, lbs-resid/lb-c三talyst & 0 & 187 & 105 & 51 & 226 & 517 \\
\hline Surface area ${ }^{2}, \mathrm{M}^{2} / g$. & 146 & 116 & 117 & 129 & 93 & 89 \\
\hline Pore volume $060,0 \mathrm{CO} \mathrm{psi}{ }^{2}, \mathrm{~cm}^{3} i \mathrm{~g}$ & $0.3 ? 4$ & 0.235 & 0.236 & $0.25 \varepsilon$ & 0.168 & 0.138 \\
\hline $\begin{array}{l}\text { Bulk density of dried catalyst, } \\
\mathrm{g} / \mathrm{cm}^{3}\end{array}$ & 0.784 & 1.000 & 0.950 & 0.954 & 1.026 & 1.050 \\
\hline $\begin{array}{l}\text { Apparent density of dried catalyst, } \\
\mathrm{g} / \mathrm{cm}^{3}\end{array}$ & 3.48 & 2.89 & 2.58 & 2.67 & 2.70 & 2.64 \\
\hline Carbon, wt. \% & - & 8.9 & 10.5 & $9.8 ?$ & 9.40 & 14.9 \\
\hline Hydrogen, wt \% & - & 1.14 & 1.17 & 1.27 & 1.21 & 1.68 \\
\hline $\mathrm{H} / \mathrm{C}$ atomic ratio & - & 1.54 & 1.34 & $1.5 ?$ & 1.54 & 1.35 \\
\hline Sulfur, wt \% & - & 8.32 & 7.34 & 6.93 & 7.27 & 6.87 \\
\hline Iron, wt \% & 0.013 & 0.33 & 0.085 & 0.071 & 0.47 & 0.34 \\
\hline Silicon, wt \% & 0.077 & 0.19 & 0.067 & $0.05]$ & 0.11 & 0.87 \\
\hline Titanium, wt \% & $0.0 \Xi 7$ & 0.21 & 0.046 & 0.038. & 0.47 & 0.35 \\
\hline
\end{tabular}

1 As-produced catalys : in the axide forn. Catalyst was presulfided for eash of the bench-scale runs.

2 Based on mercury porosimeter test. 


\section{Section 7}

\section{BATCH REACTOR TEST PROGRAM - TASK 2}

SCOPE OF WORK

The objective of the batch tests completed in this quarter was to develop a batch reactor test procedure for evaluating different coal-derived resids and catalysts in terms of catalyst deactivation. Screening and evaluating catalysts in a continuous pilot-plant scale unit is known to be expensive. Therefore, it is desirable to have a batch reactor test that can be used to expedite the testing of various resids and catalysts in terms of catalyst life at low cost. The data ob-

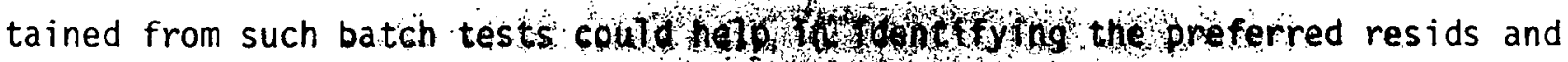
catalysts for testing in continuous units.

A series of batch tests were made to determine if meaningful catalyst deactivation data could be obtained using a batch test. The preliminary exploratory work, included here, investigated various aspects of such a test procedure. The experimental variables evaluated included,
o Reactor heat-up
- Catalyst particle size: crushed vs extrudates
o Catalyst form: oxide vs presulfided
- Catalyst age
o Type of resid processed.

The catalyst deactivation was measured in terms of changes in catalyst composition and catalyst properties including,

- Percent carbon and trace metal deposition

- Available surface area reduction.

- Available pore volume reduction

o Change in volume pore size dfstribution.

Changes in resid conversion with catalyst age were also used as a measure of catalyst deactivation. 
Some tests covered in this section were completed using EPRI and Kerr-McGee funds prior to the award of this DOE contract but are included in order to provide a better overview of the catalyst deactivation studies.

\section{EXPERIMENTAL}

All tests were conducted in a 1-liter batch reactor using Shell 324M catalyst. The different resids tested were obtained from the $15 \mathrm{lb} / \mathrm{hr}$ continuous Bench-Scale Unit or from the Advanced Coal Liquefaction Facility at Wilsonville, AL. The analyses of these materials are given in Appendix E.

A typical three-cycle test procedure, corresponding to a ratalyct. age of 120 pounds of resid per pound of catalyst (lbs-resid/ib-cat) is used. In this procedure, fresh catalyst and fresh feed are used in the first cycle. Fresh feed and aged catalyst from the previous cycle are used in the subsequent cycles. First, the reactants along with the catalyst to be tested are charged to the batch reactor liner. After completion of the reaction at the desired reaction conditions, the products in the reactor liner from the first cycle are diluted with THF and centrifuged to obtain the aged catalyst for the next cycle. The standard conditions for all the batch reactor tests are given in Table 7-1. Additional fresh reactants, except for catalyst, are added to bring the total charge to the same ratio of reactants to catalyst as used in the first cycle. This procedure is repeated for the desired number of cycles. After the last cycle, the catalyst is washed with hot pyridine to remove residual resid, vacuum-dried to remove pyridine and then analyzed. The distillate and resid fractions of the reaction are also analyzed. After each cycle, the reaction products are analyzed for $\mathrm{C}, \mathrm{H}, \mathrm{N}, \mathrm{S}$ and $\mathrm{O}$ and the resid conversion is calculated. The product workup procedure and product analyses scheme for these batch tests are shown in Figure 7-1. Catalyst deactivation is determined by evaluating changes in available surface area, and available total pore volume, changes in volume pore size distribution, residual carbon deposition, and heavy metals deposiLiun of the aged catalyst.

The reason for selecting the three-cycle test (equivalent to 120 pounds of resid processed per pound of catalyst) was based primarily on literature data which indicates that a fresh catalyst deactivates very rapidly in the first 24 to 28 hours of use, representing less than 50 pounds of resid processed per pound of catalyst. Testing at the level of 120 pounds of resid processed per pound of catalyst minimizes the initial activity effects of a new catalyst. Since the catalyst is still fairly active and not totally deactivated, it is possible to relate the observed 
differences in carbon and metal deposition, reduction in available surface area and pore volume to other process parameters such as the type of resid and its characteristics. In addition to the three-cycle tests, several single cycle and one six-cycle test were also completed. This corresponded to a catalyst age of 40 pounds of resid and 240 pounds of resid per pound of catalyst, respectively. The data from these batch reactor tests were compared with the data from the Bench-Scale Unit to establish the relationship between two types of testing.

\section{Reactor Heat-Up Effect}

The objective of this test segment was to determine the effect of a heat-up period on the catalyst properties in terms of catalyst deactivation. The normal time cycle in a batch reactor test includes a heat-up period of 50 to 60 minutes, followed by a 120-minute isothermal reaction period.

Test $83 A 3$ was made using Ful1-Range Deashed Resid (FR-DAR) as a feedstock with only the heat-up period (no reaction period) to determine the change in catalyst properties during this heat-up period. Test $83 \mathrm{~A} 1$ was a repeat of test $83 \mathrm{~A} 3$ with a normal heat-up period followed by a 120 -minute isothermal reaction period. The results of the aged catalyst analyses from these two tests are summarized in Table 7-2.

The carbon contents of the catalysts from tests $83 \mathrm{~A} 3$ and $83 \mathrm{~A} 1$ are 11.9 and 10.6 $w t \%$, respectively. These values are within the precision of the experimental determinations and indicate that there is no significant difference in carbon deposition in these two tests. Moreover, most of the deposition appears to have occurred during the heat-up period of the normal batch reactor test.

The sulfur and titanium contents of the catalysts from tests $83 \mathrm{~A} 3$ and $83 \mathrm{Al}$ are substantially different. The sulfur content of the catalyst from test $83 A 1$ is about $4.3 \mathrm{wt} \%$ which is approximately 3.5 times higher than that in test $83 \mathrm{~A} 3$ ( $1.24 \mathrm{wt} / \mathrm{c})$. Similarly, the titanium content of the catalyst from test $83 A 1$ is 0.13 wt\% which is approximately 2.5 times higher than in test $83 \mathrm{~A} 3(0.05 \mathrm{wt} \%)$. These results suggest that the increase in sulfur content and titanium deposition on the catalyst are a direct function of the total contact time. Moreover, a reaction time of at least 120 minutes is needed for adequate metal deposition to occur to permit evaluating its effect on catalyst deactivation. 
The reduction in available pore volume and surface area of the catalysts fron test $83 A 3$ and $83 A 1$ are not significantly different. The pore volume of the catalyst from test $83 A 3$ decreased from 0.374 to $0.212 \mathrm{~cm}^{3} / \mathrm{g}$ during the heat-up period while the pore volume of the catalyst from test $83 A 1$ decreased from 0.374 to $0.215 \mathrm{~cm}^{3} / \mathrm{g}$ after the 120 minute reaction period. Percent reduction in the surface area of the above catalysts exhibited a behavior similar to the pore volume results for both tests. The catalyst surface area reductions for tests $83 A 3$ and $83 A 1$ are 11 and $8 \%$, respectively, and indicates that normal heat-up period does not significantly alter this catalyst property.

To examine the patterns of pore plugging, the pore size distributions of fresh and aged Shell 324M catalyst are compared in Figure 7-2. These data indicate that the pores of radii ranging from 50 to $70 \mathrm{~A}^{\circ}$ in the fresh catalyst are completely plugged off in the aged catalyst. The volume pore size distribution for catalysts from tests $83 A 3$ and $83 A 1$ are identical.

The $+850^{\circ} \mathrm{F}$ resid conversion to distillate obtained in tests $83 \mathrm{~A} 3$ and $83 \mathrm{Al}$ are 26 and $18 \mathrm{wt} \%$, respectively. These results indicate a rapid decline in resid conversion as a result of some retrograde reactions after initial catalyst contact.

Analysis of this data reveals that catalyst deactivation occurs very rapidly during the heat-up period. A comparison of the results obtained using heat-up period alone and a heat-up period followed with a 120-minute reaction period indicates that there is little difference between the physical properties of the catalysts at the end of these two tests. Also, within the precision of the experiments, there is little difference in the carbon deposits. The titanium deposit, however, is much higher for the test with 120 minutes reaction period. This indicates that at least the 120 minute reaction time is needed for evaluating metal deposition as related to catalyst deactivation.

\section{Catalyst Particle Size Effect: Crushed vs Extrudates}

Diffusional effects within a catalyst particle are known to affect the catalyst performance. To minimize the impact of these intraparticle diffusion effects and to obtain a measure of true catalyst activity, researchers have evaluated crushed catalyst of various range of particle sizes. Results of such studies (1) have shown that the

(1) Catalyst Development for Coal Liquefaction - EPRI Project Report No. AF-190(1976) by Amoco 0 il Company. 
smaller the particle size, the lesser the diffusion problems and greater the catalyst activity and the resultant resid conversion.

In order to help determine the particle size of catalyst which is more suited for the batch reactor test procedure to be used for resid screening, two tests MM-4 and MM-5 were carried out using crushed and extrudate forms of catalyst. Both tests were made using a 50 wt\% Full-Range Deashed Resid (FR-DAR) in process solvent. The results are summarized in Table 7-3.

The carbon contents of the catalysts from tests MM4 and MM5 are 10.68 and $14.50 \mathrm{wt} . .$, respectively. Both aged catalysts samples from tests MM4 and MM5 show significant decrease in available pore volume and surface area as compared to the fresh catalyst. In addition, the results also indicate that extrudates experienced much more decrease in pore volume and surface area compared to the crushed catalyst. It is believed that the excessive decrease in pore volume and surface area for extrudates is a result of greater intraparticle diffusional resistance to coal compounds in the extruded form of catalyst.

As a catalyst is crushed, it results in increasing the external surface area of the catalyst particles. Similarly, some internal pores which may have been blocked off before are now accessible and result in an increase in available pore volume.

The titanium contents of the crushed and extrudate forms of aged catalyst are also markedly different. The titanium content of crushed catalyst used in test MM4 is about $1.10 \mathrm{wt} \%$ while that of extrudate form of catalyst is about $0.13 \mathrm{wt} \%$. The titanium content of the crushed catalyst is about 8 times higher than that of the extrudates. This increased titanium deposition observed for crushed form of catalyst leads to the conclusion that titanium deposition phenomenon is surface related and it is likely that most of the titanium in a aged catalyst is concentrated in the outer region of the catalyst.

The resid conversions averaged $20 \mathrm{wt} \%$ for crushed catalyst versus $14 \mathrm{wt} \%$ for extrudates. This again is to be expected due to the greater external surface area and reduced intraparticle diffusional effects for the crushed form of catalyst. 
The volume pore size distribution for fresh and aged catalysts from tests MM4 and MM5 are shown in Figure 7-3. This figure clearly shows the unimodal pore distribution for the fresh Shell 324M catalyst with an average pore radius of $60 A^{\circ}$ and the shift in volume pore size distribution for aged catalyst samples as the pores in the $50-70 A^{\circ}$ radi $i$ are plugged off.

Analyses of this data reveals that the intraparticle diffusional effects have a direct influence on the carbon deposition and resid conversion characteristics of a catalyst. Moreover, the catalyst poisoning by heavy metals such as titanium is a surface-related phenomenon. A crushed catalyst had much less decrease in available surface area and pore volume compared to the extrudates during these tests. However, since the intent of the test procedure is to be able to differentiate between catalyst performance when used with different types of resids, a large, measurable change in catalyst properties is desirable. Hence, the extrudates as used are determined to be the preferred choice of catalyst for this test procedure.

\section{Catalyst Form Effect: Oxide vs Presulfided}

The Co-Mo or $\mathrm{Ni}$-Mo type of heterogeneous catalyst are usually presulfided prior to their use in hydroprocessing. In order to help determine what form of catalyst is more suited for the batch reactor test, two tests, MM5 and E-15B, were conducted using Shell $324 \mathrm{M}$ catalyst in the oxide and the sulfided forms, respectively. The sample of presulfided 324M catalyst was obtained from the Wilsonville Coal Liquefaction pilot plant where the sulfiding was accomplished using fule oil as a carrier solvent during the sulfiding operation.

The analyses of the fresh as well as aged catalysts for both the oxide and presulfided forms are given in Table 7-4. These analyses indicate that an initial catalyst deactivation has occurred during the catalyst presulfiding step. A comparison of the properties for fresh (oxide and presulfided) catalysts indicates that as much as $4.9 \mathrm{wt} \%$ of the carbon deposition, $26 \%$ of the pore volume reduction, and $10 \%$ of the surface area reduction has occurred as a result of the presulfiding of the catalyst. Comparison of the aged-oxide and aged-presulfided catalysts indicate that presulfided form of catalyst exhibited more drastic reduction in the available pore volume and surface area than the oxide form of catalyst. A comparison of the carbon contents of these aged-catalysts indicate that the presulfided form of catalyst has a higher level of carbon deposition than the oxide form of catalyst. 
One could thus speculate that the presulfided form of catalyst deactivates faster than the oxide form of catalyst under similar hydrotreating conditions. This may perhaps be the result of higher reactivity exhibited by the presulfided form of catalyst as evidenced by its higher (26 wt\%) resid conversion ability over the oxide form (14 wt\%).

Pore size distributions for fresh as well as aged oxide and presulfided forms of catalysts are shown in Figure 7-4. "Curves 1 and 2 show the volume pore size distribution of oxide and presulfided forms of fresh Shell 324M catalyst. Curves 3 and 4 shows the volume pore size distribution of oxide-derived and presulfided-derived aged catalyst. These data indicate that presulfided aged-catalyst had more shift in volume pore size distribution than the oxide-derived aged-catalyst.

Properties of some batch and continous processed catalysts are summarized in Table 7-5. Such a comparison of the aged-catalyst properties from batch and continuous process was made in order to help select the right form of catalyst for use in the batch reactor test procedure. It appears from these results that presulfided aged catalyst from the batch hydrotreatment has a high carbon deposition, and corres-pondingly, a significantly greater reduction in the available pore volume and surface area than a spent catalyst with twice the age from a continuous hydrotreatment process. A similar comparison of a oxide-derived aged catalyst from the batch treatment and a presulfided-derived aged catalyst from the continuous treatment both with about the same age show fairly good agreement in terms of carbon deposition, pore volume and surface area reduction. Based on these findings, it was decided that the oxide form of catalyst for a batch reactor test will be appropriate for simulating the performance of a sulfided catalyst in a continuous unit.

\section{Catajyst Aging Effect}

Tests were carried out using LDAR and FR-DAR feedstock to study changes in the catalyst properties as a result of its aging. The pore volume, surface area, and carbon deposition of the spent catalysts were compared to study the effect of catalyst age in terms of catalyst deactivation.

Aging with LDAR as a Feedstock. Two tests, $83 A 2$ and MM-8, were made using LDAR as a feedstock for a total catalyst age of 43 and 131 pounds of resid per pound of catalyst (lbs-resid/lb-cat). The properties of the aged 
catalyst from these two tests are summarized in Table 7-6. A $36 \%$ reduction in pore volume was observed in the initial catalyst age of 43 lbs-resid/lb-cat. There was no further decline in pore volume as the catalyst age was increased from 43 to 131 lbs-resid/lb-cat. The available surface area, however, continued to decline with the net reduction in surface area increasing from 5 to $29 \%$ as the catalyst age increased from 43 to 131 lbs-resid/lb-cat. Elemental and trace metal analyses of the aged catalysts were not significantly different. The observed resid conversions gradually declined from 42 to 27 wt\% with each cycle as the catalyst age increased from 43 to 131 ibs-resid/1b-cat. The volume pore size distributions of fresh and aged catalysts are compared in Figure 7-5. These graphs indicate that the pores of radii ranging from 50-70 $\mathrm{A}^{\circ}$ were completely plugged as a result of hydroprocessing LDAR.

Aging with FR-DAR as a Feedstock. Three more tests, 83A1, MM-5, and E-18, were carried out using FR-DAR as a feedstock to observe the changes in the catalyst properties as a result of aging of the catalyst. The catalyst age for these tests ranged from 40 to 240 lbs-resid/lb-cat. The properties of these aged catalysts are summarized in Table 7-7. Results indicate that significant reduction in pore volume and surface sirea occurred during the initial processing at an age of 120 lbs-resid/lb-cat. The surface area and pore volume reduction appear to level off after reaching a catalyst age of 120 lbs-resid/lb-cat. The carbon deposition increased rapidly and then lfveled off after reaching a catalyst age of 120 lbs-resid/lb-cat. Resid conversions declined from 18 to 11 $w t \%$ as the catalyst age increased from 42 to 240 ibs-resid/lb-cat. The effect of catalyst age on volume pore size distribution is shown in Figure 7-6. These graphs show the shift in volume pore size distribution as a result of catalyst aging and plugging of pores with radi $i$ ranging from $45-70 \mathrm{~A}^{\circ}$. It is likely that the decrease in pore volume and surface area with increasing catalyst age are caused by carbon and metal deposition.

\section{Effect of Resid Type}

Three different types of resids, H-LDAR, LDAR and FR-DAR, were evaluated as related to their effect on catalyst deactivation using Shell 324M catalyst. The aim of these tests was to arrive at a test procedure which was sensitive enough to different feedstocks to result in measurable and distinguishable differences in the properties of the aged catalyst. H-LDAR, LDAR and FR-DAR feeds were used in single cycle 
evaluation in which the spent catalyst age ranged from 30 to 43 lbs-resid/lb-cat. Additional tests completed used LDAR and FR-DAR feeds in a three-cycle evaluation in which the catalyst age ranged from 120 to 131 lbs-resid/lb-cat.

Single Cycle Test. In the first set of tests, the spent catalyst age ranged from 30 to 40 lbs-resid/lb-cat. The catalyst analyses and the catalyst properties from these tests are summarized in Table 7-8. There was no appreciable difference in properties of aged catalyst using LDAR and FR-DAR feeds. However, the aged catalyst obtained with H-LDAR feed exhibited the best performance. This is to be expected since the feed material has al ready been hydroprocessed once. The lowest carbon deposition and least reduction in the available pore volume and surface area occurred for H-LDAR. The reported increase in the surface area for H-LDAR is believed to be due to an error in analytical measurement. The resid conversions decreased significantly as the resid type was changed from H-LDAR to LDAR to FR-DAR. The resid conversions for H-LDAR, LDAR and FR-DR were 42,32 and $18 w t \%$, respectively. The volume pore size distribution for the different resid treated aged catalyst are shown in Figure 7-7. These results indicate that the catalyst processing FR-DAR has a greater accumulation of carbon and titanium deposits and experiences greater pluggage of available surface area and pores than catalyst processing H-LDAR and LDAR feeds.

Three Cycle Tests. In a second set of tests, the age of the catalyst ranged from 120 to 131 lbs-resid/lb-cat. These three cycle tests were completed using only LDAR and FR-DAR feedstocks. Results show a significant difference in the properties of aged catalysts. These properties of the LDAR and FR-DAR treated aged catalysts are summarized in Table $1-9$. The results indicate that both pore volume and surface area of the catalyst were dramatically affected by its exposure to the FR-DAR. By hydroprocessing FR-DAR the available pore volume decreased by $56 \%$, while the available surface area decreased by $37 \%$ for a catalyst age of 120 lbs-resid/lb-cat. On the other hand, in case of LDAR hydroprocessing, the pore volume decreased by $34 \%$ and the surface area decreased by $29 \%$ for a catalyst age of 131 lbs-resid/lb-cat. It is evident from this data that LDAR is a better hydrotreating feedstock than FR-DAR under similar hydrotreating conditions and results in much lower surface area and pore volume reduction of the catalyst. These results also show that the batch reactor test 
procedure used is adequately sensitive in terms of catalyst deactivation for different types of resids tested. The volume pore size distribution of LDAR and FR-DAR treated aged catalysts are compared in Figure 7-8. These data clearly indicate how the resid type could substantially affect the catalyst properties in terms of accumulation of carbon and metal deposits and catalyst pore plugging. For the same catalyst age, the FR-DAR feed resulted in blockage of pores with radii ranging from $45-70 \mathrm{~A}^{\circ}$.

\section{Parametric Study - Effect of Temperature}

Tests were conducted to evaluate the effect of reaction temperature on catalyst properties in terms of catalyst deactivation. It was intended to compare results obtained under comparatively mild hydroprocessing conditions with those obtained at a more typical liquefaction condition. The temperatures studied were $675,700,725$ and $750^{\circ} \mathrm{F}$. Other process conditions were kept the same as standard test conditions. LDAR from Wilsonville Run 241 was used as a feedstock in evaluating the deactivation of Shell 324M catalyst at different temperatures.

Properties of the aged catalysts from tests 83A.6-1 through 83A6-4 are summarized in Table 7-10. The catalyst age for all four tests was identical (40 1bs-resid/1b-cat). Results indicate that the temperature has very little effect on physical properties of the aged: catalyst. Elemental and trace metal analyses of the aged catalysts were also not significantly different. Percent reduction in the available pore volume and surface area was almost identical for all temperatures tested and amounted to $35-37 \%$ for pore volume and $6-8 \%$ for surface area.

The primary difference was observed in the value of resid conversions obtained. Resid conversions ranged from a negative value of $10 \mathrm{wt} \%$ to $+8 \mathrm{wt} \%$ as the temperature of hydroprocessing was increased from $675^{\circ} \mathrm{F}$ to $750^{\circ} \mathrm{F}$. It is obvious from the neqative value of resid conversion at $675^{\circ} \mathrm{F}$ that this temperature is too low for the reactions involved and no beneficial effect from the catalyst was obtained. At this temperature level, retrograde reactions were more pronounced causing a net negative resid conversion.

There were differences in the quality of the distillate and residuum products obtained by these hydroprocessing reactions. Analyses of the distillate and resid fractions 
from these tests are summarized in Table 7-11. These results indicate that the $H / C$ atomic ratio of the distillate fraction increased from 1.12 to 1.16 as temperature increased from 675 to $700^{\circ} \mathrm{F}$. As the temperature increased further from 700 to $750^{\circ} \mathrm{F}$, the $\mathrm{H} / \mathrm{C}$ atomic ratio of the distillate apppears to level off. Similarly, the $H / C$ atomic ratio of the residuum fraction increased from 0.81 to 0.89 as the temperature was increased.

The level of denitrogenation of resid was fairly low, ranging only to about 7-8 rel\%. The desulfurization of resid was a little more pronounced. Although the values range between $21-45$ rel \%, an average of about $32-33$ rel is more representative of the level of desulfurization obtained. "In conclusiph, as far as catalyst properties are concerned, the temperature sensitivity appears to be very low for the temperature range tested.

\section{Comparison of Aged Catalysts: Batch vs Continuous Processing}

A comparison of aged catalyst properties from a batch and continuous hydroprocessing step was made earlier in order to help ascertain the right form of catalyst for use in the batch reactor test procedure. Such a comparison is shown in Table 7-5. The continuous hydroprocessed aged catalyst (presulfided) was obtained from the Bench Scale Unit (Runs 15 through 20). The batch hydroprocessed aged (oxide) catalyst was obtained from Test E-18. Although the process conditions in the batch and continuous hydroprocessing were somewhat different, the catalyst age was similar with the exception of additional LDAR and process solvent processing in the continuous unit. The results shown in Table 7-5 indicate a fairly good agreement between the properties of aged. catalysts obtained from a continuous and a batch reactor test in terms of carbon deposition, pore volume and surface area reduction. A comparison of the available volume pore size distribution of these aged catalysts is given in Figure 7-9.

A similar comparison of aged catalyst from a batch versus continuous hydroprocessing with LDAR as a feedstock is given in Table 7-12. The continuous unit aged catalyst was of the presulfided type and was obtained from Bench Scale Run 32 , completed under the current DOE program. The batch hydroprocessed aged catalyst was of the oxide variety and was obtained from Test MM-8. Although there is a small difference in the age of these catalysts, the results indicate that there is a good 
agreement between the batch and continuous hydroprocessed catalyst properties in terms of carbon deposition, pore volume and surface area reduction, The level of titanium deposition appears to be unusually high for the type of resid processed and cannot be explained.

A comparison of the available volume pore size distribution of these aged catalysts is given in Figure 7-10. The catalyst appears to have less deactivation with LDAR in the continuous unit even at a $40 \%$ greater catalyst age over the batch reactor test. Pores in the 55-70 $\mathrm{A}^{\circ}$ radii appear to be plugged off in both cases.

\section{SUMMARY AND CONCLUSIONS}

The batch reactor tests completed during this reporting period were primarily aimed at developing and evaluating a batch reactor test procedure for use in coke=precursor studies. The most important finding from the work to date was that a batch reactor test as carried out under this laboratory test program will permit quick evaluation and screening of different resids and catalysts.

The as-produced, oxide form of catalyst in the extrudate shape when used in the batch reactor test is able to simulate closely the aging of presulfided, extrudate form of catalyst used in the continuous reactor. The results obtained from such batch reactor tests were fairly representative of the data obtained from a continuous unit and could be obtained in a short time at a low cost as compared to the high cost of testing in a continuous unit.

A three cycle test corresponding to a catalyst age of 120 ibs-resid/lb-cat appears to be adequate to evaluate different resids in terms of initial catalyst deactivation. Single cycle test corresponding to a catalyst age of only 40 lbs-resid/lb-cat may show the differences in the catalyst properties. However, these differences will be over shadowed by the high reactivity changes of a new catalyst and may not provide a true picture of catalyst performance in the long run.

The methodology of evaluating catalyst deactivation by studying the changes in the available surface area, total pore volume and volume pore size distribution of the aged catalyst in addition to its chemical analyses for residual carbón deposition and heavy metal contamination appears to provide the needed answers to the catalyst performance. 
Other findings and conclusions from these tests are:

- Significant carbon deposition, loss of available pore volume and surface area occur rapidly during the heat-up stages.

- The extrudate form of catalyst appears to be more susceptible to deactivation than the crushed form of catalyst by pore blockage and loss of available surface area primarily due to increased inträparticle diffusional resistance.

The heavy metal deposition phenomenon appears to be surface-related and not a function of intraparticle diffusion.

o The presulfided form of catalyst is more reactive and as a result also deactivates at a much faster rate than its oxide form.

- Catalyst age of 120 lbs-resid/lb-cat appears to be needed for adequate metal contamination to permit evaluation in terms of catalyst deactivation.

o The catalyst age as defined by pounds of material processed per pound of catalyst has a more pronounced effect on its deactivation than total contact time.

- The type of resid processed can substantially affect the catalyst properties and thus its performance. Among the resid types tested, FR-DAR exhibited the greatest adverse effect on catalyst properties in terms of accumulation of carbon and metal deposits and loss of available surface area and pore volume by plugging. Although H-LDAR proved to be the best resid feedstock from a catalyst performance standpoint, from a practical viewpoint, LDAR is a better suited feedstock for hydroprocessing than FR-DAR under similar hydrotreating conditions, and results in much less surface area and pore volume reduction and provides prolonged catalyst life. 


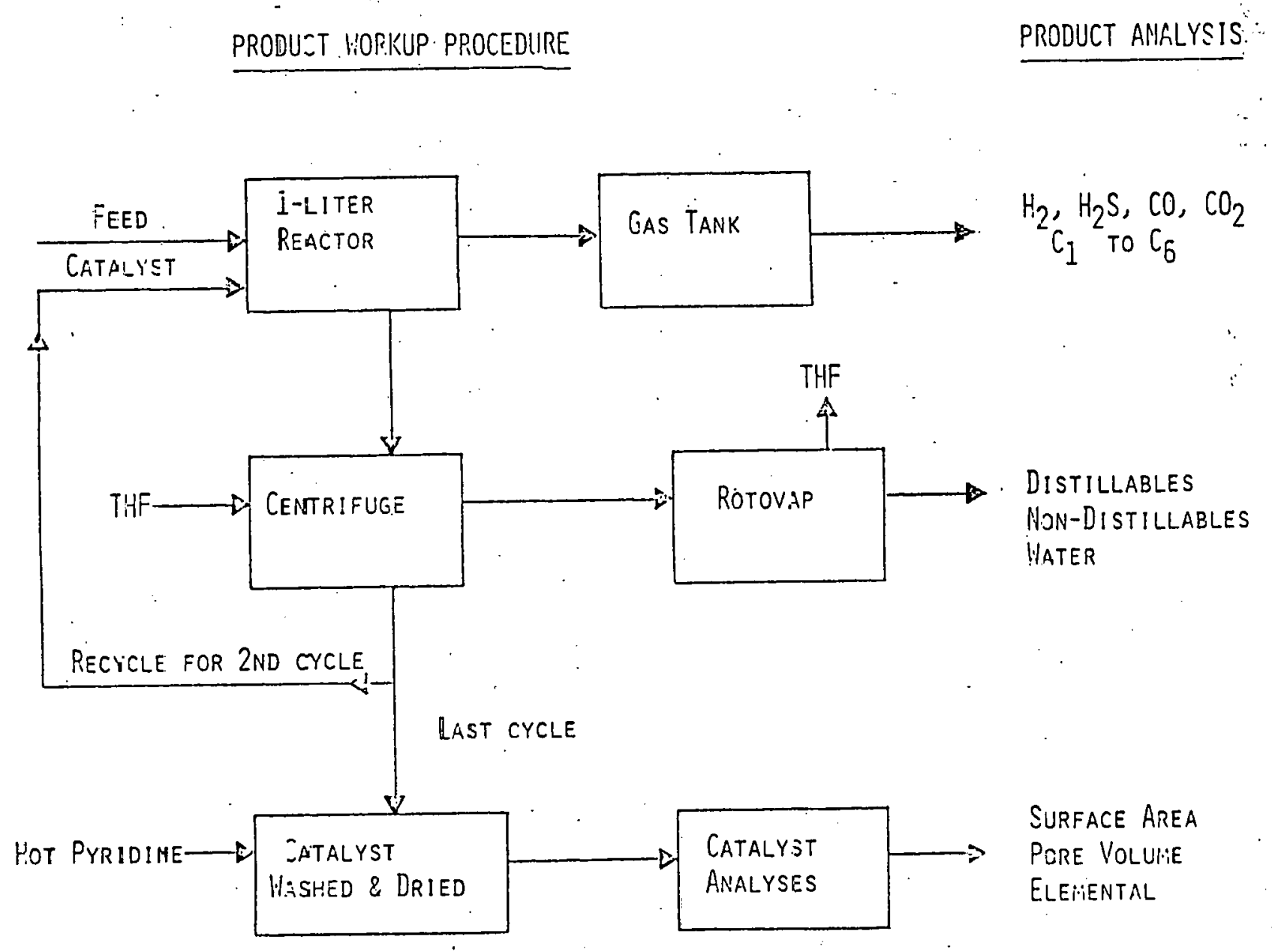

Material Handling Scheme for Batch Reactor Test

Figure 7-1. 
Shell 324M Time at

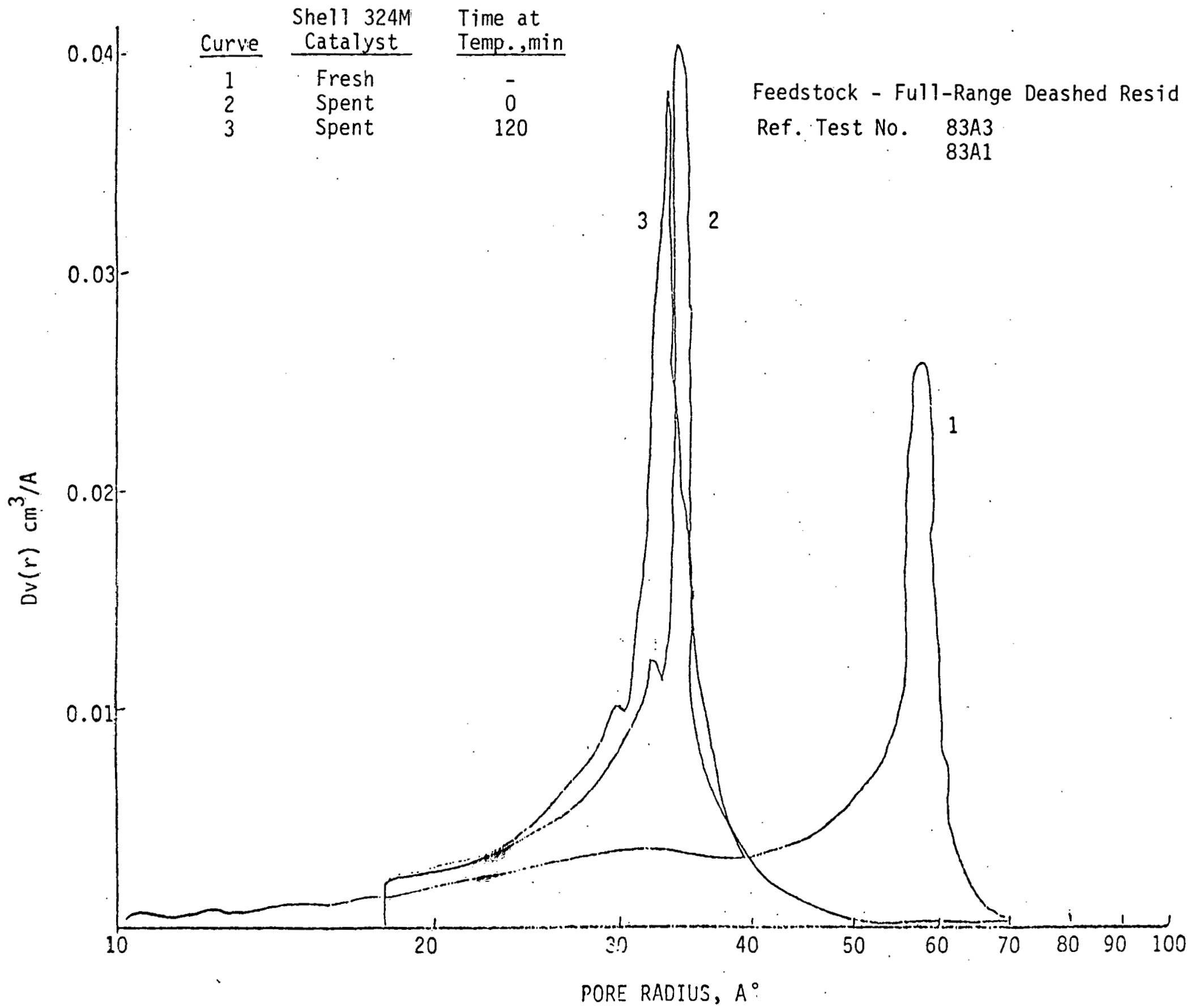

Catalyst Volume Pore Size Distrib!tion - Reactor Heatup Effect

Figure $7-2$. 


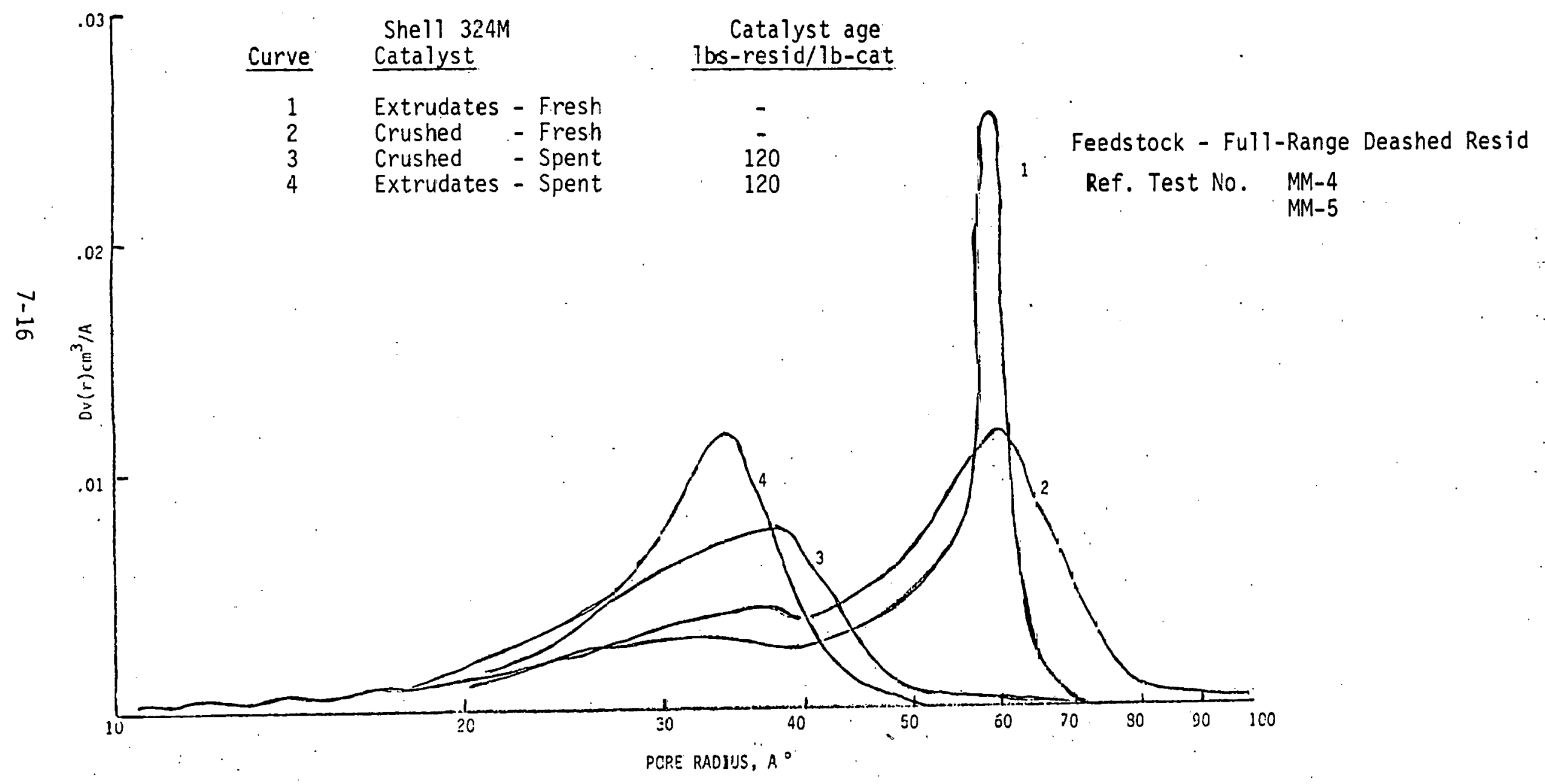

Catalyst Volume Fore Size Distribution - Extrudates vs Crushed Catalyst

Figure 7-3. 


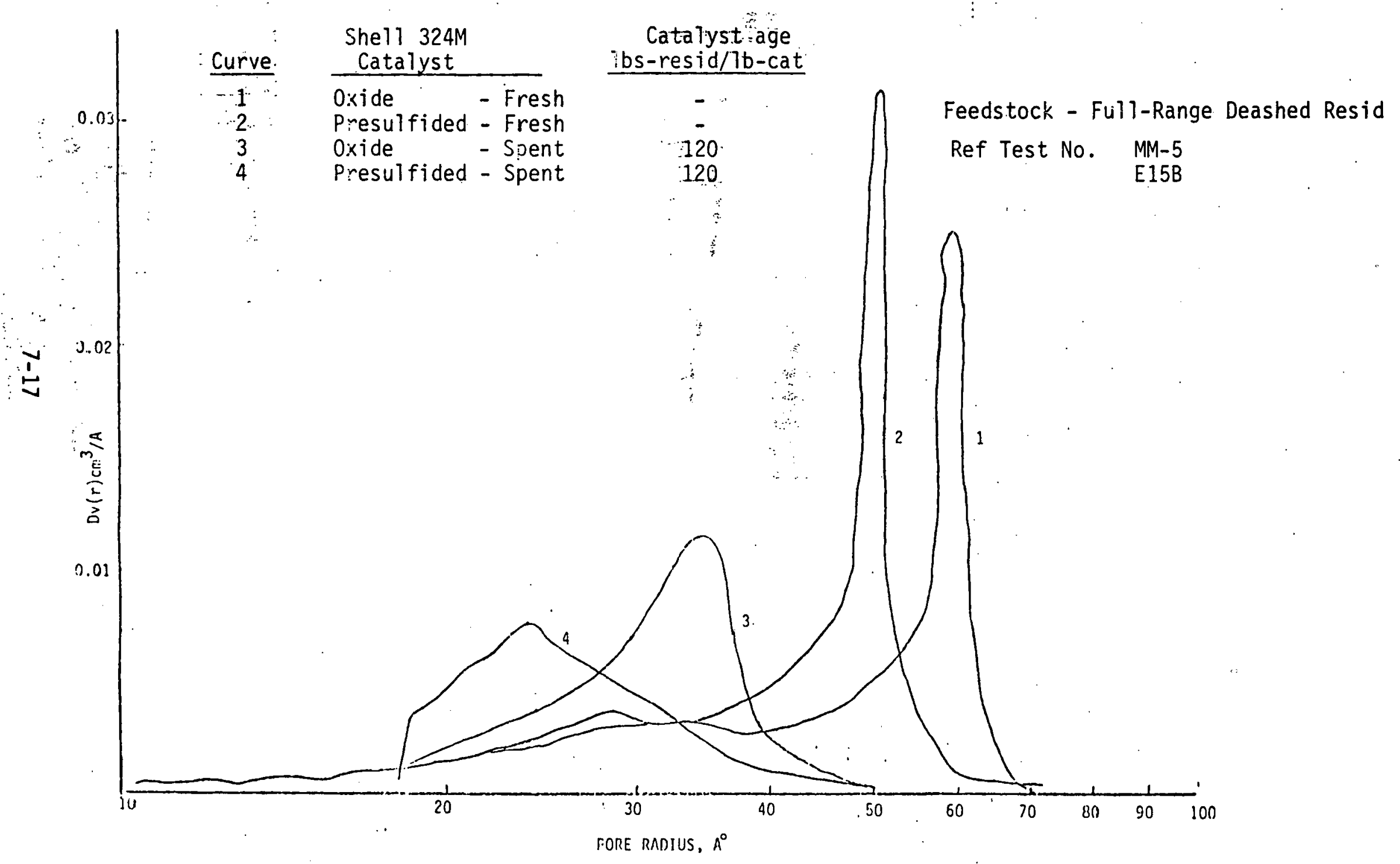

Catalyst Volume Pore Size Distribution - Oxide vs Presulfided Catalyst

Figure 7-4. 


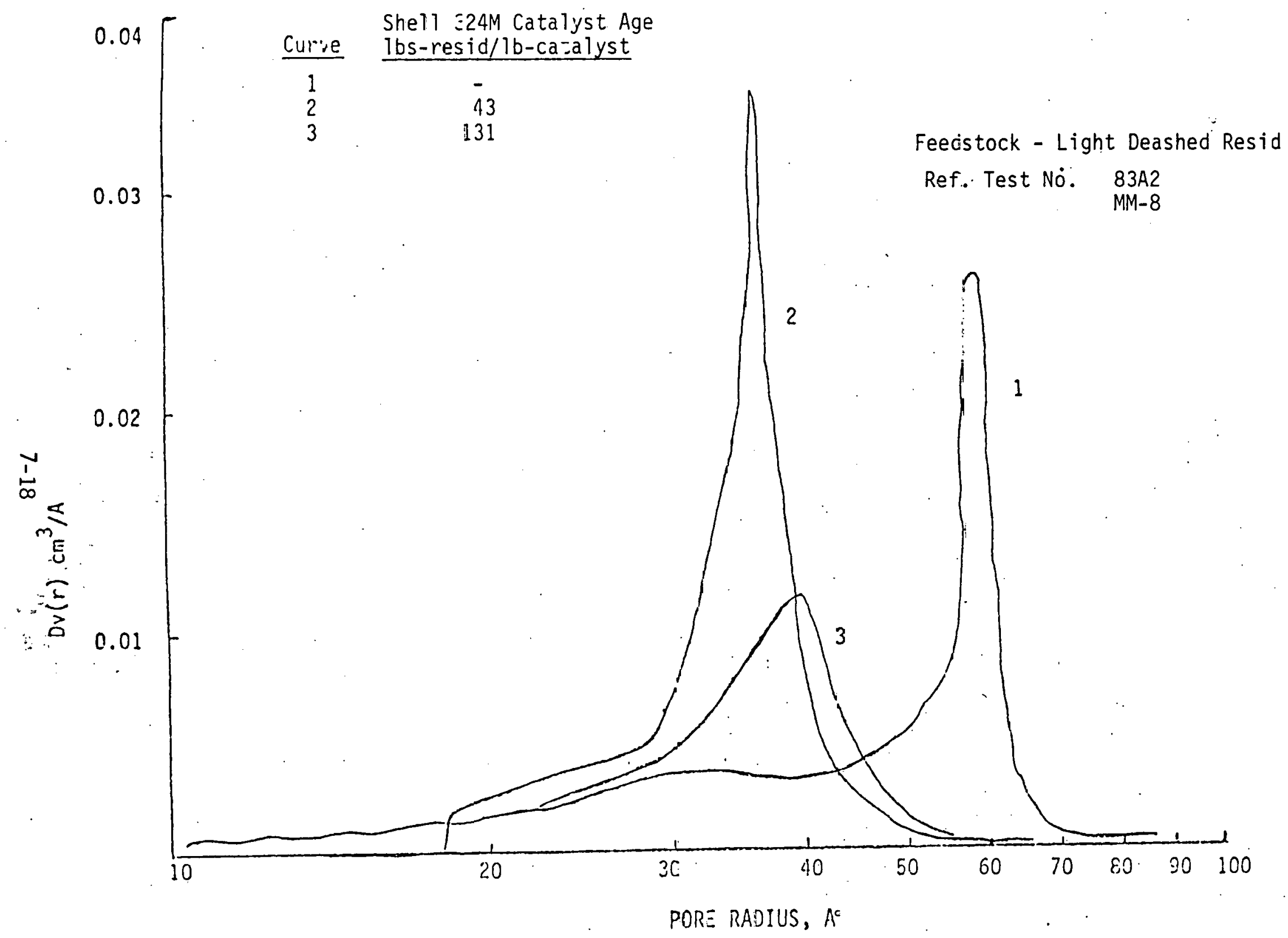

Catalyst Volume Pore Size Distribution - As a Function of Catalyst Age

Figure $7-5$. 


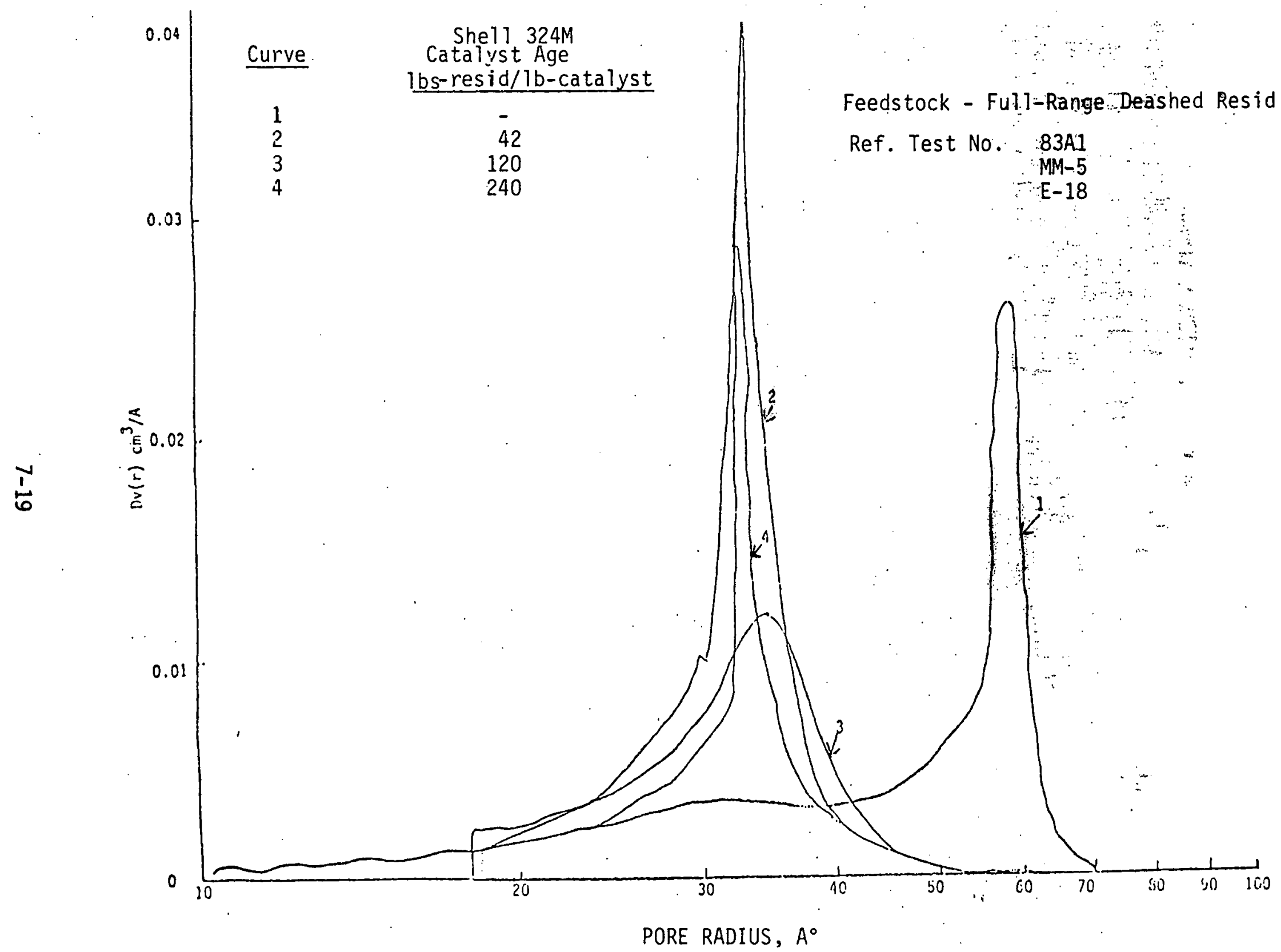

Catalyst Volume Pore Size Distribution - As a Function of Catalyst Age

Figure 7-6. 
Shel1 324M

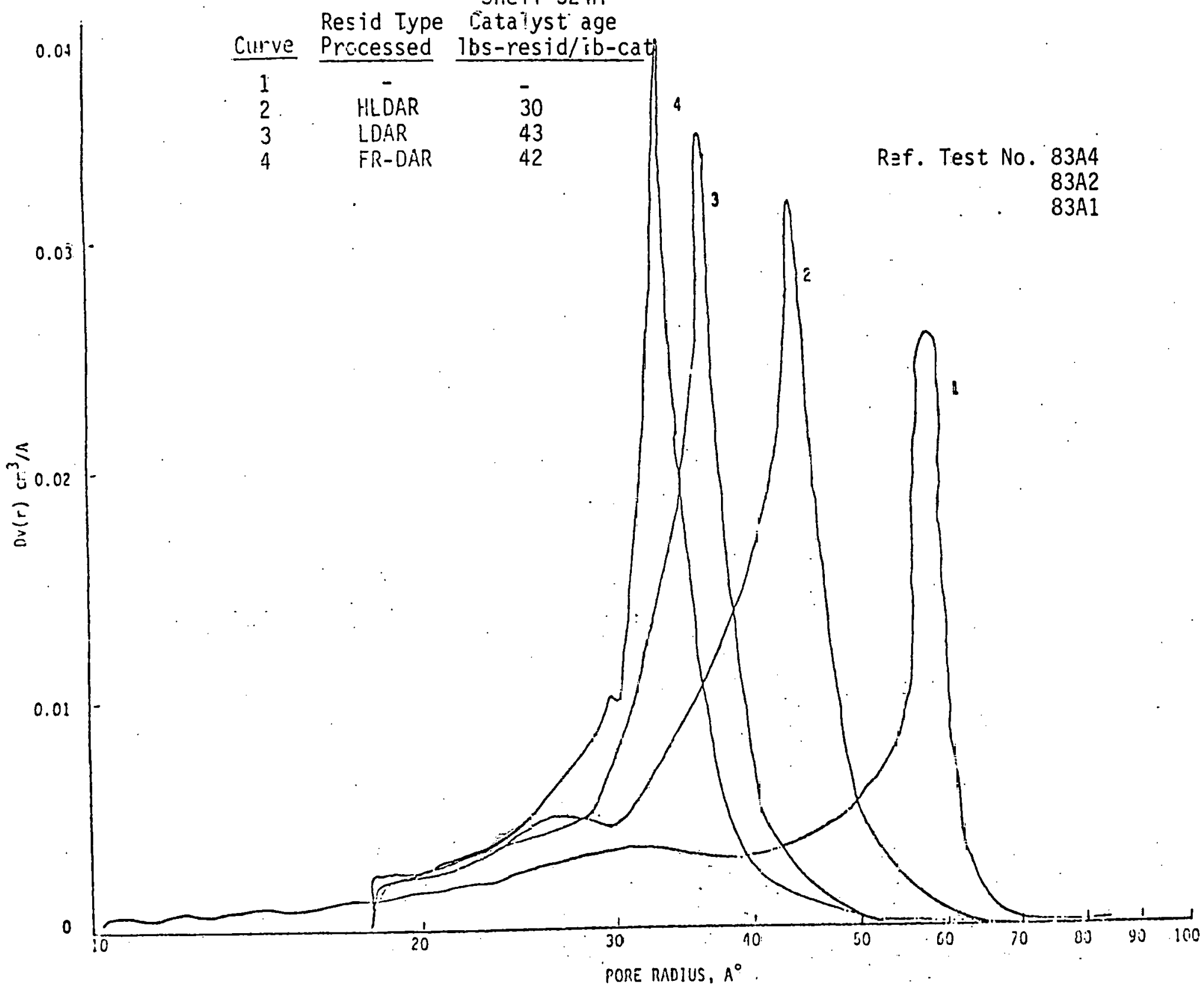

$\infty$

Catalyst Yolume Pore jize Distribu:ian - As a Function of Resid Type

Figure 7-7. 


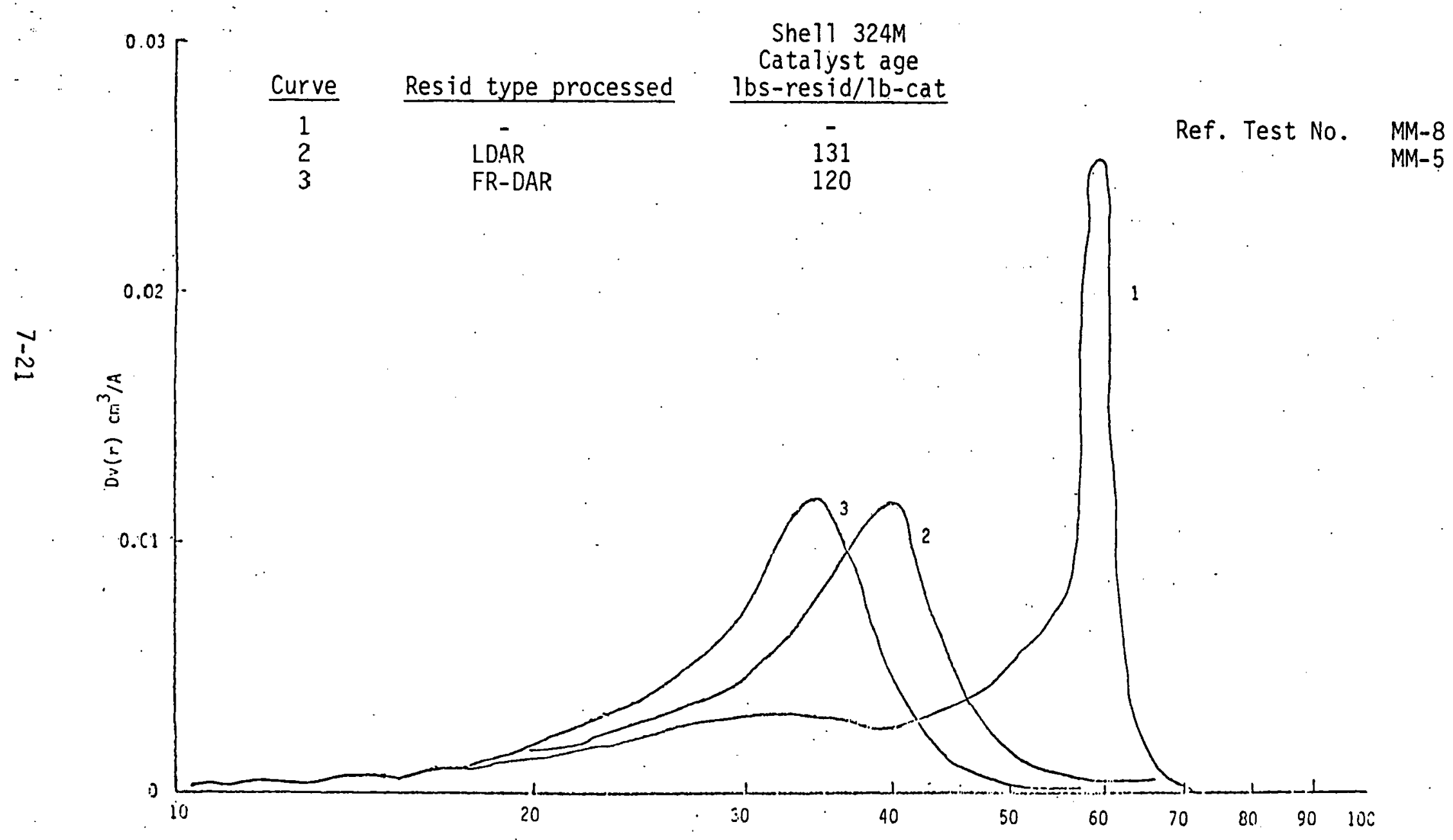

PCRE RADIUS, $\Lambda^{\circ}$

Citalyst Volune Pore Size Distribution - As a Function of Resid Type

Figure 7-8. 


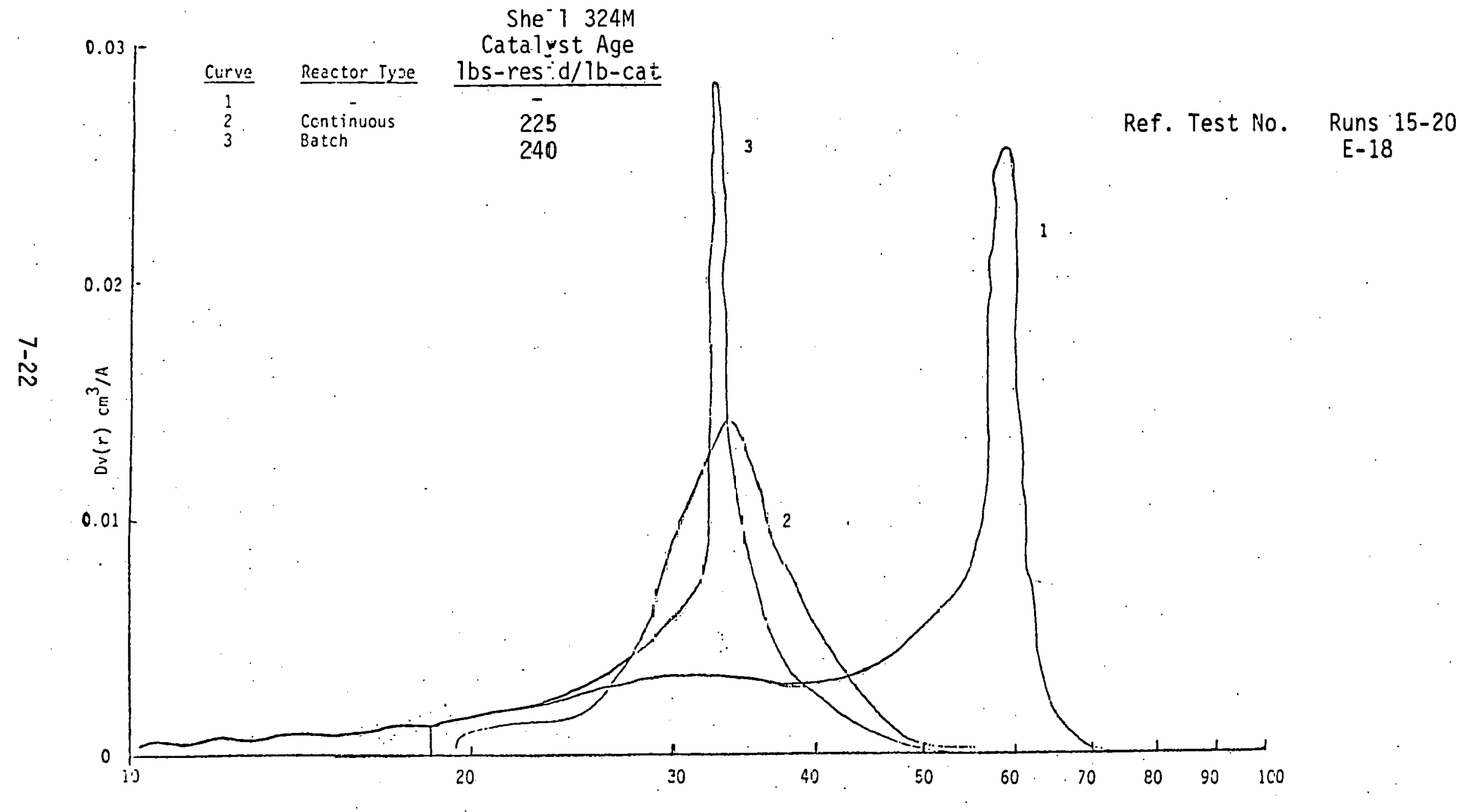

PDRE RADZUS: AC

Catalyst l'olume Pore Size Distribution - eatch vs Continuous Hydrotreatment of Fill-pance Deashes Resid.

Figure 7-9. 


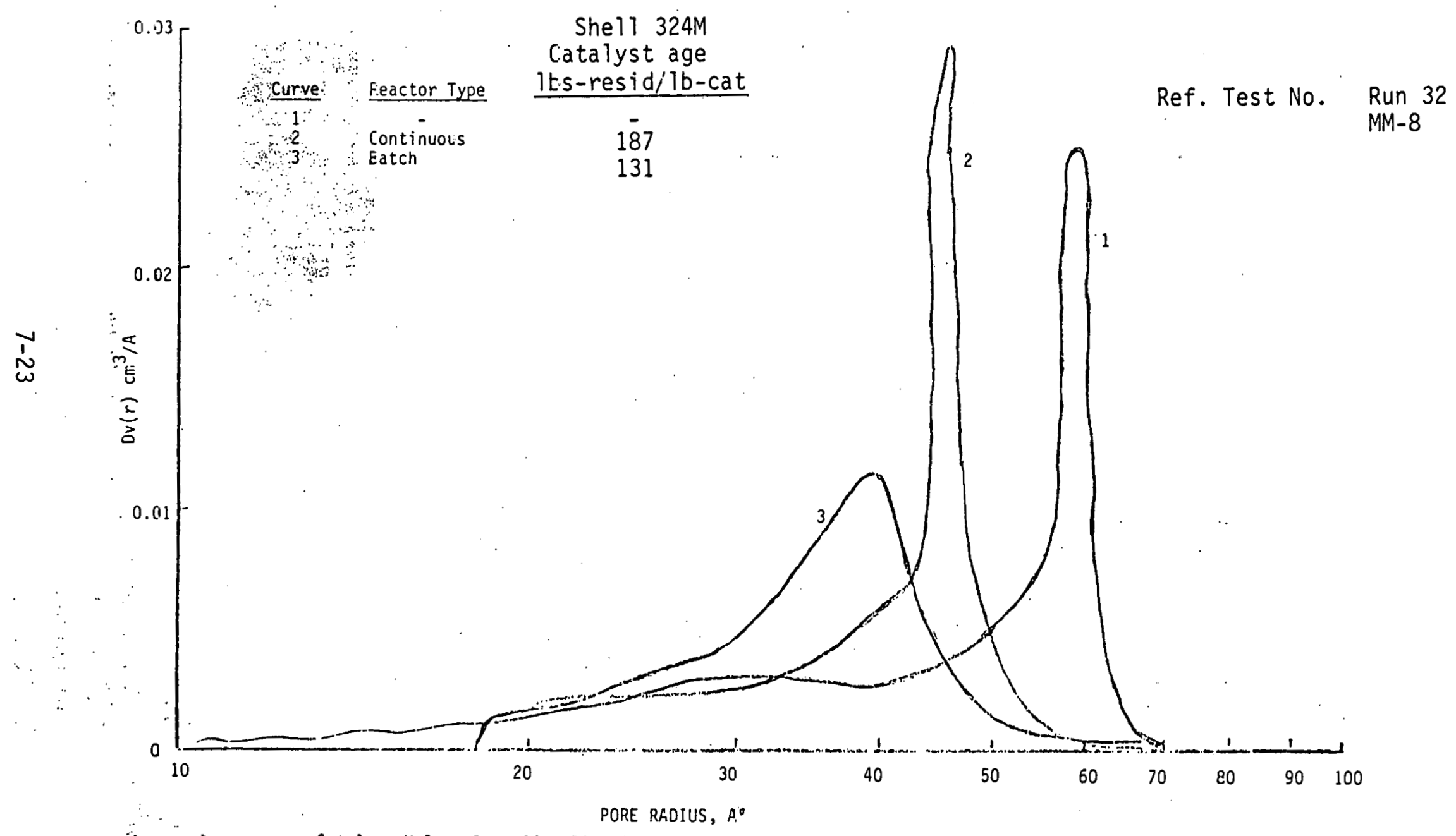

Catalyst Volume Pore Size Distribution - Batch vs Continuous Hydrotreatment of Light Deasked Resid

Figure 7-10. 
Table 7-1

Resid Evaluation by Catalyst Deactivation

Batch Reactor Test Conditions

Feed, grams

400

$+850^{\circ} \mathrm{F}$ resid in the feed, $w t \%$

50

Catalyst, grams

5

Reaction time, mins $\quad 120$

Reaction temperature, ${ }^{0} \mathrm{~F} \quad 750$

Hydrogen pressure(cold), psig 1400

No. of cycles 1 to 6

NOTE: Ayed catalysi frum the pirse cycle is used in the successive cycles to achieve desired catalyst age.

Table 7-2

Reactor Heat-Up Effect on Catalyst Feedstock ${ }^{1}-$ Full-Range Deashed Resid

Shell 324M Catalyst

Age (ibs-resid/lb-cat)

Test No.

Time a temp., min

Properties

Pore volume $\left(\mathrm{cm}^{3} / \mathrm{g}\right)$

$\%$ Reduction

Surface area $\left(M^{2} / g\right)$

$\%$ Reduction

Composition, wt\%

\section{Carbon \\ Hydrogen \\ $\mathrm{H} / \mathrm{C}$ atomic ratio \\ Sulfur \\ Titanium \\ t850 $0^{\circ}$ Resid Conv., wt\%. \\ t8500 Resid Conv.}

Fresh Aged Aged

- 42

42

- $\quad 83 A 3$

$83 A 1$

$-0$

120

$0.374 \quad 0.212$

0.215

$-43$

42

$146 \quad 130 \quad 135$

- 11

8

$\begin{array}{lll}- & 11.9 & 10.4\end{array}$

-1.281 .20
$-\quad 1.29$

$\begin{array}{lll}- & 1.29 & 1.39\end{array}$

- $1.24 \quad 4.3$

$\begin{array}{lll}- & 0.05 & 0.13\end{array}$

1 For analysis, see Table E-1, Appendix E. 
Catalyst Particle Size Effect

Feedstock ${ }^{3}$ - Full-Range Deashed Resid
Shell 324M Catalyst

Physical form

Age (1bs-resid/lb-cat)

Test No.

Properties

Pore volume $\left(\mathrm{cm}^{3} / \mathrm{g}\right)$

$\%$ Reduction

Surface area $\left(\mathrm{M}^{2} / \mathrm{g}\right)$

$\%$ Reduction

Composition, wt\%

Carbon

Hydrogen

$\mathrm{H} / \mathrm{C}$ atomic ratio

Sulfur

Titanium

Avg $+850^{\circ} \mathrm{F}$ Resid Conversion, wt $\%$

1 cycle

2 cycle

3 cycle
Fresh Aged

Crushed ${ }^{1}$

- $\quad 120$

- $\quad$ MM-4

$0.528 \quad 0.359$

\begin{tabular}{l}
$-\quad 32$ \\
\hline
\end{tabular}

138

103

25

$-\quad 10.68$
$-\quad 1.39$

- $\quad 1.39$

- $\quad 1.59$

- 4.40

- $\quad 1.10$

20

25

21

16
Fresh Ayed

Extrudates ${ }^{2}$

- $\quad 120$

- MM-5

$0.374 \quad 0.165$

$\begin{array}{ll}- & 56\end{array}$

$146 \quad 92$

37 
Effect of Câtalys presulfiding

Feedstock ${ }^{1}$ - Fül1-Range Deashed Resid

Shell 324M Catalyst

Chemical form

Age (1bs-resid/lb-cat)

Test No.

Properties

$$
\begin{aligned}
& \text { Pore volume }\left(\mathrm{cm}^{3} / \mathrm{g}\right) \\
& \% \text { Reduction } \\
& \text { Surface area }\left(\mathrm{m}^{2} / \mathrm{g}\right) \\
& \% \text { Reduction }
\end{aligned}
$$

Composition, wt\%

Carbon

Hydrogen

$\mathrm{H} / \mathrm{C}$ atomic ratio

Sulfur

Titanium

Avg $+850^{\circ} \mathrm{F}$ Resid Conv.; wt\%

1 cycle
2 cycle
3 cycle
Fresh Aged

Oxide

- $\quad 120$

- $\quad$ MM-5

0.374

$-$

146

-

$\overline{-}$

$-$

$-$

$-$

$-$

$-$

92
Fresh Aged

Presulfided

- $\quad 120$

- $\quad E-15 B$

0.278

26

0.094

75

131

70

10

52

$\begin{array}{rrrr} & 14.50 & 4.94 & 19.40 \\ - & 1.74 & 1.40 & 2.02 \\ - & 1.44 & 3.40 & 1.25 \\ - & 4.26 & 5.66 & 6.16 \\ - & 0.39 & 0.06 & 0.16 \\ -\quad 14 & - & 20 \\ 16 & & . & 38 \\ 11 & & & 22 \\ 15 & & & 19\end{array}$

1

For analysis, see Table E-1, Appendix E.

Table 7-5

Comparison of Spent Catalyst Properties

From Batch and Continuous Hydrotreatment of Full-Range Deashed Resid

Reactor Type

Shell 324M Catalyst

Chemical form

Age (lbs-resid/lb-cat)

Test No.

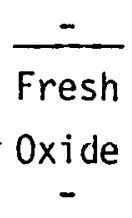

\begin{tabular}{lc}
\multicolumn{2}{c}{ Batch } \\
Aged & Aged \\
Oxide & Presulfided \\
240 & 120
\end{tabular}

0.374

$-$

146

Surface area $\left(M^{2} / g\right)$

$\%$ Reduction

Composition, wt\%

Carbon

Hydrogen

$\mathrm{H} / \mathrm{C}$ atomic ratio

Sulfur

Titanium
$\mathrm{E}-18^{1}$

$E-15 B^{1}$

- $E-18^{1} \quad E-15 B^{1}$

0.153

0.094

75

70

52

35

14.82

19.40

2.02

1.25

6.16

0.16
Continuous Aged

Presulfided 225

Runs $15-20$

ก. 168

55

98

33

$\begin{array}{rrrr}- & 14.82 & 19.40 & 12.35 \\ - & 1.58 & 2.02 & 1.51 \\ - & 1.29 & 1.25 & 1.47 \\ - & 4.06 & 6.16 & 8.15 \\ - & 0.17 & 0.16 & 0.47\end{array}$

1 For feedstock analysis, see Table E-1, Appendix E. 
Table 7-6

Catalyst Aging Effect using LDAR Feedstock ${ }^{1}$

Shell 324M Catalyst

Fresh Aged Aged

Age (1bs-resid/1b-cat)

43

131

Test No.

$83 A 2$

MM-8

Properties

Pore volume $\left(\mathrm{cm}^{3} / \mathrm{g}\right)$

$\%$ Reduction

Surface area $\left(\mathrm{M}^{2} / \mathrm{g}\right)$

$\%$ Reduction

Composition, wt\%

Carbon

Hydrogen

$\mathrm{H} / \mathrm{C}$ atomic ratio

Sulfur

Titanium

Avg $+850^{\circ} \mathrm{F}$ Resid Conv., wt $\%$

1 cycle

2 cycle

3 cycle
0.374

0.238

36

146

-

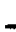

$-$

- $\quad 1.42$

$-\quad 1.95$
$-\quad 5.05$

- $\quad 5.05$

-. 0.07

- 34

- 34

- $\quad-$

-
0.245

34

103

29

1 For analysis, see Table E-1, Appendix E.

Table 7-7

Catalyst Aging Effect using FR-DAR Feedstock ${ }^{I}$

Shell 324M. Catalyst

Age (1bs-resid/7b-cat)

Test No.

Properties

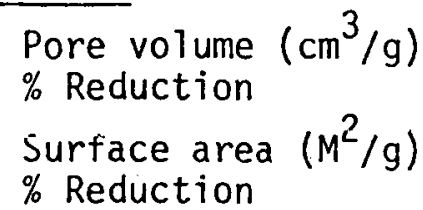

Composition, wt\%

Carbon

Hydrogen

$\mathrm{H} / \mathrm{C}$ atomic ratio

Sulfur

Titanium

Avg $+850^{\circ} \mathrm{F}$ Resid Conv., wt $\%$

1 cycle

3 cycle $\because:$

6 cycle

$\begin{array}{crrr}\text { Fresh } & \text { Aged } & \text { Aged } & \text { Aged } \\ - & \ddots 42 & 120 & 240 \\ - & 83 A 1 & M M-5 & \text { E-18 }\end{array}$

$\begin{array}{cccc}0.374 & 0.215 & 0.165 & 0.153 \\ - & 42 & 56 & 59 \\ 146 & 135 & 92 & 95 \\ -: & 7 & 37 & 35\end{array}$

- $\quad 10.40$

14.50

1.74

1.44

4.26

0.39

$-\quad 0.13$

1.20

4. 30

$-18$

14

14.82

1.58

1.29

4.06

0.17

18

16

$\begin{array}{ll}18 & 15\end{array}$

15

1 For analysis, see Table E-1, Appendix E. 
Table 7-8

Effect of Resid ${ }^{\mathbf{l}}$ Type on Catalyst

Single Cycle Test

She17 324M Catalyst

Age (1bs-resid/lb-cat)

Test No.

Resid type processed

Properties
Fresh Aged

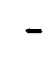

- 83A4

- $\quad$ H-LDAR
Aged

43

$83 \mathrm{~A} 2$

LDAR

0.374

0.330

12

146

169

$\%$ Reduction

\section{/g)}

Cumpusition, wt\%

\section{Carbon}

Hydrogen.

$\mathrm{H} / \mathrm{C}$ atomic ratio

Sulfur

Titanium

$+850^{\circ} \mathrm{F}$ Resid Conv., wt\%

$\begin{array}{cc}- & 5.38 \\ - & 1.06 \\ - & 2.36 \\ - & 1.62 \\ - & 0.04 \\ - & 42\end{array}$

8.72

1.42

1.95

5.05

0.07

34
Aged

42

$83 A 1$

FR-DAR

1 For feedstock analysis, see Table E-1, Appendix E.

Table 7-9

\section{Effect of Residl Type in Catalyst}

Three Cycle Test

Shell 324M Catalyst

Age (1bs-resid/1b-cat)

Test No.

Resid type processed

Properties

$$
\begin{aligned}
& \text { Pore volume }\left(\mathrm{cm}^{3} / \mathrm{g}\right) \\
& \% \text { Reduction } \\
& \text { Surface area }\left(\mathrm{M}^{2} / \mathrm{g}\right) \\
& \% \text { Reduction }
\end{aligned}
$$

Composition, wt\%

Carbon

Hydrogen

$\mathrm{H} / \mathrm{C}$ atomic ratio

Sulfur

Titanium

Avg $+850^{\circ} \mathrm{F}$ Resid Conv., wt\%

1 cycle

2 cycle

3 cycle
Fresh Ayed

131

MM-8

- LDAR

0.374

0.245

$-$

146

-

103

29

$-\quad 9.80$
$-\quad 1.60$

- $\quad 1.60$

$-\quad 1.96$
$-\quad 4.94$

- 4.94

- 0.14

- 36

42

38

27
Aged

120

$M M-5$

FR-DAR

0.165

56

प्र

37

14.50

1.74

1.44

4.26

0.39

1 For feedstock analysis, see Table E-1, Appendix E. 
Table $7-10$

Effect of Temperature on Catalyst Deactivation

Shell 324M Catalyst

Age (lbs-resid/lb-cat)

Test No. 1

Temperature, ${ }^{\circ} \mathrm{F}$
Fresh

$\begin{array}{ccccc}- & 40 & 40 & 40 & 40 \\ - & 83 A 6-1 & 83 A 6-2 & 83 A 6-3 & 83 A 6-4 \\ - & 675 & 700 & 725 & 750\end{array}$

Properties
0.374

$-$

146

$\%$ Reduction

Composition, wt\%

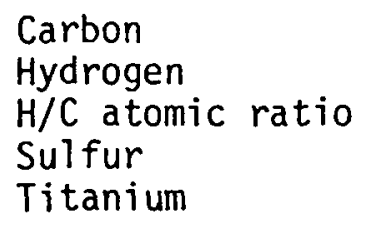

$+850^{\circ} \mathrm{F}$ Resid Conv., wt\%

$\begin{array}{ll}- & 8.28 \\ - & 1.56 \\ - & 2.26 \\ - & 3.00 \\ - & 0.05 \\ - & <10>\end{array}$

8.48

1.39

1.96

0.235

37

0.238

36

0.242

134

8

135

8

35

138

6
3.66

0.06

2
8.43

1.26

1.79

3.70

0.05

5
7.89

1.28

1.95

4.46

0.06

8

1 For feedstock analysis, see Table E-1, Appendix E. 
Table 7-11

Elemental Analyses of Distillate and Resid Fractions DISTILLATE FRACTION

\begin{tabular}{|c|c|c|c|c|c|}
\hline \multirow[b]{2}{*}{ Test No. } & \\
\hline & Feed & $83 A 6-1$ & $83 A 6-2$ & $83 A 6-3$ & $83 A 6-4$ \\
\hline action Temp, of & - & 675 & 700 & 725 & 750 \\
\hline
\end{tabular}

RESID FRACTION

\section{Elemental Analyses, $w t \%$}

\begin{tabular}{|c|c|c|c|c|c|c|c|c|c|c|}
\hline Carbon & 88.00 & 88.00 & 88.20 & 87.90 & 88.00 & 87.30 & 87.60 & 87.40 & 87.60 & 87.60 \\
\hline Hydrogen & 8.06 & 8.24 & 8.56 & 8.48 & 8.50 & 5.87 & 6.08 & 6.44 & 6.51 & 6.42 \\
\hline Nitrogen & 0.73 & 0.68 & 0.67 & 0.73 & 0.77 & 1.86 & 1.69 & 1.81 & 1.82 & 1.79 \\
\hline isulfur. & 0.24 & 0.26 & 0.28 & 0.18 & 0.19 & 0.73 & 0.46 & 0.56 & 0.49 & 0.40 \\
\hline Oxygen(diff) & 2.97 & 2.82 & 2.29 & 2.79 & 2.54 & 4.23 & 4.17 & 3.79 & 3.58 & 3.79 \\
\hline $\mathrm{H} / \mathrm{C}$ atomic ratio & 1.10 & 1.12 & 1.16 & 1.16 & 1.16 & $0 . \varepsilon_{1}$ & 0.83 & 0.88 & 0.89 & 0.88 \\
\hline$\% \mathrm{~N}$ Reduction & - & 7 & 8 & 0 & $<5>$ & - & 9 & 3 & 2 & 4 \\
\hline os S Reduction & - & $<8>$ & $<17\rangle$ & 35 & 21 & - & 37 & 23 & 33 & 45 \\
\hline
\end{tabular}


Table 7-12

Comparison of Aged Catalyst Properties from Batch and Continuous Hydrotreatment of Light Deashed Resid.

Shell 324M Catalyst

Chemical form

Age (1bs-resid/1b-cat)

Test No.

Reactor type

Properties

$\begin{array}{ccc}\text { Fresh } & \text { Aged } & \text { Aged } \\ \text { Oxide } & \text { 0xide } & \text { Presulfided } \\ - & 131 & 184 \\ - & \text { MM-8 } 1 & \text { Run } 32 \\ - & \text { Batch } & \text { Continuous }\end{array}$

0.374

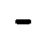

0.245

34

0.235

37

146

103

29

116

21

Composition, wt\%

Carbon

Hydrogen

H/C Atomic ratio

Sulfur.

Titanium $-\quad 9.8$
$-\quad 9$

- $\quad 1.6$

- $\quad 1.96$

- 4.94

- $\quad 0.14$

8.9

1.14

1.54

8.32

0.21

1 For feedstock analysis, see Table E-1, Appendix E. 


\section{Section 8 .}

\section{FUTURE PROGRAM}

A modification to the work statement for Task 2 has been submitted. In accordance to this modification, during the next reporting period the following work was proposed.

\section{Task 2}

Immediately following Run 34, two runs of about 10-days duration will be made using Process Configuration No. 6 and a single batch of Shell 324M catalyst to further confirm the results obtained in Run 32. These two runs (Run 35 and 36) will be completed with some additional process changes. These include 1) the effective coal dissolver volume reduced from 0.34 to 0.24 cubic feet, thereby increasing the dissolver coal space rate from 22 to $31 \mathrm{lb} / \mathrm{hr}$-cu ft and 2) alter the LDAR to (LDAR+DAR) split in the CSD section. The objectives of these changes are to ascertain improved distillate yield and what effect, if any, the increased coal space velocity has on the performance of the CSD unit and the quality of the deashed resids.

A third run (Run 37) will be made with subbituminous coal. The process conditions witl be set after completion of the above two runs.

Following the completion of these runs, the coal feed for the Bench-Scale runs will be changed over to Illinois Bituminous No. 6 coal for the balance of the work under this task.

Also to be completed under Task 2 are batch reactor tests made in support of Task 2 Bench-Scale runs using process-derived materials obtained in the first quarter of this contract period.

\section{Task 3}

Proposed batch reactor tests to evaluate various disposable catalysts in the thermal stage will be started during the next quarter.

Task 4

No work under this task is planned during the next quarter. 


$$
\ldots \quad \ldots \text { APPENDIX A }
$$

BENCH-SCALE UNIT - PROCESS DESCRIPTION 
Appendix $\dot{A}$.

BENCH-SCALE UNIT - PROCESS DESCRIPTION

The facilities and equipment for continuous integrated bench-scale direct coal liquefaction operations are located at the Kerr-McGee Cimarron Facility on 900 acres about 6 miles south of Crescent, Oklahoma; 35 miles north of Oklahoma City.

The integrated bench-scale unit has a capacity of five to fifteen pounds per hour of raw coal. The unit is composed of three basic sections: (i) a liquefaction (LFU) section which can liquefy coal at high temperatures and pressures under an atmosphere of pure hydrogen to produce distillates and vacuum bottoms, (ii) a Critical Solvent Deashing (CSD) section for deashing vacuum bottoms produced in the liquefaction unit and producing CSD products by removal of ash and unconverted coal, and ( $i$ ii) a hydrotreater (HTR) section for hydrogenation of distillates or CSD products to produce recycle liquefaction solvent and/or final products.

The bench-scale unit has the flexibility of varying, either in tandem or independently, the processing rates of each of the three sections. The bench-scale unit is designed to operated continuously with all three sections operating in an integrated mode or as three separate sections to study the individual section conditions.

The integrated bench-scale unit, with the exception of some of the auxiliary equipment, is installed indoors in an area of 5000 square feet. Indoor facilities include a control room, material storage, grinding and blending equipment. Some of the process equipment is mounted in a multi-level arrangement because of the physical sizes of some pieces of equipment, and to provide for material flow requirements. Some process liquid storage vessels are located outdoors in a dyked area. The utilities also located outdoors include the heat media, cooling water, chiller, vacuum pumps, nitrogen storage, hydrogen storage, and hydrogen compression systems,

The entire bench-scale unit is self-contained in that provisions are available to prepare the feed stocks, process the feed stocks, and package the products. All of the utilities necessary to support the operating equipment are available at the site. 
The process capabilities of the bench-scale unit are shown in Table A-1. The entire unit has been designed to match a coal capacity from five to fifteen pounds per hour of moisture-free coal. More details on the range of operability for each section are shown in Table A-2.

\section{LIQUEFACTION SECTION}

The process schematic for the liquefaction section (Figure A-1) shows the coal slurry preparation in the upper left hand corner. This slurry preparation section is designed to handle a heavy liquefaction solvent containing large concentrations of either CSD resid or hydrotreated resid. A centrifugal pump continually recirculates the slurry in the agitated slurry makeup tank as the raw milled coal and liquefaction solvents are introduced on a continuous basis.

A separate agitated slurry feed tank which utilizes continuous recycle to minimize solids buildup serves as a hold tank for the solvent-drying of coal, if desired. Both the slurry feed and slurry hold tanks are designed for high temperature (up to $500^{\circ} \mathrm{F}$ ) operation and are designed for variable hold-up times to minimize the potential risk of forming high viscosity gels at the elevated temperatures.

The success of solvent refined coal liquefaction operation depends upon the production of adequate quantities of recycle process solvent of high quality, representative of steady state conditions. During the design of the bench-scale unit, particular attention was given to the preparation and control of process solvent.

This section has a process solvent surge drum that is capable of storing a sufficient quantity of preblended solvent adequate for as much as eight hours of continuous operation. However, provisions are also made to permit recycling of the recovered process solvent directly with minimum solvent inventory to ensure a quick turnover and rapid approach to the steady state conditions.

The coal-solvent slurry is pumped to reaction pressure using positive displacement pumps and mixed with pure hydrogen gas feed prior to entering the preheater. The preheater consists of four heat-exchangers arranged in series to control the slurry heat-up rate. One of these exchangers is heated with Therminol-66, one with VP-1, and two with molten salt. 
The first two sections of the preheater are of a double-pipe exchanger design. The Therminol-66 exchanger contains a total of 80 feet of $3 / 8^{\prime \prime}$ autoclave tubing $\left(0.203^{\prime \prime}\right.$ ID) in a 4 pass arrangement. The VP-1 exchanger contains a total of 40 feet of $3 / 8^{\prime \prime}$ and 40 feet of $9 / 16^{\prime \prime}(0.312$ ID) autoclave tubing. The last two sections of the preheater consists of a coil arrangement immersed in molten salt. Each coil is fabricated from 127 feet of 3/8" (0.203" ID) autoclave tubing.

Heated solvent-coal slurry and hydrogen co-currentiy upwards through a tubular backmixed (agitated) dissolver. The dissolver is a custom designed reactor (Autoclave Engineers) of 5-inch ID equipped with a Magnedrive agitator. The dissolver is heated with an electric furnace. Reaction products are withdrawn near the top. The residence time in the dissolver can be varied by changing the liquid level in the dissolver. When the plant is operated in the short-residence-time (SRT) mode, the dissolver is bypassed and only the preheater is used for reaction.

The dissolver effluent is first separated into liquid and vapor streams, without external cooling, in a hot separator, followed by a series of flash separations. The liquid from the low-pressure flash is fed to a vacuum flash drum to produce vacuum bottoms for further processing. Sour gases are vented following removal of condensables. Condensates from these various steps are first collected and later fractionated, if desired, by distillation into naphtha, middle distillate and heavy oil products. In recent operation, portions of the oils recovered by vacuum flash are recycled back as process solvent.

\section{CRITICAL SOLVENT DEASHING SECTION}

The process schematic for the three stage CSD section (Figure A-2) shows the extraction stages used for recovery and fractionation of liquefied coal. The CSD section produces an ash concentrate, Deashed Resid (DAR) and a Light Deashed Resid (LDAR) fractions. The ash concentrate is removed as a by-product of this section while the DAR and Light DAR materials are used either directly or indirectly through hydrotreating as a part of the process solvent, or they may be removed as products.

The CSD feed (or vacuum bottoms) stream from the coal liquefaction step is metered by a positive displacement, variable speed feed pump out of the CSD feed tank. This material is a slurry of liquefied coal and suspended solids consisting of unconverted 
coal and ash particles. Deashing solvent (DAS) from the solvent tank is recycled to the front end and mixed with the incoming CSD feed. The combined coal feedrecycle DAS stream enters the first-stage primary extractor. After light and heavy phase separation, the heavy phase enters the solvent separation vessel where the deashing solvent is separated and recovered for recycle and the coal ash along with unconverted coal and some coal values are discarded as Ash Concentrate. The light phase from the first-stage primary extractor is further fractionated into 1 ight and heavy phases in the second-stage settler. The heavy phase from the second-stage settler undergoes a solvent separation step for solvent recovery and the resultant coal liquid, following solvent separation, is recovered as Deashed Resid (DAR) product. In a similar fashion, the second-stage settler overhead stream is first separated into a solvent stream and an underflow containing the balance of the soluble coal in the third-stage settler. The third-stage underflow undergoes a solvent separation step for solvent recovery and the resultant soluble coal liquid, following DAS solvent separation, is recovered as Light Deashed Resid product (LDAR). A11 of the recovered deashing solvent is recycled back to the first-stage to be used again. A small net-solvent loss to the various products is made up by external addition of DAS to the solvent tank.

The CSD section is also equipped to be operated as a two-stage extraction unit. This mode is used for improved soluble coal recoveries from the CSD unit when the performance of the one-stage extraction unit is not adequate. When the secondary extractor is used, the heavy phase from the first stage primary extractor is mixed with additional deashing solvent and fed into the first stage secondary extractor. The light phase from the secondary extractor is recycled since it may contain some ash. The heavy phase from secondary extractor is fed into the deashing solvent separation. vessel, from which the deashing solvent is taken overhead and returned to the deashing solvent tank and the coal ash along with unconverted coal and some coal values are discarded as Ash Concentrate.

\section{HYDROTREATING SECTION}

The process schematic for the Hydrotreating section (HTR) is shown in Figure A-3. It consists of an ebullating bed catalytic reactor designed by Hydrocarbon Research, Inc. This section is designed to hydrogenate, on a continuous basis, feeds containing high concentrations of residuum or deashed coal products. Typically, deashed 
resid (DAR) or Light deashed resid (LDAR) products from the CSD unit are used as feeds. This feed is mixed with a carrier solvent prior to entering the reactor. Hydrogen gas required for the reaction is added to the feed-solvent mixture, as is the reactor recycle stream obtained from the ebullating pump. The reactor effluent undergoes gas-liquid separation in the hot separator. Gases are vented following removal of condensables. Sour water from the condensate is drained off to obtain a hydrotreated oil product.' The underflow from the hot separator undergoes an atmospheric flash for recovery of hydrotreater solvent. The residual liquids consisting of hydrotreated resid bottoms and a small quantity of hydrotreater solvent are sent either to liquefaction or deashing for further processing, or may be removed as hydrotreater product. 


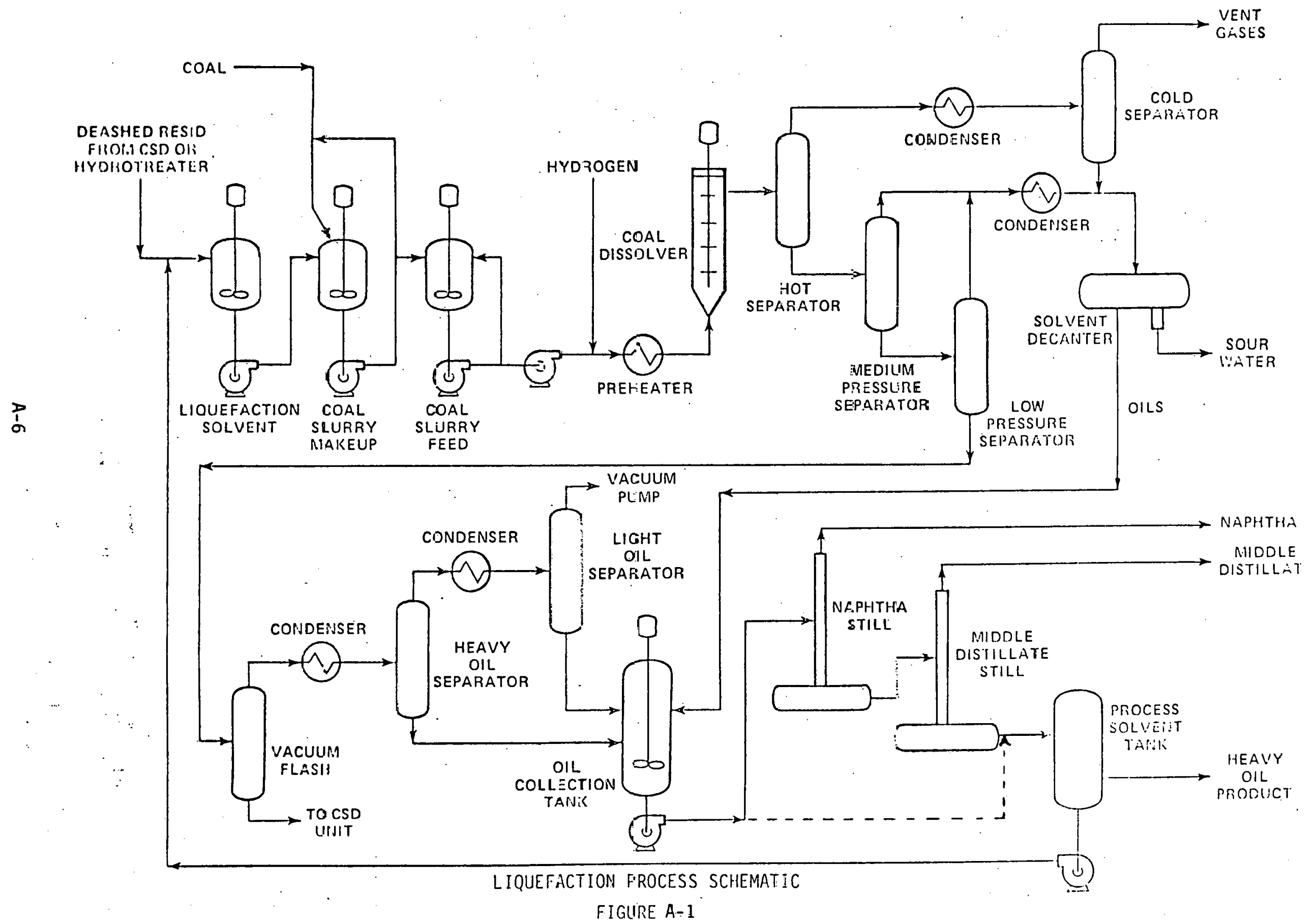




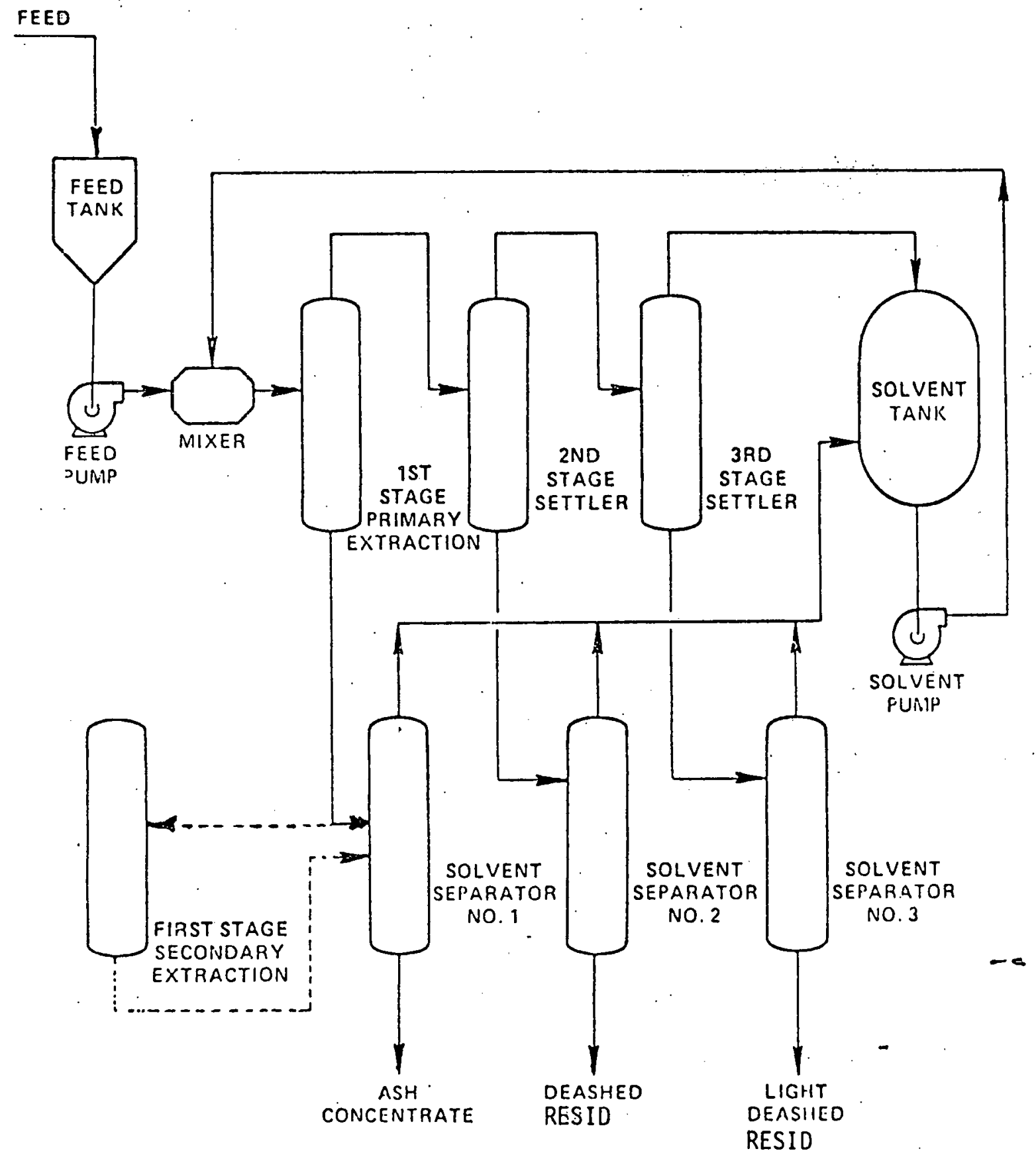

THREE-STAGE CSD PROCESS WITH SECONDARY EXTRACTION

FIGURE $\quad A-2$ 


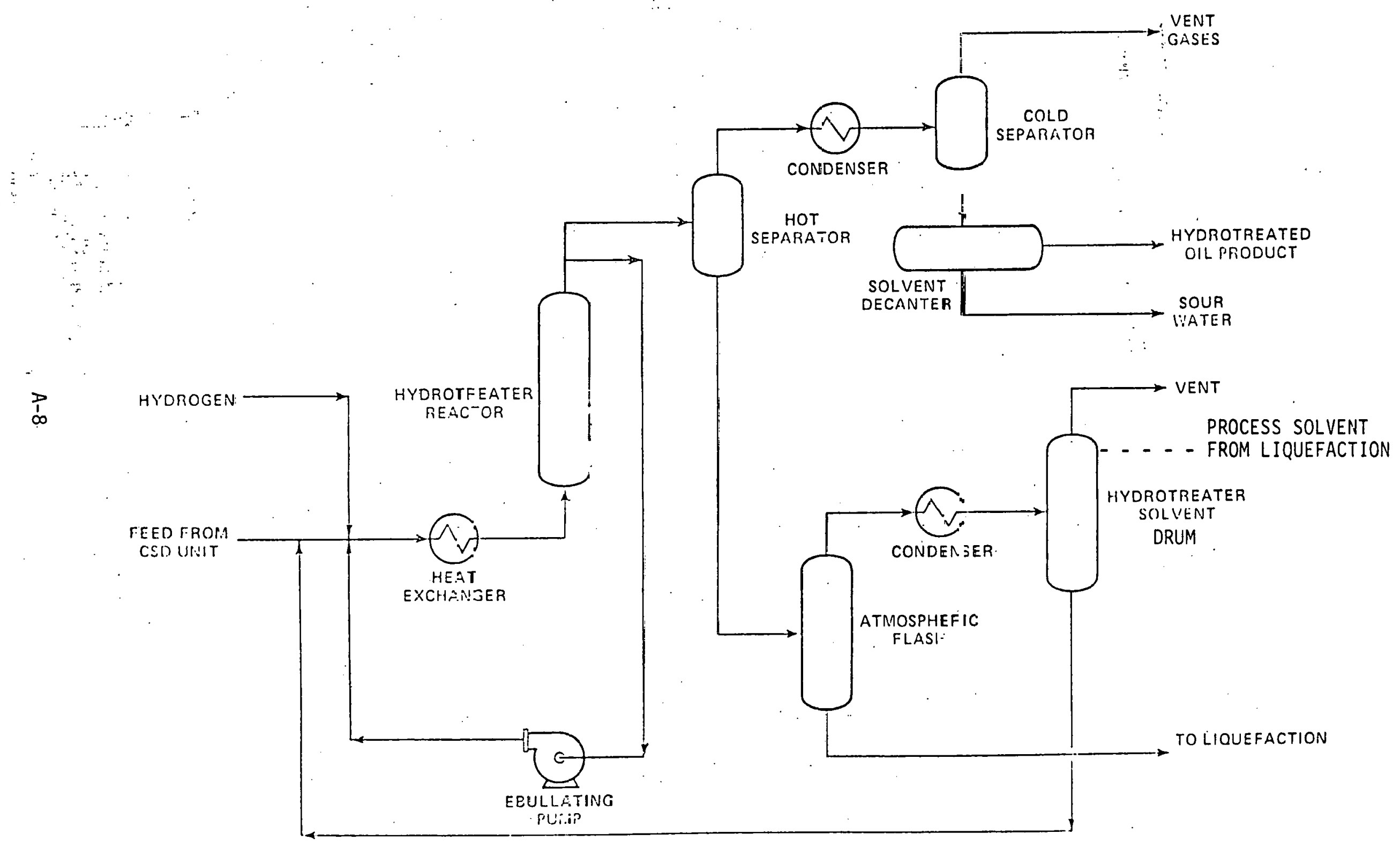

HYDRDTREATEF PROCESS SCHEIRTIC

FEGURE A-3 
Table $1-1$

INTEGRATED BENCH-SCALE UNIT RANGE OF OPERABILITY

\section{COAL LIQUEFACTION}

Coal Feed, $1 \mathrm{~b} / \mathrm{hr}$

Liquefaction Solvent, $\mathrm{lb} / \mathrm{hr}$

$+850^{\circ} \mathrm{F}$ in Liq. Solvent, wt $\%$

Hydorgen Purity (no recycle), mole \%

Dissolver

Volume range, $\mathrm{cu} \mathrm{ft}$

Coal space rate, $1 \mathrm{~b} / \mathrm{hr}$ cu ft

Pressure, psig

Temperature, of

Underflow Vacuum Flash

Pressure, psia

Temperature, of

Atmospheric Distillation Colums

1st column overhead cut, ${ }^{\circ} \mathrm{F}$

2nd column overhead cut, ${ }^{\circ} \mathrm{F}$

CRITICAL SOLVENT DEASHING

Feed Rate, $1 \mathrm{~b} / \mathrm{hr}$

Deashing Solvent/Feed Ratio

Pressure - Each stage

Temperature - Each stage

First Stage Upflow Velocity

HYDROTREATING

Feed Rate, $\mathrm{lb} / \mathrm{hr}$

Buffer 0i: Rate, 1b/hr

+850 of in Feed, wt \%

Hydrogen Purity (no recycle), mole \%

Reactor

Catalyst charge, 1b

Reactor space rate, $1 \mathrm{~b} / \mathrm{hr}-\mathrm{lb}$ catalyst

Pressure, psig

Underflow Atmospheric Flash

Temperature, of
RANGE

5 to 15

9 to 30

0 to 60

100

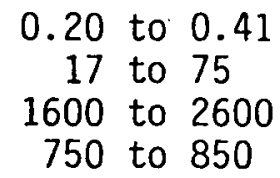

1 to 3

550 to 600

IBP to 450

450 to 550

RANGE

6 to 20

As required for

proprietary operation

of the unit

RANGE

10 to 30

2 to 10

0 to 80

100

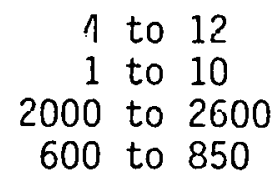

500 to 600 
Table A-2

INTEGRATED BENCH-SCALE UNIT PROCESS CAPABILITIES

COAL PREPARATION

CRUSHING

MILLING

SCREENING

BLENDING

LIQUEFACTION

CONTINUOUS COAL FEEDING

SOLVENT COAL DRYING

STIRRED DISSOLVER

VACIUUM FLASH ON UNDERFLOW

DISTILLATION COLUMNS (2)

CRITICAL SOLVENT DEASHING

THREE-STAGES

SECONDARY EXTRACTOR

HYDROTREATING

EBULLATING-BED REACTOR

ATMOSPHERIC FLASH ON UNDERFLOW

UTILITIES

HYDROGEN COMPRESSORS (2)

HEAT MEDIA - THERMINOL-66, DOWTHERM-A, AND MOLTEN SALT

COOLING MEDIA - CLOSED LOOP, AIR-COOLED

VACUUM PUMPS (2)

REFRIGERATION - CLOSED LOOP, FREON-12 COOLED

SUPPORT FACILITIES

ONE-LITER BATCH REACTOR SET-UP

MIC̄ROAUTOCLAVE SET-UP

LABORATORY - GENERAL ANALYYSES

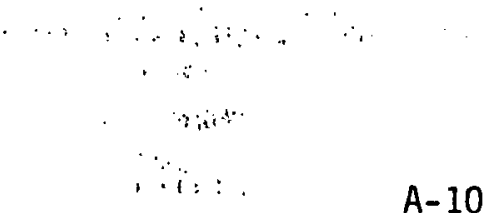

if $1:$ 
APPENDIX B

OPERATING LOG 
Table $B-1$

DAILY OPERATING LOG

Run 32

Sept 8 Initial startup. Started DAS flows in the CSD section.

9 CSD operating on external vac-bottoms feed. Commenced presulfiding of hydrotreater catalyst.

10-11 Continuing to presulfide the Shell 324M catalyst using dimethyldisulfide in No. 2 Diesel oil.

Liquefaction section brought to system pressure and solvent flows established.

12 Completed presulfiding of the Shell 324M catalyst. CSD section continuing to operate using external vac-bottoms feed.

13 Started resid feed to hydrotreater. CSD section in a DAR recycle mode following ash carryover. Several plugging problems in the liquefaction section.

14-15: Liquefaction section in a recycle mode while vacuum-flash process lines were cleaned. CSD in a DAR recycle mode and the feed to DAS ratio adjusted to stop ash carryover: Hydrotreater operating at run parameter conditions.

16 Resid feed to hydrotreater interrupted due to plugged feed 1 ine. A process leak in the CSD section resulted in a forced CSD shutdown. Liquefaction on coal feed starting at 1700 hours.

17-19. Cleared plugiged feed innes in the HTR section. However, no resid feed to hydrotreater for lack of adequate Light DAR. CSD back on line after process leak was repaired but plugging in overhead 1 ines forced a shutdown for cleaning.

20 Cleaning process jnes jn the CSO section. Coal feed to LFU discontinued and the unit operated in the solvent recycle mode. Hydrotreater on solvent only for lack of Light DAR feed.

Melted Wi lsonyil Be Bun 241 Light DAR as feed for hydrotreater and introduced at 1730 hours.

22 Started coal feed at 1200 hours.

Completed cleaning, reassembly and pressure check of CSD process 1 ines.

23-25 Continued to add Wilsonville Run 241 Light DAR as feed to hydrotreater, Established DAS flows in the CSD section and started vac-bottom feed at 2245 hours on 23 September. Problems with 42-PT-100 sensing 1 ine forced to operate 42-PV-100 in wide open position. Not able to deash adequately and using frequent DAR flushes. 
Table B-1 cont'd

Daily Operating Log

$\frac{\text { Run } 32}{\text { Sept }}-$ cont'd

26-30 Hydrotreater operated using Wilsonville LDAR feed. Checked calibration of all nuclear level gauges in the CSD section. Adjusting first stage pressure or temperature failed to give proper deashing. Deashing solvent composition adjusted to ascertain if proper deashing could be obtained. Liquefaction on and off coal feed several times following some instrument and pump problems.

oct $1-3$

DAS solvent composition change did not yield desired phase separation. After one of the DAS solvent lines was discovered partially plugged and by-passing the mixer unit, shut CSD down for removal of the plugged line. Also vac-bottoms in feed vessels were drained out in preparation of Wilsonville Run 244 vac-bottom feed to CSD.

4-5 Used Wilsonville LDAR (Run 244) as feed to hydrotreater and Wilsonville vac-bottoms (Run 244) as feed to CSD. Unit deashed and fractionated without any difficulty. Process derived vac-bottoms were either drummed out or accumulated.

Started mixing process derived vac-bottoms with Wilsonville Run 244 feed. After Solvency Index test result.s from laboratory, the DAS composition adjusted for more soluble process vacuum bottoms.

Developed a plug in one of the coal slurry preheaters.

8 After unsuccessful attempt to clear the plug by solvent flushes, the preheater was by-passed. HTR and CSD operating smoothly.

9 Reduced the quantity of Wilsonville vac-bottoms being added to CSD feed. Started MB No. 2 at 2300 hours.

10-12 Completed a total of three 24-hour MB's. During MB-4, shurtage of LDAR feed for HTR was cumpensated by fricreasing the solvent flows.

13 Trying to build-up resid levels within the unit. off coal feed for 8 hours due to pump seal problem.

14-15 Process vacuum bottoms drummed out earlicr, added back to satisfy process resid requirements. The current vac-bottoms are more soluble and resulting in increased rejection to Ash Concentrate. Completed MB No. 5 .

16-18 Building resid levels within the unit by external vac-bottoms addition till 18 0ctober at which time CSD feed rates were lowered to match vac-bottoms production rate from the LFU. Started MB No. 6 at 2300 hours on 18 october. 
Table B.-1 cont'd

Daily Operating Log

$\frac{\text { Run } 32}{\text { Oct }}$ - cont'd

19-20 Completed two 24-hour MB periods. Process upsets in CSD section resulted in improper deashing and a high content in the DAR. Coal feed was interrupted for about 2 hours due to mechanical problems. Ended Run 32 at 2400 hours.

21-22 Unit flushed, cooled and depressured. Removed spent catalyst from R-5101 and filled with a new batch of catalyst in preparation of next run. Dissolver agitator removed for repair and worked on other maintenance items.

Run 33

Oct 23

Started presulfiding the catalyst.

24 Completed presulfiding the catalyst. Dissolver reassembled and leak checked. Completed leak checking CSD unit.

25-29 Hydrotreater resid feed started on 26 0ctober and unit operated at run parameters. LFU operating at program conditions after correcting minor plugging problem. On coal feed since 1000 hours on 26 0ctober. CSD on feed using Run 32 vac-bottoms starting 2025 hours on 25 0ctober. Minor ash carryover problems being corrected by changing DAS composition.

30-31 Stopped external resid addition to CSD at 2300 hours on 30 0ctober and completed the first 24-hour MB.

Nov 1-4 Unit operated in integrated fashion, though at lower resid levels than desired. CSD first stage temperature lowered and solvent-to-feed ratio increased to improve soluble coal recoveries. Completed two 24-hour MB periods (MB-2 and MB-3).

5-6 Completed MB No. 4

7-8 Completed MB No. 5 and terminated Run 33.

Run 34

Nov 9

Hydrotreater section flushed with process solvent and cooled down for catalyst removal. New catalyst charged and reactor leak checked and presulfiding started at 2100 hours.

Dissolver agitator repaired and unit leak checked; CSD section operated in DAR recycle mode.

10-11 . Completed presulfiding of the fresh batch of She11 324M catalyst. Established Light DAR flows to LFU and started coal feed at 0800 hours on 11 November. Used Run 32 vac-bottoms to operate CSD section and build-up resid levels. 
Table B-1 cont'd

Daily Operating Log

Run 34 - cont'd

Nov 12-15. Liquefaction and hydrotreater section operated with minor problems. Vac-bottoms from Run 32 blended with process-derived vac-bottoms to operate CSD section. This addition discontinued at 2300 hours on 15 November as the first MB was started.

16 Completed the first MB. Slurry preheater flushed with solvent when a plug developed by accidental loss of flow.

17 CSD off-feed for 3 hours due to a pump problem.

18-21 Completed a total of three 24-hour material balance periods. During MB No. 2, CSD was off feed for short periods for repairing a leak and replacement of a relief valve.

22-23 Flushed all three sections, cooled and depressured. Removed spent catalyst from R-5101 and added new batch of Shell 324M catalyst for Run 35. Installed new type of steady bearing in the dissolver.

24-26 Shutdown for holidays.

27-29 After leak checks, presulfiding of the catalyst was completed by 29 November. Liquefaction and CSD sections were brought to operating conditions using solvent flows. Minor problems in CSD feed pumps delayed introduction of vac-bottom feed.

30. Liquefaction and hydrotreater section in solvent recycle mode awaiting rèsid from the isü section. 
Table B-2

COAL LIQUEFACTION BENCH-SCALE OPERATION ON-STREAM FACTOR Sept-Nov 1983

Operation Under. DOE Contract No. DE-AC22-83PC60048

$\cdots$

\begin{tabular}{|c|c|c|c|c|c|c|c|c|}
\hline \multirow[b]{3}{*}{ Run No. } & \multirow{3}{*}{$\begin{array}{l}\text { Run } \\
\text { Duration } \\
\text { (day's) }\end{array}$} & \multicolumn{7}{|c|}{ ON-STREAM TIME - DAYS } \\
\hline & & \multirow{2}{*}{$\frac{\text { Integrated }}{\text { Resid\& Coal }}$} & \multicolumn{2}{|c|}{ Liquefaction } & \multicolumn{2}{|c|}{ CSD } & \multicolumn{2}{|c|}{ Hydrotreater } \\
\hline & & & Solvent & Coal & Solvent & Resid & Solvent & Resid \\
\hline 32 & 44 & 20.0 & 42.7 & 29.1 & 41.0 & 27.5 & 36.8 & 32.1 \\
\hline 33 & 15 & 12.4 & 15.0 & 13.3 & 15.0 & 13.2 & 15.0 & 13.9 \\
\hline 34 & 12 & 8.4 & 11.9 & 10.3 & 11.6 & 9.7 & 12.0 & 9.8 \\
\hline & Total & 40.8 & 69.6 & 52.7 & 67.6 & 50.4 & 63.8 & 55.8 \\
\hline
\end{tabular}

\% On-Stream Timel (71) 57.5

(71) 98.0

(71) 74.2

(71) 95.2

(71) 71.0

(71) 89.9

(71) 78.6 NOTES:

1 Numbers in paranthesis are the total operating days used in calculation of percent on-stream time. 
Table B-3

\section{BENCH SCALE UNIT - HYDROTREATER CATALYST AGE LOG}

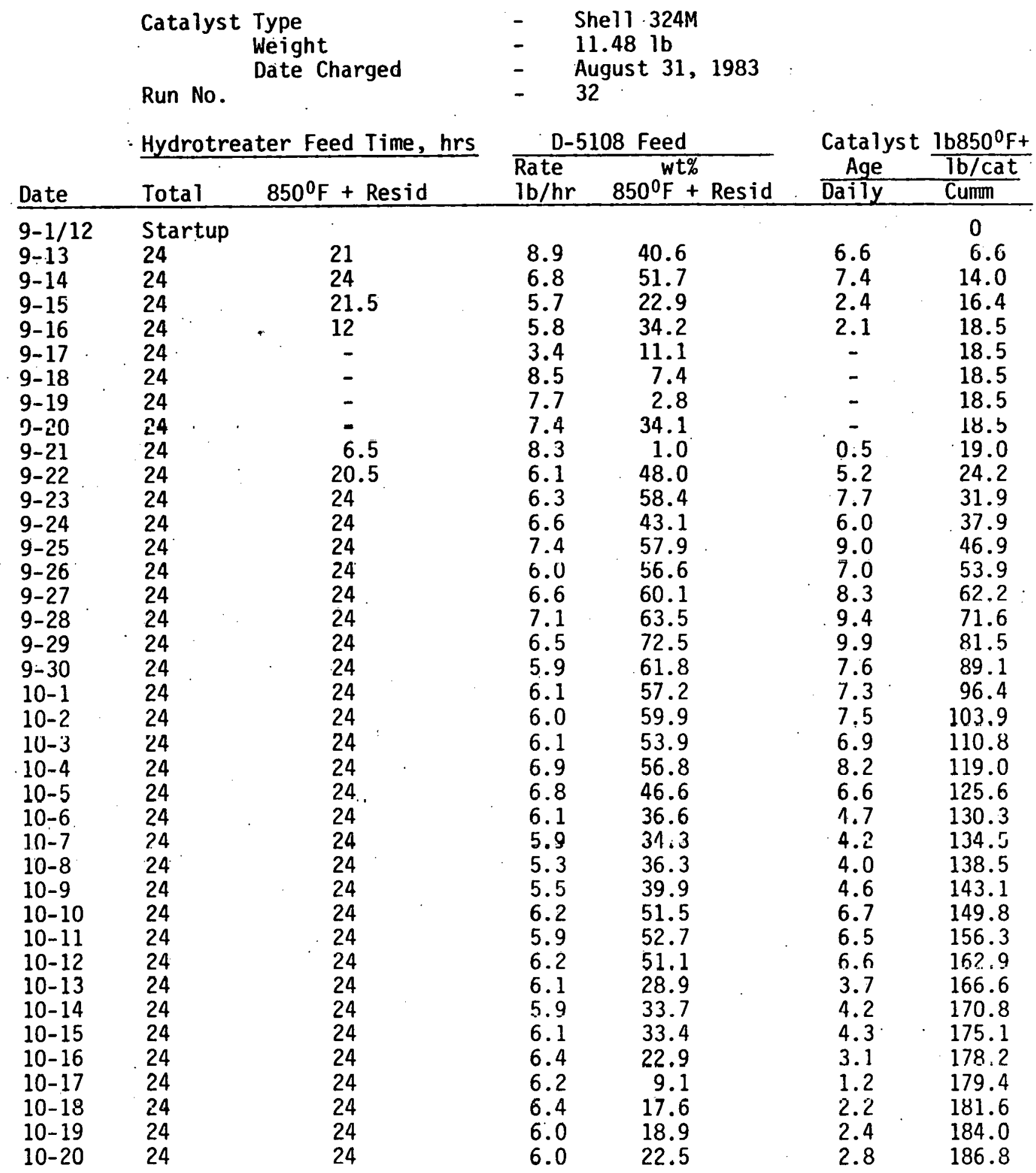

10-21-83 Run 32 terminated and catalyst removed.

10-21-25 Maintenance period. 
Table B-3 - cont'd

BENCH SCALE UNIT - HYDROTREATER CATALYST AGE LOG

$\begin{array}{lll}\text { Catalyst Type } & - & \text { Shell 324M } \\ \text { Weight } & - & 11.48 \text { 1b } \\ \text { Date Charged } & - & \text { October 25, } 1983 \\ \text { Run No. } & - & 33\end{array}$

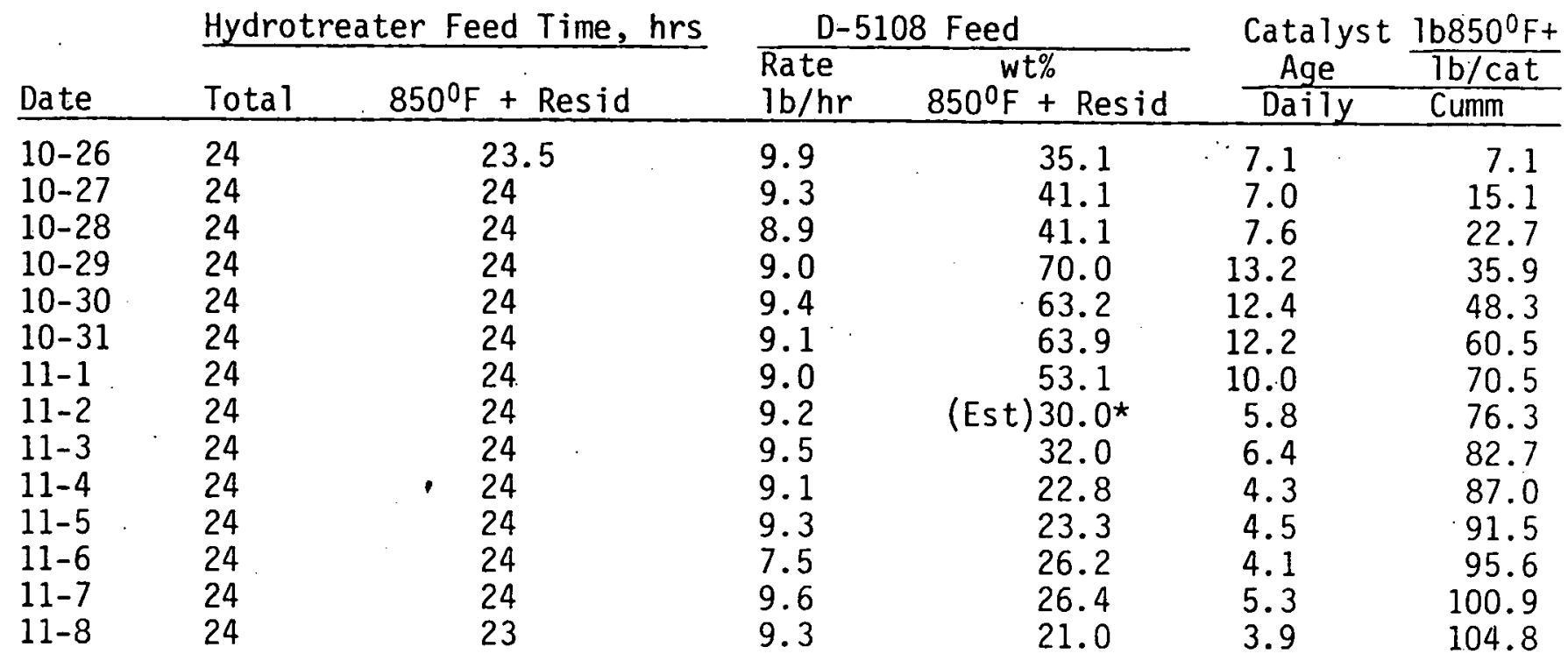

* Reported feed sample resid content of $2.1 \mathrm{wt} \%$ appears to be in error in view of 19.0 wt\% resid in the underflow.

11-8-83 Run 33 terminated and catalyst removed.

\begin{tabular}{|c|c|c|c|c|c|c|c|c|c|}
\hline \multirow[b]{2}{*}{ Date } & \multicolumn{3}{|c|}{$\begin{array}{l}\text { Catalyst Type } \\
\text { Weight } \\
\text { Date Charged } \\
\text { Run No. } \\
\text { Hydrotreater Feed Time, hrs } \\
\end{array}$} & \multicolumn{4}{|c|}{$\begin{array}{l}\text { Shell 324M } \\
11.481 \mathrm{~b} \\
\text { October } 8,1983 \\
34 \\
\quad 0-5108 \text { Feed }\end{array}$} & \multirow{2}{*}{\multicolumn{2}{|c|}{ 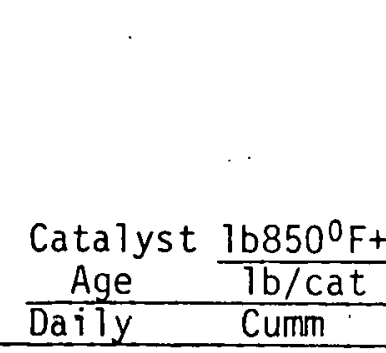 }} \\
\hline & $\begin{array}{l}\text { Hydrotre } \\
\text { Total }\end{array}$ & $\begin{array}{l}\text { ater Feed Time, } \\
850 \mathrm{~F}^{0}+\text { Resid }\end{array}$ & hrs & $\begin{array}{l}\frac{D-5}{\text { Rate }} \\
\mathrm{lh} / \mathrm{hr}\end{array}$ & $\begin{array}{r}108 \mathrm{~F} \\
8 \\
\end{array}$ & 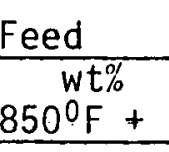 & Resid & & \\
\hline $\begin{array}{l}11-9 \\
11-10 \\
11-11 \\
11-12 \\
11-13 \\
11-14 \\
11-15 \\
11-16 \\
11-17 \\
11-18 \\
11-19 \\
11-20 \\
11-21\end{array}$ & $\begin{array}{l}12 \\
24 \\
24 \\
24 \\
24 \\
24 \\
24 \\
24 \\
24 \\
24 \\
24 \\
24 \\
24\end{array}$ & $\begin{array}{l}- \\
- \\
- \\
22.5 \\
21 \\
24 \\
24 \\
24 \\
24 \\
24 \\
24 \\
24 \\
24\end{array}$ & & $\begin{array}{r}- \\
- \\
- \\
7.9 \\
9.1 \\
7.7 \\
10.0 \\
8.5 \\
8.1 \\
7.9 \\
8.4 \\
8.0 \\
8.2\end{array}$ & $m$ & $\begin{array}{l}- \\
- \\
- \\
11 . \\
30 . \\
26 . \\
39 . \\
34 . \\
33 . \\
37 . \\
29 \\
22 . \\
27 .\end{array}$ & $\begin{array}{ll}4 & \\
9 & \\
7 & \\
6 & \\
1 & \\
3 & \\
1 & \\
9 & \\
9 & \cdots \\
4 & \end{array}$ & $\begin{array}{c}- \\
- \\
- \\
1.8 \\
5.1 \\
4.3 \\
8.3 \\
6.1 \\
5.6 \\
6.1 \\
5.3 \\
3.8 \\
4.7\end{array}$ & $\begin{array}{r}- \\
- \\
- \\
1.8 \\
6.9 \\
11.2 \\
19.5 \\
25.6 \\
31.2 \\
37.3 \\
42.6 \\
46.4 \\
\quad 51.1\end{array}$ \\
\hline $11-22-83$ & Run $34 t$ & erminated and ca & tal & remo & & & & & \\
\hline
\end{tabular}


APPENDIX C

OPERATING DATA 
Table C-1

OPERATING DATA (Part 1)

Thermal Stage

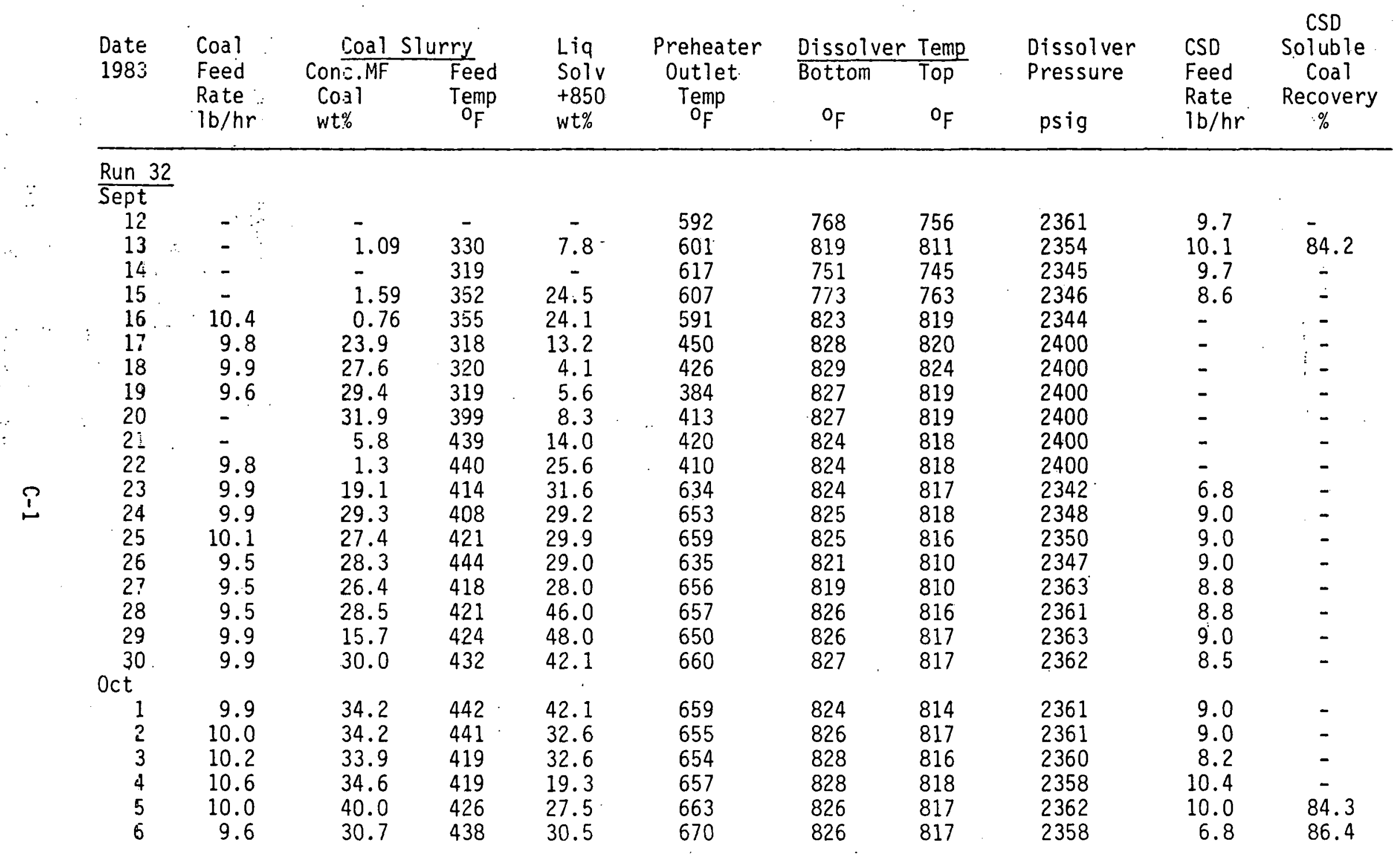


Table C-1 - cont'd

OPERATING DATA (Part 1)

Thermal Stage.

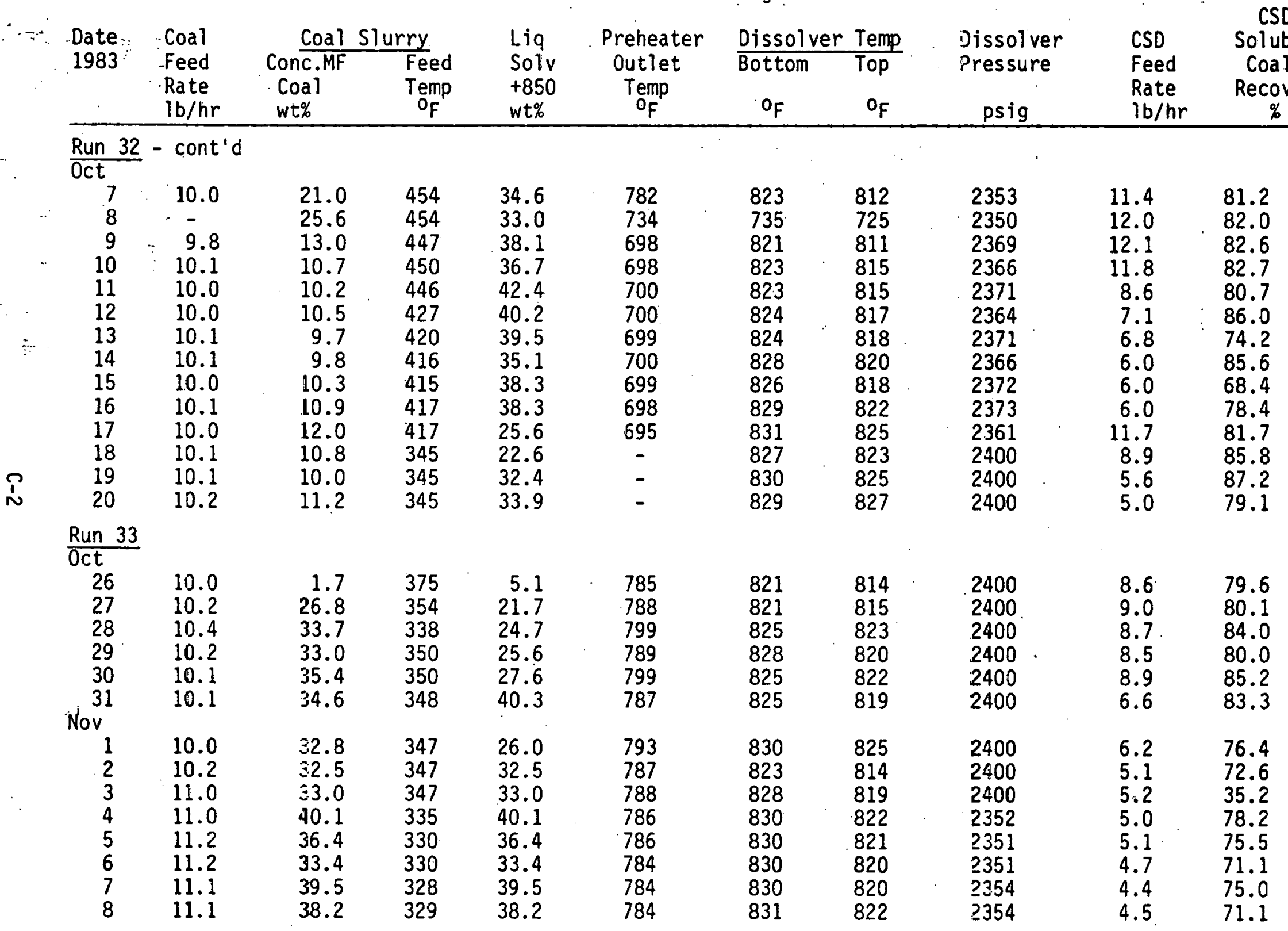


Table C-1 - cont'd

OPERATING DATA (Part 1)

Thermal Stage

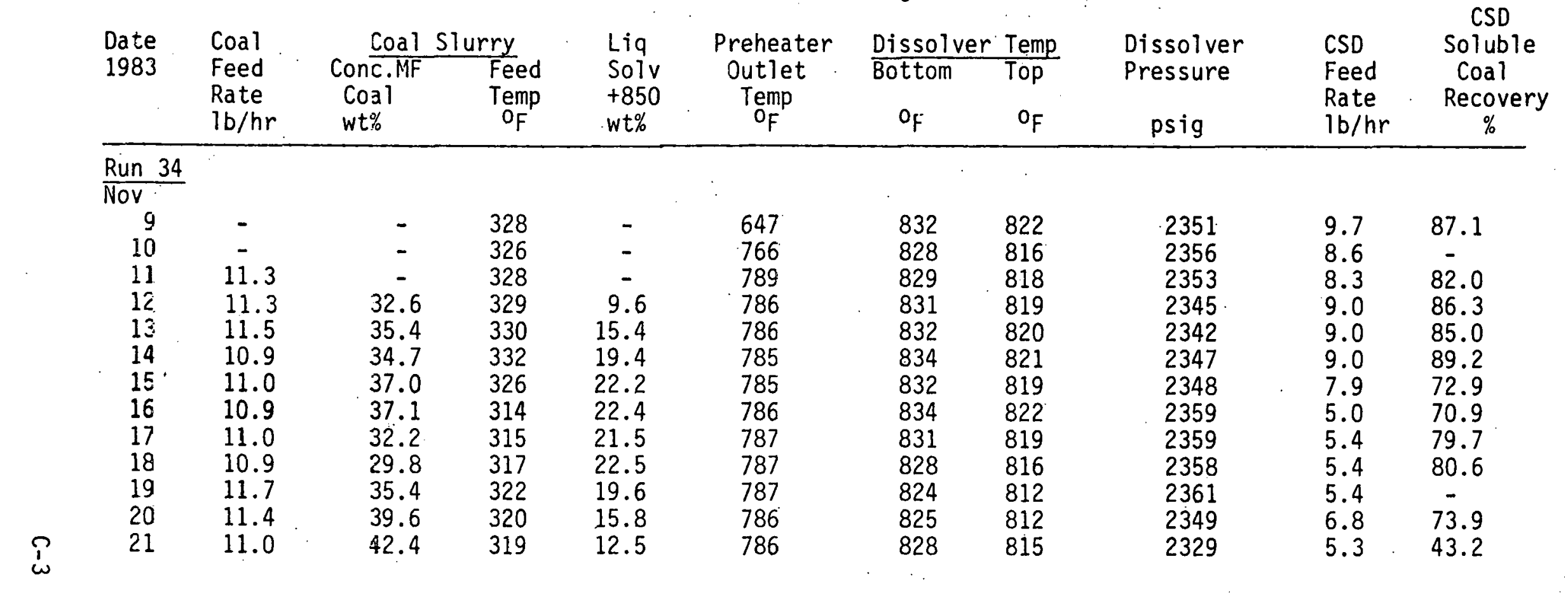


Table C-2

OFERATING DATA (Part ?)

Catalytic Stage

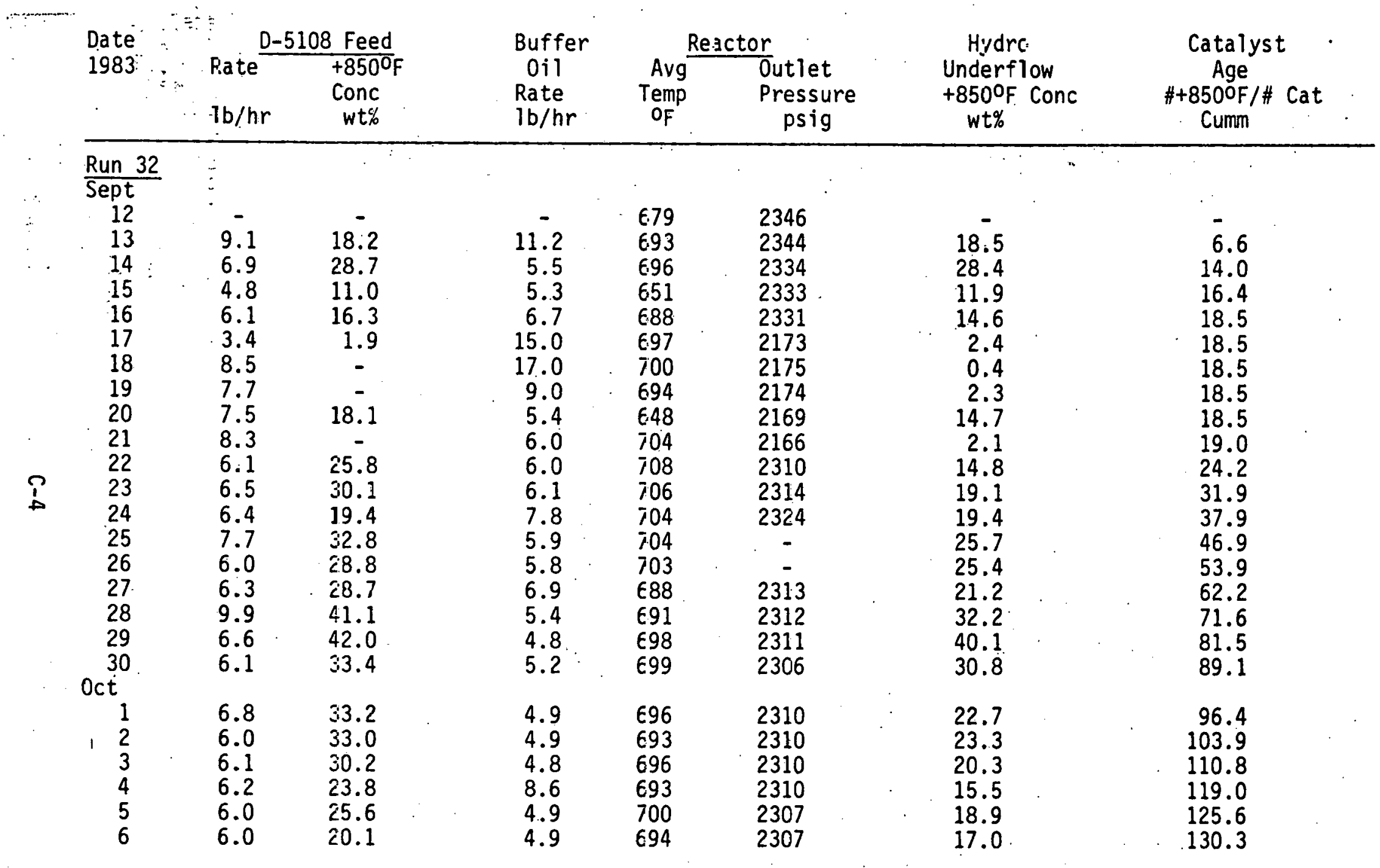


Table C-2 - cont'd

OPERATING DATA (Part 2)

Catalytic Stage

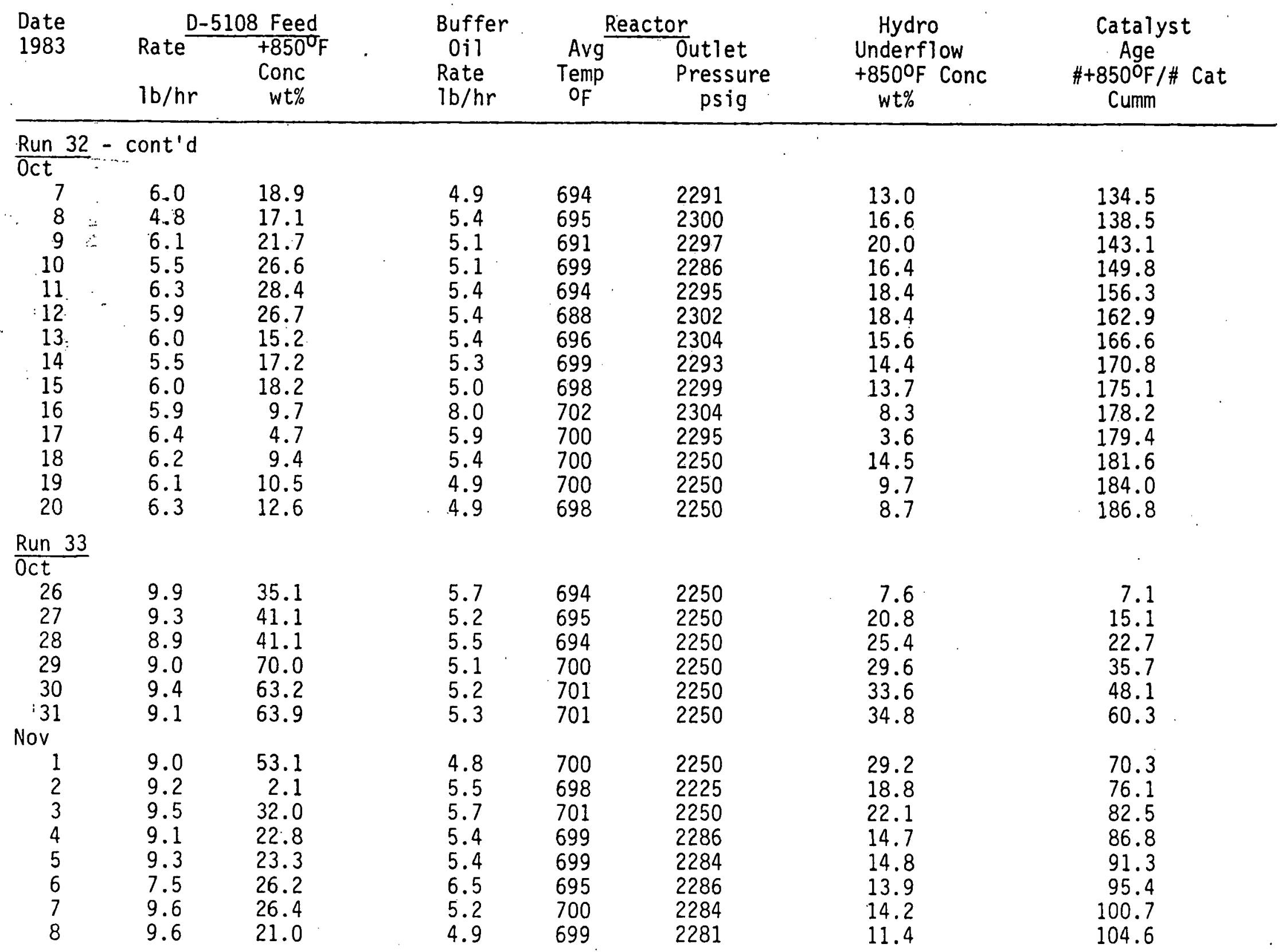


Table C-2 - cont'd

OPERATING DATA (Part ?)

Catalytic Stage

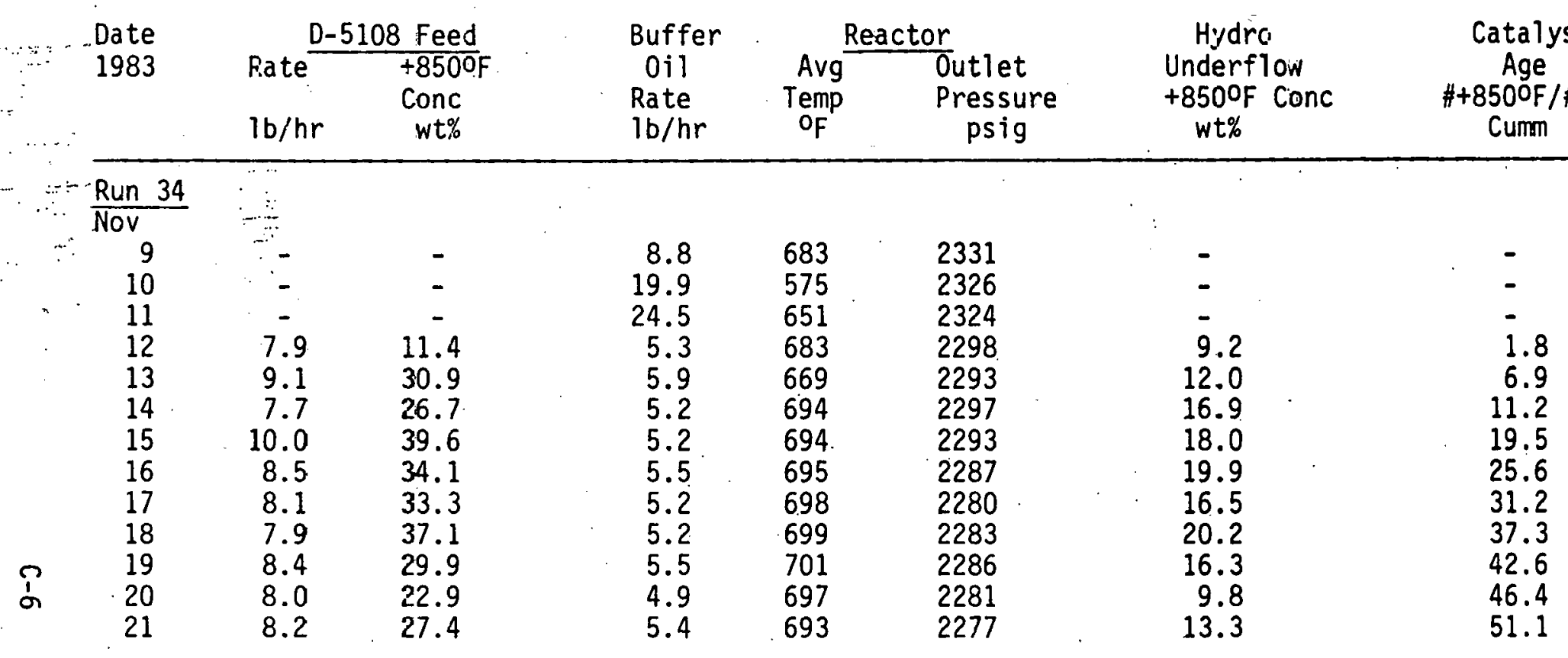


$\therefore \quad$ APPENDIX D

ANALYTICAL DATA - BENCH SCALE.

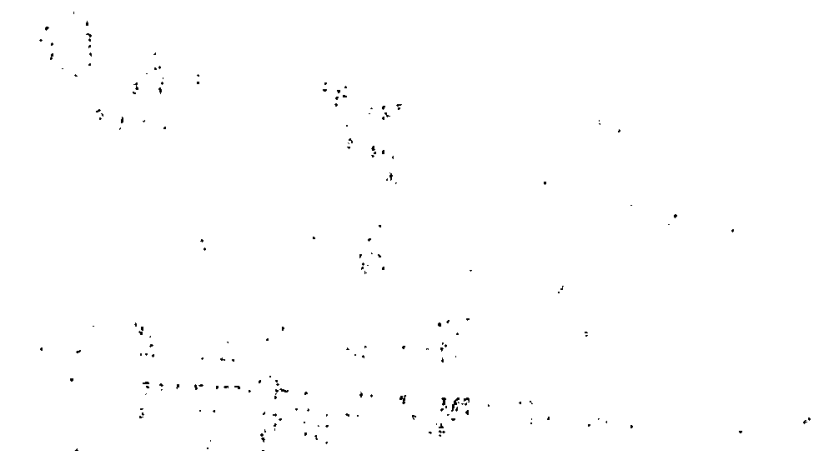


Table $0-1$

ANALYTICAL DATA (Sheet 1)

Liquefaction

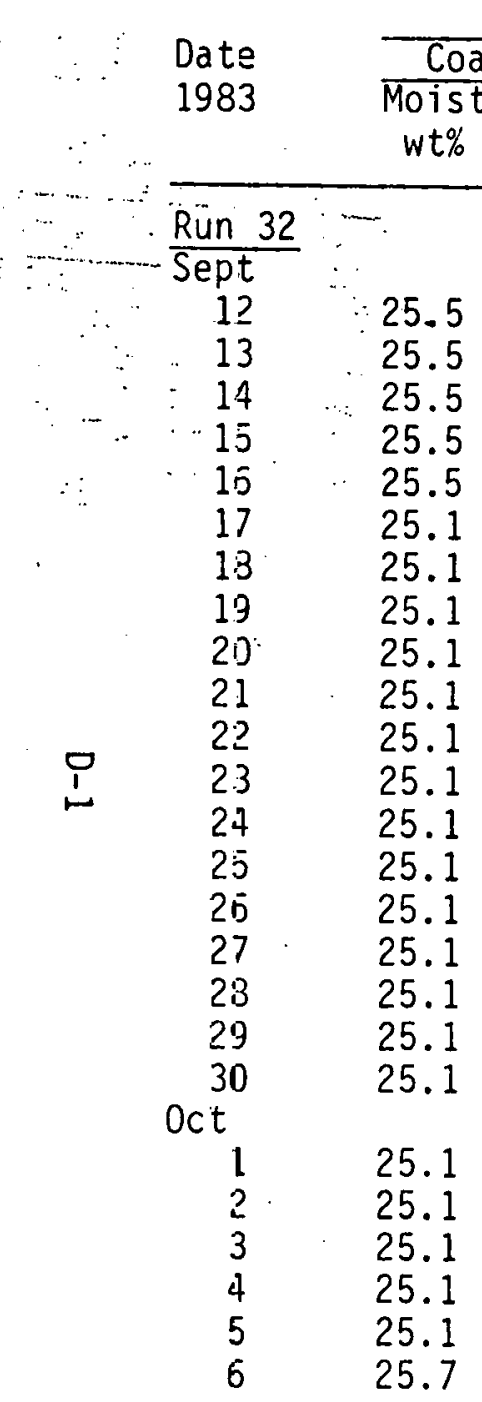

Solv

Ash
wt $\%$

wt\%

$\frac{\text { Vent Gas }}{\mathrm{H}_{2} \mathrm{~S}, \mathrm{CO}, \mathrm{CO}_{2} \mathrm{C}}$

wt $\%$ wt\%

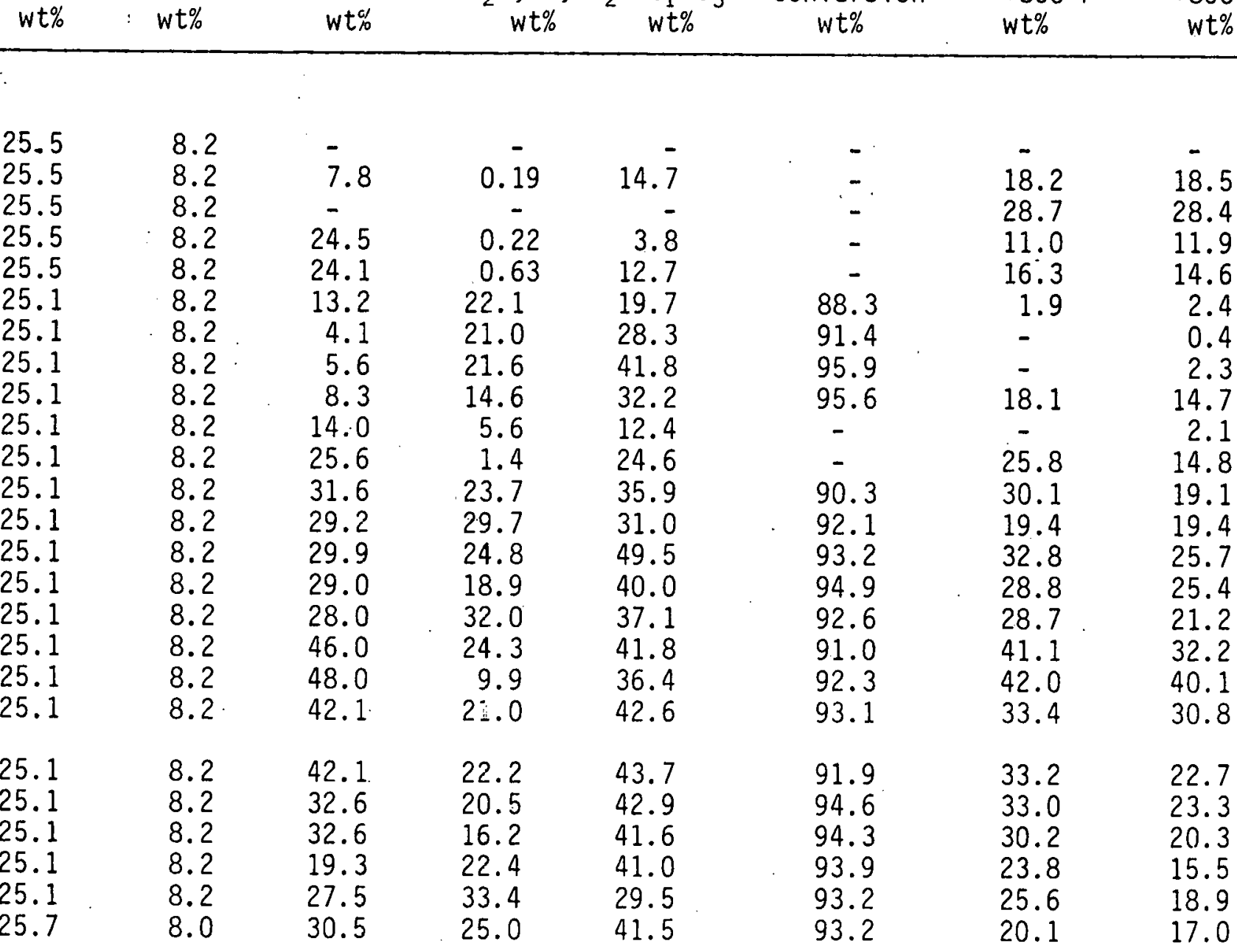

\begin{tabular}{|c|c|}
\hline$S$ & Coa 1 \\
\hline $\begin{array}{l}\mathrm{C}_{1}-\mathrm{C}_{5} \\
w+\%\end{array}$ & $\begin{array}{c}\text { Conversion } \\
\text { wt } \%\end{array}$ \\
\hline
\end{tabular}

\begin{tabular}{lccc}
\multicolumn{4}{c}{ Hydrotreater } \\
\hline Feed & Underflow & \multicolumn{2}{c}{ Vent Gas } \\
\cline { 2 - 2 }$+850^{\circ} \mathrm{F}$ & $+8500^{\circ} \mathrm{F}$ & $\mathrm{H}_{2} \mathrm{~S}$ & $\mathrm{C}_{1}-\mathrm{C}_{5}$ \\
$w t \%$ & $w t \%$ & wt $\%$ & wt $\%$
\end{tabular}

wt\%

18.5
28.4
11.9
14.6
2.4
0.4
2.3
14.7
2.1
14.8
19.1
19.4
25.7
25.4
21.2
32.2
40.1
30.8
22.7
23.3
20.3
15.5
18.9
17.0

$\begin{array}{ll}- & - \\ 0.77 & 2.11 \\ - & 1.24 \\ - & 2.48 \\ - & 3.57 \\ - & 0.62 \\ - & 0.71 \\ 0.38 & 4.69 \\ 0.22 & 1.39 \\ 1.07 & 2.12 \\ 1.63 & 2.03 \\ 1.69 & 0.62 \\ 1.96 & 0.71 \\ 1.95 & 4.69 \\ 1.50 & 1.39 \\ 2.84 & 2.12 \\ 0.90 & 2.03 \\ 1.16 & 2.83 \\ 2.14 & 2.64 \\ 1.97 & 3.92 \\ 1.65 & 4.21 \\ 0.91 & 5.84 \\ 0.19 & 3.27 \\ 0.68 & 3.07 \\ & \end{array}$


Table D-1 - cont'd

ANALYTICAL DATA (Sheet 1)

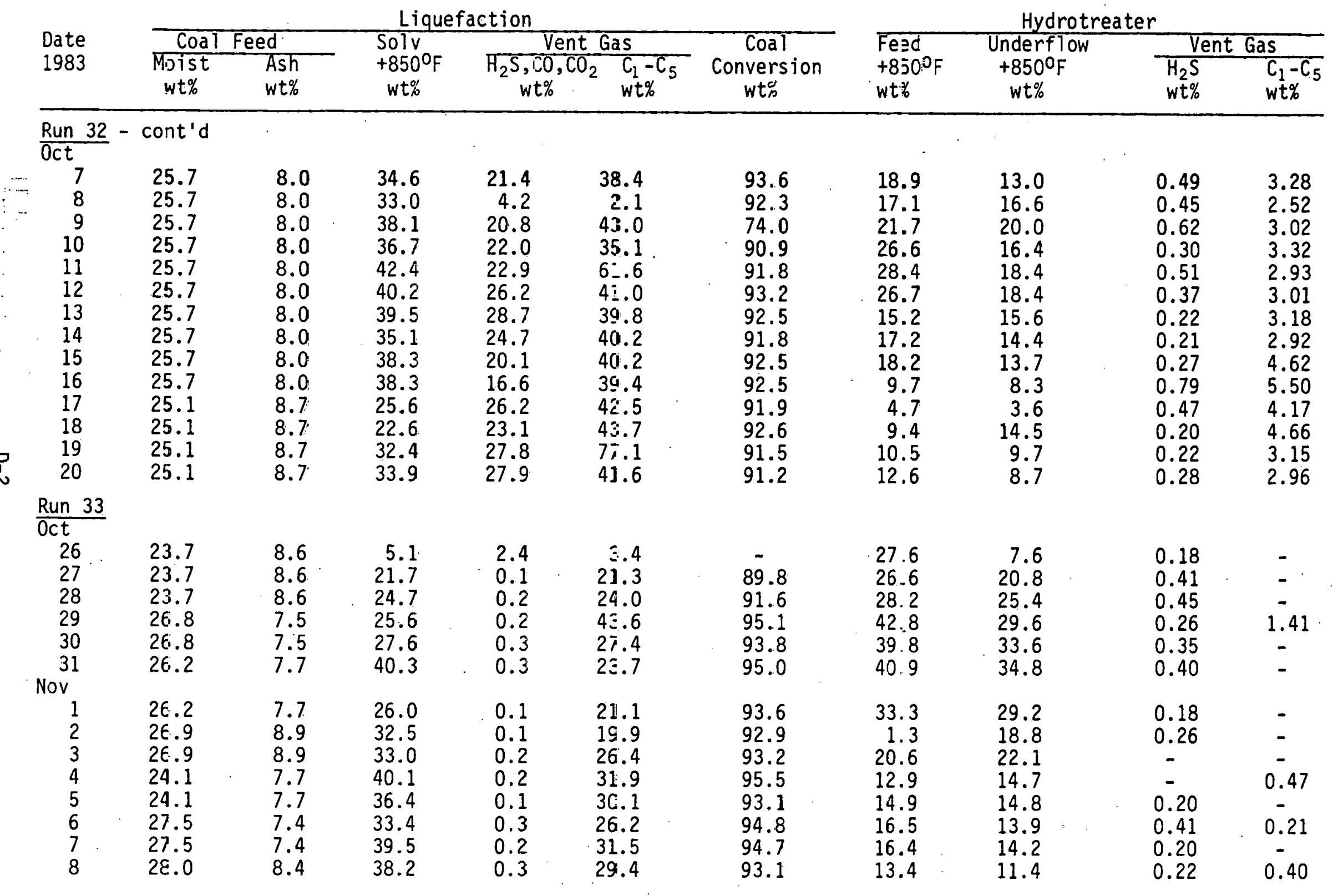


Table D-1 - cont'd

ANALYTICAL DATA (sheet 1)

\begin{tabular}{|c|c|c|c|c|c|c|c|c|c|c|}
\hline \multirow{3}{*}{$\begin{array}{l}\text { Date } \\
1983\end{array}$} & \multicolumn{6}{|c|}{ Liquefaction } & \multicolumn{4}{|c|}{ Hydrotreater } \\
\hline & \multicolumn{2}{|c|}{ Coal Feed } & \multirow{2}{*}{$\begin{array}{l}\text { Solv } \\
+850^{\circ} \mathrm{F} \\
\text { wt\% }\end{array}$} & \multicolumn{2}{|c|}{ Vent Gas } & \multirow{2}{*}{$\begin{array}{c}\text { Coal } \\
\text { Conversion } \\
\text { wt } \%\end{array}$} & \multirow{2}{*}{$\begin{array}{l}\text { Feed } \\
+850^{\circ} \mathrm{F} \\
\text { wt } \%\end{array}$} & \multirow{2}{*}{$\begin{array}{c}\text { Underflow } \\
+8500^{\circ} \mathrm{F} \\
\text { wt\% }\end{array}$} & \multicolumn{2}{|c|}{ Vent Gas } \\
\hline & $\begin{array}{l}\text { Moist } \\
\text { wt\% }\end{array}$ & $\begin{array}{l}\text { Ash } \\
\text { wt\% }\end{array}$ & & $\begin{array}{c}\mathrm{H}_{2} \mathrm{~S}, \mathrm{CO}, \mathrm{CO}_{2} \\
\text { wt } \%\end{array}$ & $\begin{array}{l}C_{1}-C_{5} \\
w t \%\end{array}$ & & & & $\begin{array}{l}\mathrm{H}_{2} \mathrm{~S} \\
\mathrm{wt} \%\end{array}$ & $\begin{array}{l}C_{1}-C_{5} \\
w t \%\end{array}$ \\
\hline$\frac{\text { Rur: } 34}{\text { Nor: }}$ & & & & & & & & & & \\
\hline 9 & - & - & - & - & - & - & - & - & - & - \\
\hline 10 & - & 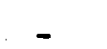 & - & - & - & - & - & - & - & - \\
\hline 11 & & - & - & - & - & - & - & - & - & - \\
\hline 12 & 27.0 & 8.1 & $9 . \tilde{5}$ & 22.8 & 35.2 & 95.8 & 6.9 & 9.2 & 0.36 & 4.36 \\
\hline 13 & 27.0 & 8.1 & 15.4 & 16.8 & 39.2 & 92.5 & 15.7 & 12.0 & - & 4.11 \\
\hline 14 & 26.8 & 8.8 & 19.4 & 32.1 & 36.6 & 92.3 & 15.1 & 16.9 & 0.56 & 5.83 \\
\hline 15 & 26.8 & 8.8 & 22.2 & 32.0 & 37.9 & 93.8 & 23.0 & 18.0 & 0.39 & 3.75 \\
\hline 16 & 26.8 & 8.8 & 22.4 & 31.8 & 41.3 & 95.6 & 21.3 & 19.9 & 0.44 & 4.78 \\
\hline 17 & 26.9 & 8.0 & 21.5 & 32.6 & 40.2 & 94.7 & 20.1 & 16.5 & 0.35 & 3.66 \\
\hline 18 & 26.9 & 8.0 & 22.5 & 33.5 & 33.4 & 95.1 & 22.8 & 20.2 & 0.28 & 4.52 \\
\hline 19 & 28.2 & 8.5 & 19.6 & 19.0 & 51.7 & 93.9 & 17.2 & 16.3 & 0.18 & 5.65 \\
\hline 20 & 28.2 & 8.5 & 15.8 & 28.0 & 35.7 & 90.8 & & 9.8 & 0.31 & 3.27 \\
\hline 21 & 27.3 & 9.7 & 12.5 & 32.6 & 36.3 & 90.0 & 15.0 & 13.3 & 0.19 & 3.45 \\
\hline
\end{tabular}


Table D-2

ANALYTICAL DATA (Sheet 2)

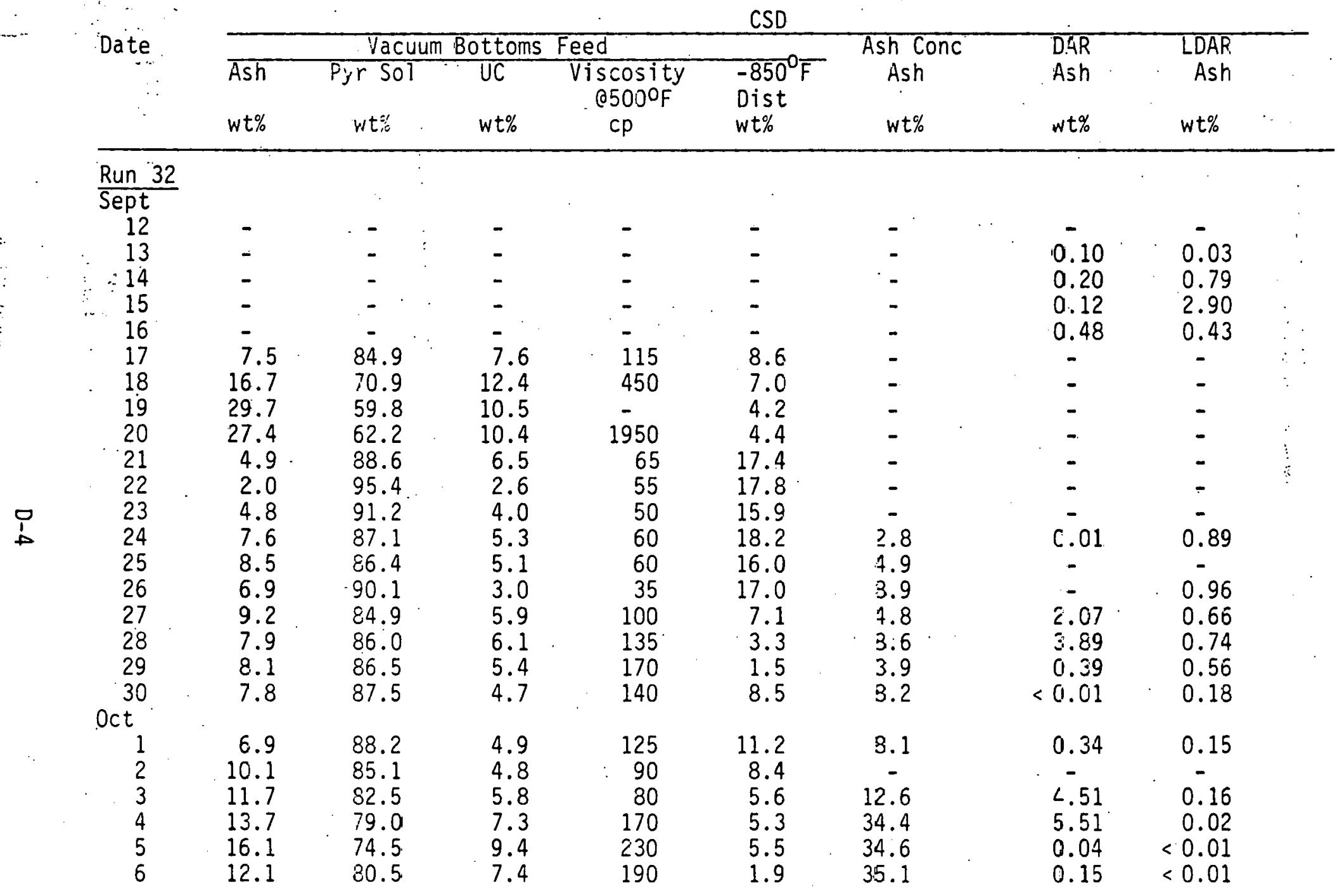


Table D-2 - cont'd

ANALYTICAL DATA (Sheet 2)

\begin{tabular}{|c|c|c|c|c|c|c|c|c|c|}
\hline \multirow{4}{*}{ Date } & \multicolumn{9}{|c|}{ CSD } \\
\hline & \multirow{3}{*}{$\begin{array}{l}\overline{A s h} \\
w t \%\end{array}$} & \multicolumn{2}{|c|}{ Vacuum Bottoms } & \multicolumn{2}{|l|}{ Feed } & \multirow{2}{*}{$\begin{array}{c}\text { Ash Conc } \\
\text { Ash }\end{array}$} & \multirow{2}{*}{$\begin{array}{l}\text { DAR } \\
\text { Ash }\end{array}$} & \multicolumn{2}{|l|}{ LDAR } \\
\hline & & Pyr So? & $U C$ & Viscosity & $-850^{\circ} \mathrm{F}$ & & & Ash & \\
\hline & & $w t \%$ & $w t \%$ & $c p$ & $w t \%$ & $w t \%$ & $w t \%$ & $w t \%$ & \\
\hline \multicolumn{10}{|c|}{$\frac{\text { Run } 32}{\text { Oct }}-$ cont $^{\prime} d$} \\
\hline$?$ & 11.4 & 82.1 & 6.5 & 165 & 5.9 & 31.2 & $<0.01$ & $<0.01$ & \\
\hline 8 & 10.6 & 82.1 & 7.3 & 175 & 2.8 & 30.0 & 0.03 & 0.03 & \\
\hline 9 & 5.2 & 82.7 & 12.1 & 130 & 10.3 & 27.2 & $<0.01$ & $<0.01$ & \\
\hline$\because 10$ & 7.4 & 86.6 & 6.0 & 110 & 6.5 & 27.1 & 0.04 & $<0.01$ & \\
\hline$\ldots 1 I$ & $\because 7.9$ & 86.3 & 5.8 & 90 & 15.1 & 27.2 & $<0.01$ & 0.02 & \\
\hline 12 & 8.3 & 86.6 & 5.1 & 125 & 9.7 & 33.1 & 0.03 & 0.14 & \\
\hline 13 & 8.1 & 86.5 & 5.4 & 115 & 10.3 & 24.8 & $<0.01$ & 0.02 & \\
\hline 14 & 7.4 & 87.1 & 5.5 & 140 & 7.2 & 30.9 & 0.04 & 0.10 & \\
\hline 15 & 8.9 & 85.1 & 6.0 & 225 & 4.3 & 28.5 & $<0.01$ & 0.02 & \\
\hline 16 & 9.2 & 84.6 & 6.2 & 245 & 6.4 & 29.0 & 0.04 & $<0.01$ & \\
\hline 17 & 10.0 & 83.4 & 6.6 & 265 & 1.7 & 33.8 & 1.76 & 0.01 & \\
\hline 18 & 10.4 & 83.3 & 6.3 & 475 & 3.0 & 36.4 & 0.07 & 0.09 & \\
\hline 19 & 10.5 & 82.3 & 7.2 & 245 & 3.3 & 38.4 & 0.34 & 0.06 & \\
\hline 20 & 9.3 & 84.1 & 6.6 & 300 & 2.1 & 35.5 & 1.86 & 0.15 & \\
\hline \multicolumn{9}{|l|}{ Run 33} & \\
\hline \multicolumn{10}{|l|}{$\overline{\text { oct }}$} \\
\hline 26 & 2.0 & 95.2 & 2.8 & 50 & 17.4 & 36.1 & 0.38 & 0.11 & \\
\hline 27 & 5.0 & 89.3 & 5.7 & 135 & 12.8 & 31.2 & 0.03 & $<0.01$ & \\
\hline 28 & 15.5 & 72.8 & 11.7 & 1090 & $<0.1$ & 36.2 & 0.20 & $<0.01$ & \\
\hline 29 & 13.0 & 80.3 & 6.7 & 315 & 3.3 & 34.8 & 0.39 & $<0.01$ & \\
\hline 30 & 11.9 & 81.2 & 6.9 & 300 & $<0.1$ & 37.8 & 3.48 & -0.01 & \\
\hline 31 & 11.7 & 82.1 & 6.2 & 240 & 2.2 & 35.8 & 0.26 & $<0.01$ & \\
\hline \multicolumn{9}{|l|}{ Nov } & \\
\hline 1 & 10.5 & 83.7 & 5.8 & 240 & 5.4 & 30.0 & 0.15 & 0.03 & \\
\hline 2 & 11.3 & 82.1 & 6.6 & 190 & $<0.1$ & 30.3 & 0.01 & 0.03 & \\
\hline 3 & 13.6 & 79.0 & 7.4 & 190 & 5.3 & 17.4 & 6.88 & $<0.01$ & \\
\hline 4 & 18.5 & 73.8 & 7.7 & 410 & 5.0 & 39.1 & 0.20 & 0.03 & \\
\hline 5 & 17.7 & 71.4 & 10.9 & 610 & 4.4 & 39.3 & 0.22 & 0.04 & \\
\hline 6 & 17.3 & 74.4 & 8.3 & 500 & $<0.1$ & 35.3 & 0.01 & 0.04 & \\
\hline 7 & 14.6 & 77.0 & 8.4 & 425 & 4.5 & 34.0 & 0.15 & $<0.01$ & \\
\hline 8 & 14.7 & 75.4 & 9.9 & 485 & 3.4 & 35.1 & 2.94 & 0.05 & \\
\hline
\end{tabular}


Table D-2 - cont'd.

ANALYTICAL DATA (Sheet 2)

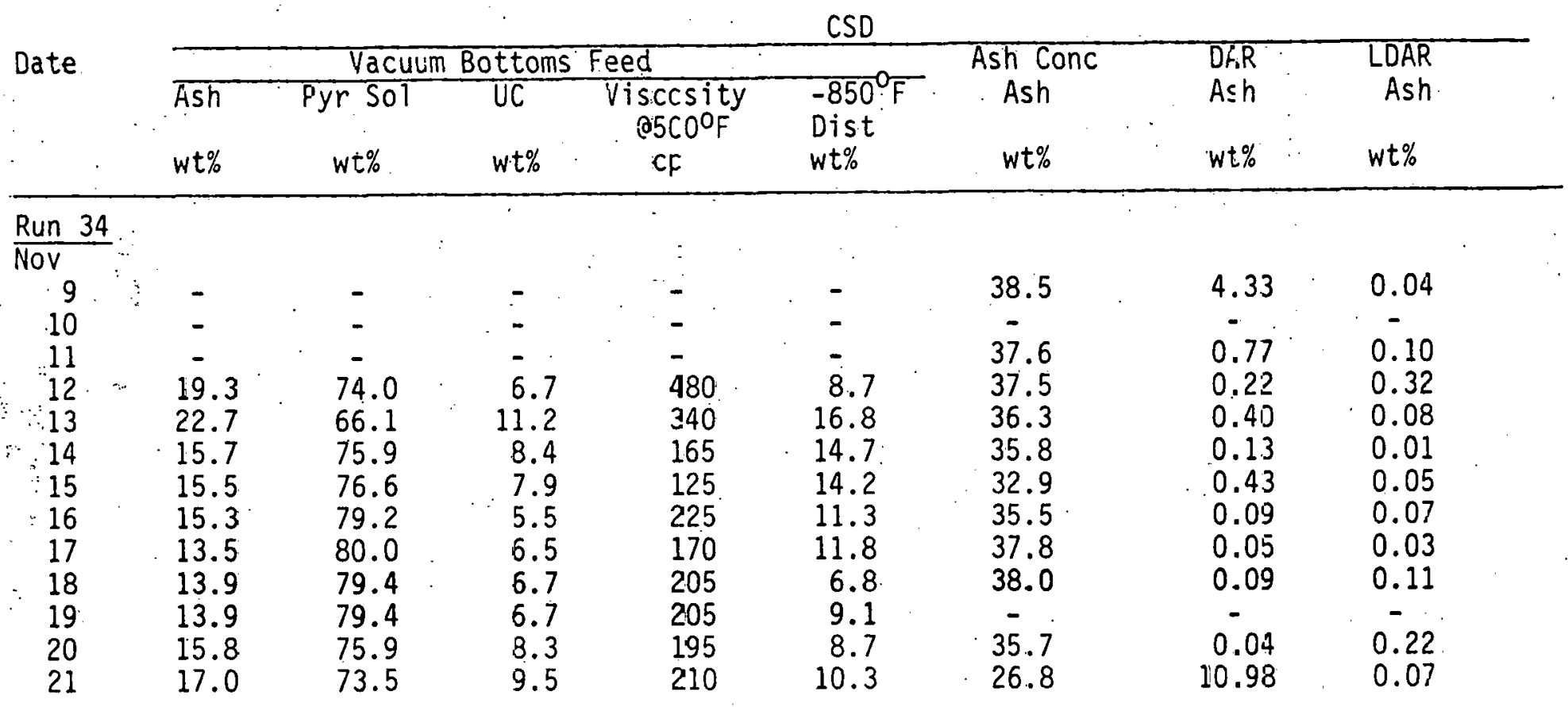


Table D-3

CLOVIS POINT COAL - UPPER SEAM

AS-MINED

SHIPMENT DATE

Program Reference

MOISTURE, WT \%
$2 / 24 / 83$

TT2

30.6

8.92

46.20

44.88

100.00
9.48

48.40

42.12

100.00

ULTIMATE ANALYSES, WT \% (MF BASIS)

Carbon

Hydrogen

Nitrogen

Sulfur forms

Total

Pyritic

Sulfate

Organic

Chlorine

Oxygen (by difference)

Ash

TOTAL
65.00

4.70

0.90

0.96

0.25

0.08

0.63

0.07

19.45

8.92

100.00
65.20

5.14

0.86

0.98

0.24

0.08

0.66

0.05

18.29

9.48

100.00

MINERAL ANALYSES OF ASH, WT \%

Silica

Ferric oxide

Alumina

Lime

Magnesium oxide

Sodium oxide

Potassium oxide

Titania

Sulfur trioxide

Phosphorus pentoxide

Undetermined

TOTAL
26.0

6.9

15.0

20.0

4.1

5.1

0.4

0.8

20.9

0.4

0.4

100.00
29.7

7.4

14.3

18.7

4.0

1.8

0.4

0.8

22.7

0.2

-.-

100.00 
Table D-4

TYPICAL ANALYSIS OF IRON OXIDE

KERR-MCGEE MOBILE PLANT

Program Reference

83E-1 QQ5 $\quad$ QQ6

ANALYSIS, WT \%

\begin{tabular}{|c|c|c|c|}
\hline Moisture & 0.6 & 2.2 & 2.1 \\
\hline Surface area, $\mathrm{M}^{2} / \mathrm{g}$ & 4.5 & 4.0 & 5.5 \\
\hline Chloride, wt\% & 0.9 & 3.8 & 5.4 \\
\hline Iron (total) & 67.3 & 60.4 & 58.8 \\
\hline$r e^{++}$ & 2.4 & $? .4$ & - \\
\hline $\mathrm{Fe}^{+++}$ & $64.9^{\prime}$ & $5 \% .6$ & - \\
\hline \multicolumn{4}{|l|}{ Other elements, wt\% } \\
\hline A1 & 0.50 & 0.63 & 0.60 \\
\hline $\mathrm{Ca}$ & 0.22 & 0.20 & 0.20 \\
\hline $\mathrm{Cr}$ & 0.02 & 0.03 & 0.03 \\
\hline $\mathrm{Mg}$ & 0.36 & 0.47 & 0.44 \\
\hline $\mathrm{Pb}$ & 0.04 & 0.15 & 0.16 \\
\hline $\mathrm{Ti}$ & 0.99 & 0.07 & 0.14 \\
\hline v & 0.07 & 0,10 & 0.05 \\
\hline $\mathrm{Zn}$ & 0.06 & 0.12 & 0.12 \\
\hline
\end{tabular}

DRY SCREEN (After milling)

$\begin{array}{rr}+60 & 0.0 \\ -60+100 & 3.1 \\ -100+200 & 84.9 \\ -200+325 & 7.1 \\ -325 & 1.9 \\ \text { TOTAL } & 100.0\end{array}$




\section{APPENDIX E}

ANALYTICAL DATA - FEED MATERIALS 
Table E-1

ANALYSIS. OF STARTING MATERIALS

USED IN BATCH REACTOR TESTS

m 0 ils

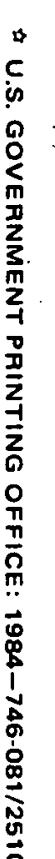

Material Type

Sample Identification

$$
\begin{aligned}
& {[i-3106} \\
& \vdots / 17 / 83
\end{aligned}
$$$$
\text { Process Solvent }
$$

Analysis, wt \%

Carbon
Hydrogen
Nitrogen
Sulfur
Oxygen (by difference)
Ash

$-85 G^{0} F$ Distillable

$\begin{array}{ccc}\text { H-LDAR } & \text { LDAR } & \text { DAR } \\ \# 1503 & & \text { Drum M-462 } \\ \text { GG-5 } & \text { WLV } & \begin{array}{l}\text { WLV } \\ \text { Run 171 }\end{array} \\ & \text { Run 240 }\end{array}$

Asphal tenes

Preasphal tenes

Used in Program
88.8

9.27

0.28

$<0.01$

1.65

$-$

95.6

90.6

7.68

88.0

6.32

0.81

1.68

0.02

0.91

0.89 .

$-$

62.8

3.09

$<0.01$

21.6

$$
\begin{array}{cc}
83 A 1 & M M 4 \\
83 A 2 & M M 5 \\
83 A 3 & M M 8 \\
E: 5-B \\
E: 8
\end{array}
$$

$83 A 4$

83A2
MM8
Run 240

86.5

5.76

5.04

6.1

4.6

56.2

39.0

$83 A 1$
(Process Solvent + LDAR)Mixture See Note 2

$\operatorname{Res} j d^{2}$

87.3

Distillate ${ }^{2}$

5.87

88.0

8.06

1.86

0.73

0.24

0.81

0.73

2.97

4.21

0.03

5.5

80.5

$83 \mathrm{~A} 3$

MM4

MM5

E15-B

E18

83A6-1 through 4.

$1500^{\circ} \mathrm{F} \times 0.1 \mathrm{~mm}$ distillation with G.C. correction of distillate.

2 Obtained by $500^{\circ} \mathrm{F} \times 0.1 \mathrm{~mm}$ distillation of a mixture consisting of 60 wt\% Process Solvent (Wilsonville SN-189j-, rec'd Sep 83) and 40 wt\% LDAR (Wilsonville Run 241, Drum. \#N-4524). 